\title{
Recommended Radiation Protection Practices for Low-Level Waste Disposal Sites
}

Prepared by D. E. Hadlock, C. D. Hooker, W. N. Herrington, R. L. Gilchrist

Pacific Northwest Laboratory

Operated by

Battelle Memorial Institute

Prepared for

U.S. Nuclear Regulatory

Commission 


\section{NOTICE}

This report was prepared as an account of work sponsored by an agency of the United States Government. Neither the United States Government nor any agency thereof, or any of their employees, makes any warranty, expressed or implied, or assumes any legal liability of responsibility for any third party's use, or the results of such use, of any information, apparatus, product or process disclosed in this report, or represents that its use by such third party would not infringe privately owned rights.

Availability of Reference Materials Cited in NRC Publications

Most documents cited in NRC publications will be available from one of the following sources:

1. The NRC Public Document Room, 1717 H Street, N.W. Washington, DC 20555

2. The NAC/GPO Sales Program, U.S. Nuclear Regulatory Commission, Washington, DC 20555

3. The National Technical Information Service, Springfield, VA 22161

Although the listing that follows represents the majority of documents cited in NRC publications, it is not intended to be exhaustive.

Referenced documents available for inspection and copying for a fee from the NRC Public Document Room include NRC correspondence and iriternal NRC memoranda; NRC Office of Inspection and Enforcement bulletins, circulars, information notices, inspection and investigation notices; Licensee Event Reports; vendor reports and correspondence; Commission papers; and applicant and licensee documents and correspondence.

The following documents in the NUREG series are available for purchase from the NRC/GPO Sales Program: formal NRC staff and contractor reports, NRC-sponsored conference proceedings, and NRC booklets and brochures. Also available are Regulatory Guides, NRC regulations in the Code of Federal Regulations, and Nuclear Regulatory Commission Issuances.

Documents available from the National Technical Information Service include NUREG series reports and technical reports prepared by other federal agencies and reports prepared by the Atomic Energy Commission, forerunner agency to the Nuclear Regulatory Commission.

Documents available from public and special technical libraries include all open literature items. such as books, journal and periodical articles, and transactions. Federal Register notices, federal and state legislation, and congressional reports can usually be obtained from these libraries.

Documents such as theses, dissertations, foreign reports and translations, and non-NRC conference proceedings are available for purchase from the organization sponsoring the publication cited.

Single copies of NRC draft reports are available free upon written request to the Division of Technical Information and Document Control, U.S. Nuclear Regulatory Commission, Washington, DC 20555.

Copies of industry codes and standards used in a substantive manner in the NRC regulatory process are maintained at the NRC Library, 7920 Norfolk Avenue, Bethesda, Maryland, and are available there for reference use by the public. Codes and standards are usually copyrighted and may be purchased from the originating organization or, if they are American National Standards, from the American National Standards Institute. 1430 Broadway, New York, NY 10018. 


\section{Recommended Radiation Protection Practices for Low-Level Waste Disposal Sites}

Manuscript Completed: September 1983

Date Published: December 1983

Prepared by

D. E. Hadlock, C. D. Hooker, W. N. Herrington, R. L. Gilchrist

Pacific Northwest Laboratory

Richland, WA 99352

Prepared for

Division of Waste Management

Office of Nuclear Material Safety and Safeguards

U.S. Nuclear Regulatory Commission

Washington, D.C. 20555

NRC FIN B2473 
NOTICE

The views, opinions, and/or findings contained in this report are those of the author(s) and should not be construed as an official Nuclear Regulatory Commission position, policy or decision, unless so designated by other documentation. 


\section{SUMMARY}

The United States Nuclear Regulatory Commission contracted with Pacific Northwest Laboratory (PNL) to provide technical assistance in estsblishing operational guidelines, with respect to radiation control programs and methods of minimizing occupational radiation exposure, at Low-Level Waste (LLW) disposal sites. The PNL, through site visits, evaluated operations at $\amalg W$ disposal sites to determine the adequacy of current practices in maintaining occupational exposures as low as is reasonably achievable (ALARA). The data sought included the specifics of: ALARA programs, training programs, external exposure control, internal exposure control, respiratory protection, survei 1lance, radioactive waste management, facilities and equipment, and external dose analysis. The results of the study indicated the following:

The Radiation Protection and ALARA programs at the three commercial $\amalg W$ disposal sites were observed to be adequate in scope and content compared to similar programs at other types of nuclear facilities. However, it should be noted that there were many areas that could be improved upon to help ensure the health and safety of the occupationally exposed individuals.

As a result, radiation protection practices were recommended with related rationales in order to reduce occupational exposures as far below specified radiation limits as is reasonably achievable. In addition, recommendations were developed for achieving occupational exposure ALARA under the Regulatory Requirements issued in 10 CR Part 61. 


\section{ACKNOWEDGMENTS}

The authors are grateful to the following Low-Level Waste disposal facilities for their assistance in providing information for this report: U.S. Ecology, Richland, Washington; U.S. Ecology, Beatty, Nevada; and Chem-Nuclear Systems, Barnwell, South Carolina.

We gratefully acknowledge the word processing assistance of Mary Eierdam and Marianna Cross. The technical editing efforts of Tonia Graham were greatly appreciated.

Finally, we wish to acknowledge the support, both monetary and technical, of the sponsors, Division of Waste Management, Office of NMSS. The support of Stan Neuder, NRC Program Manager was greatly appreciated. 
CONTENTS

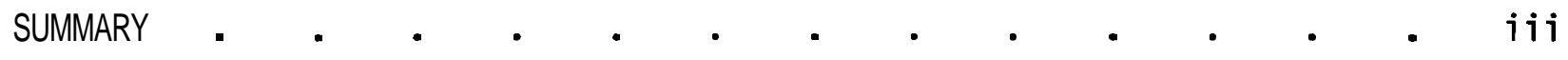

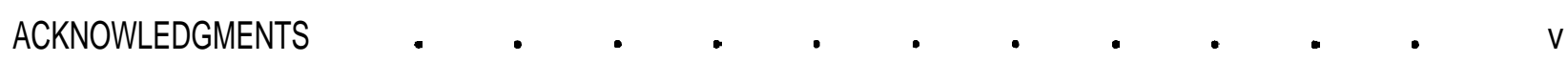

1.0 INTRODUCTION $\quad$ •

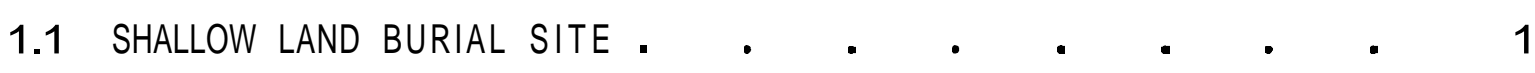

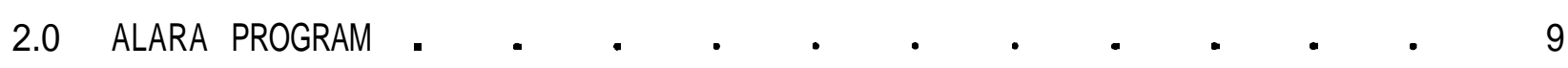

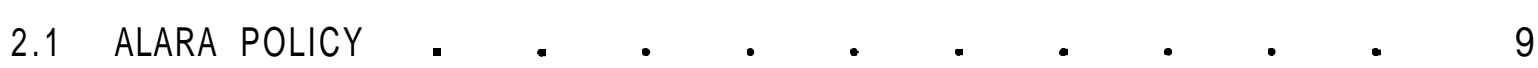

2.2 PROGRAM RESPONSIBILITY/AUTHORITY • • • • • • • 10

2.3 TRAINING $\quad$ • $\quad$ •

2.4 FACILITY/EQUIPMENT DESIGN $\quad$ •

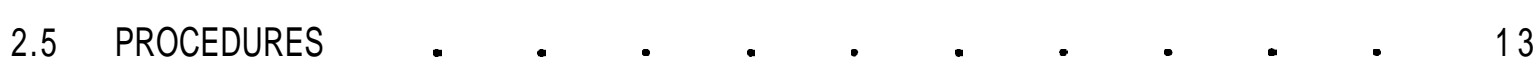

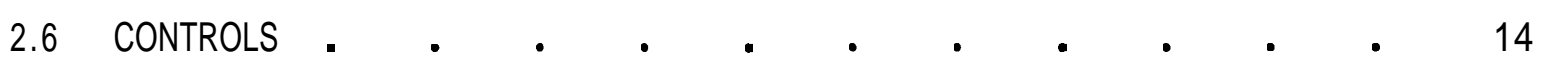

2.7 PREPLANNING/MOCK-UP TRAINING •

2.8 PROGRAM EFFECTIVENESS $\quad \cdot \quad$.

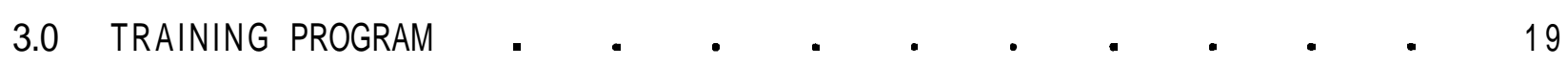

3.1 PROGRAM RESPONSIBILITY/AUTHORITY

3.2 PERSONNEL SELECTION AND QUALIFICATION • • • • • • 20

3.3 PROCEDURES/LESSON PLANS .

3.4 Radiation PROtection training . • • • • •

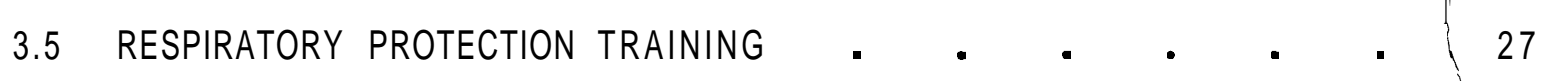

3.6 FEMALE RADIATION WORKER TRAINING • • • • • • • 29

3.7 ON-THE-JOB TRAINING/MOCK-UP TRAINING . 30

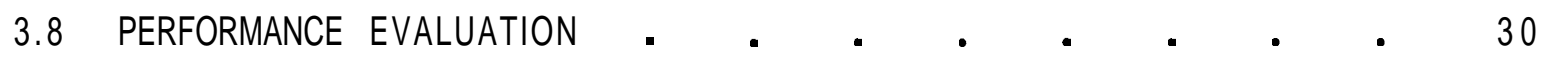

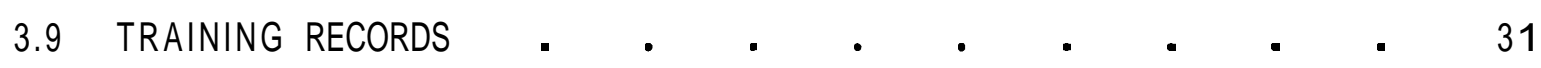

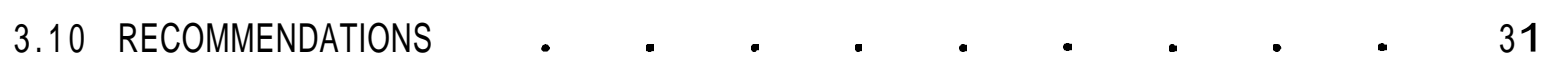


4.0 EXTERNAL AND INTERNAL EXPOSURE CONTROL . • . . . . . . 33

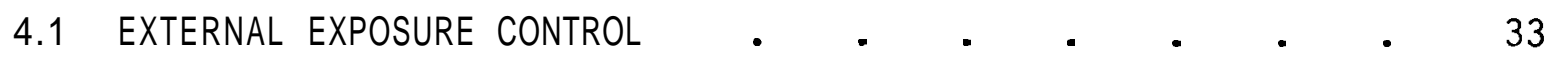

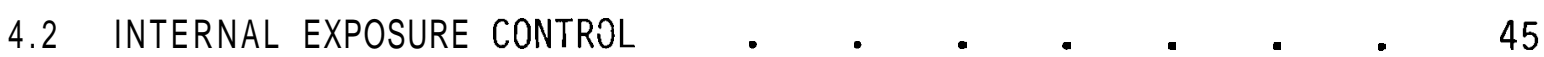

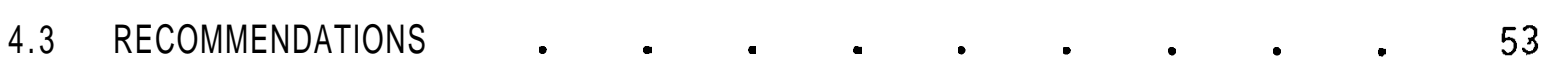

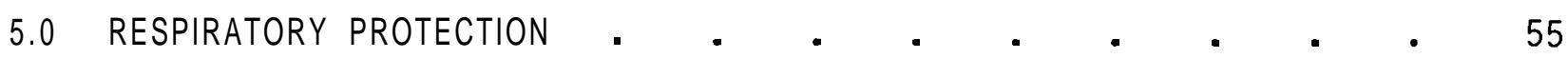

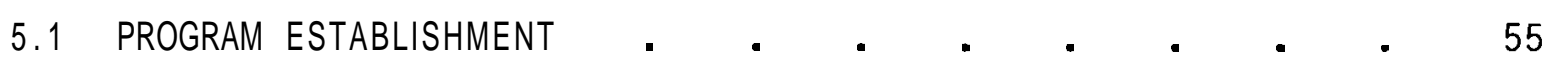

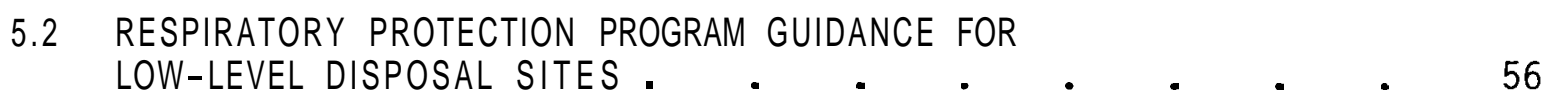

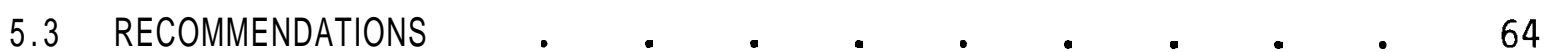

6.0 SURVEILLANCE $\quad$ • $\quad . \quad \ldots \quad$.

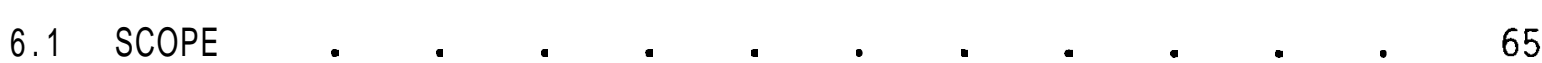

6.2 RADIOLOGICAL MONITORING OF FACILITIES . $\quad . \quad$ • $\quad$ • 66

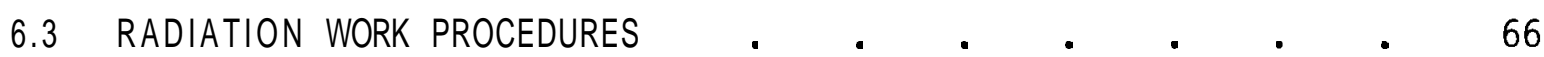

6.4 PERSONNEL DOSIMETRY .

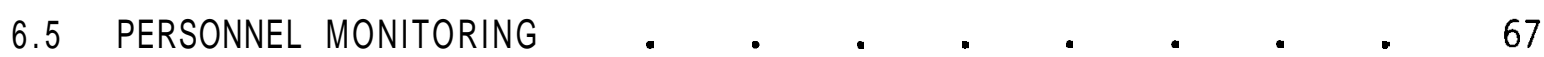

6.0 INCOMING SHIPMENT SURVEYS $\quad . \quad . \quad . \quad . \quad . \quad . \quad$. 70

6.7 BURIAL TRENCH SURVEILLANCE $\quad$ • • • • • • • • • 70

6.8 RADIATION RELEASE CRITERIA . . . . . . . . 73

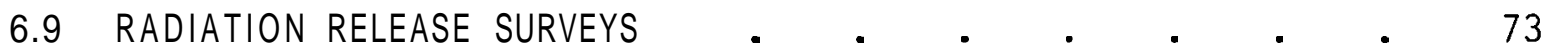

6.10 MONITORING DECONTAMINATION OPERATIONS $\quad$ • 77

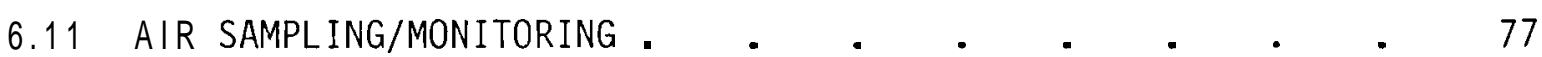

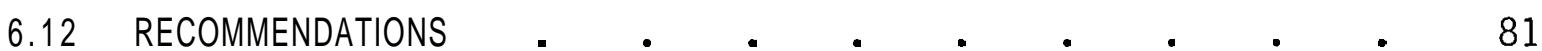

7.0 CONTAMINATION CONTROL AND DECONTAMINATION.$\quad$. $\quad$. 83

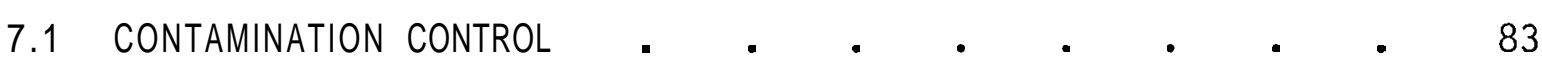

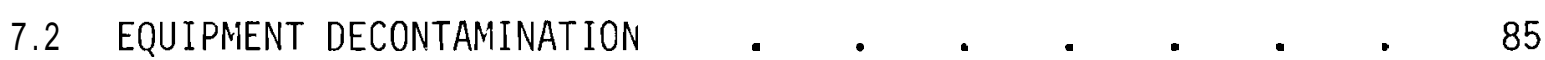




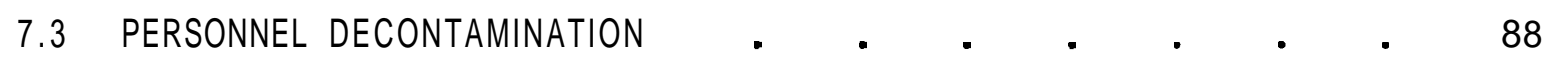

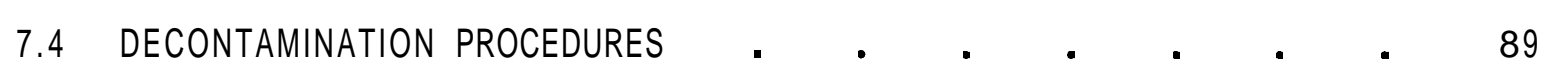

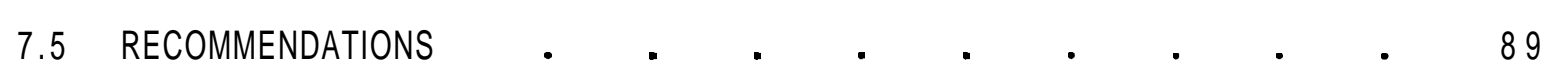

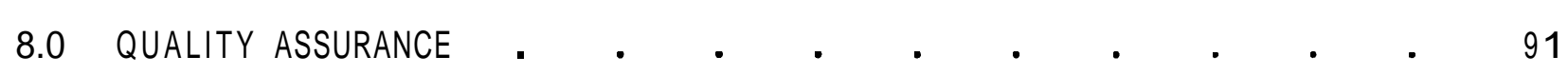

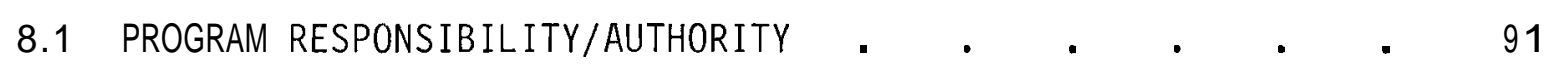

8.2 PERSONNEL SELECTION, QUALIFICATION AND TRAINING • • • • 93

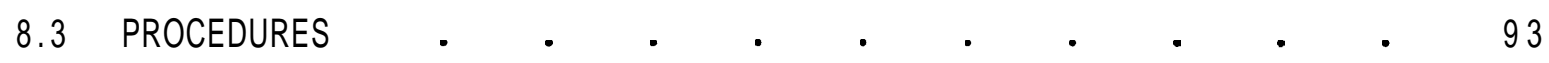

8.4 RADIATION PROTECTION PROGRAM ELEMENTS . . . . . . 93

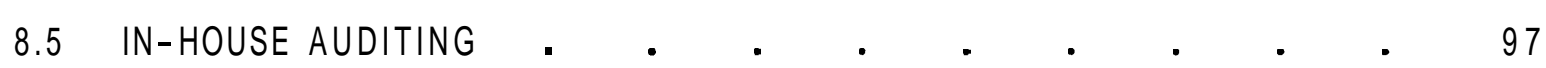

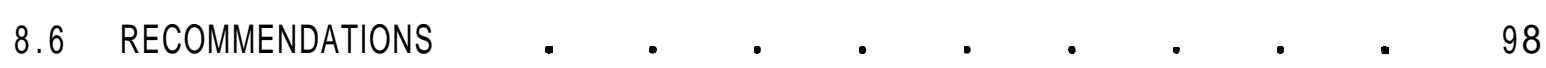

9.0 PROCEDURES/DOCUMENTATION •

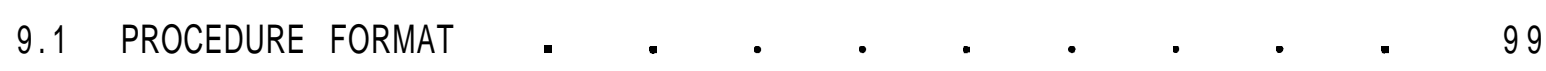

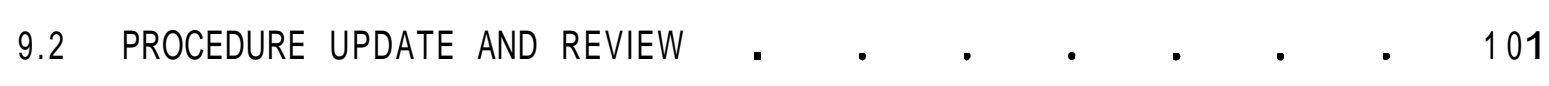

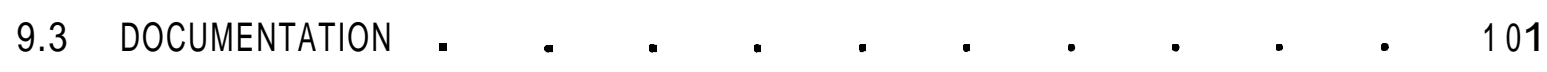

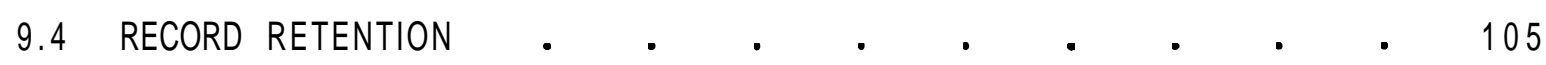

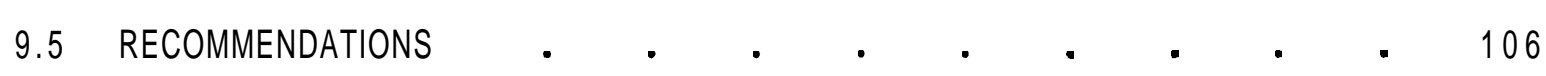

10.010 CFR $61 . \mathrm{IMPACT}$.

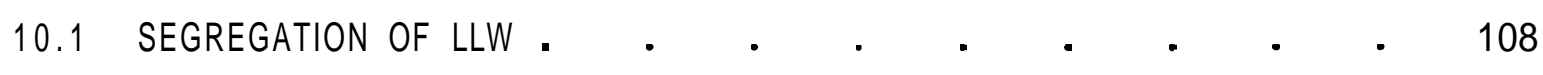

10.2 PLACEMENT OF LLW CONTAINERS . • • • • • • • 109

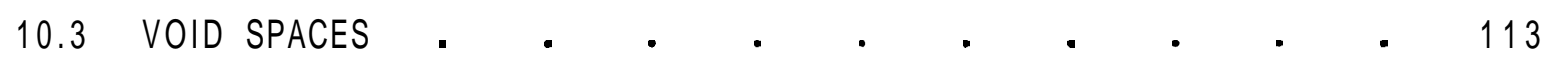

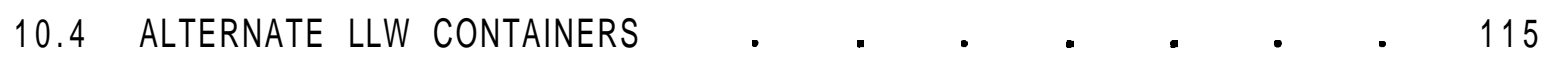

10.5 CONCLUSIONS $\quad$ • $\quad$ •

BIBLIOGRAPHY $\quad$ • $\quad$ • $\quad$ • 


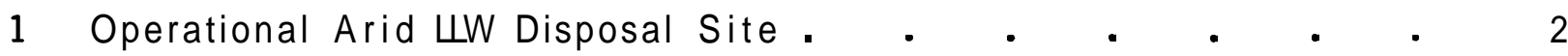

2 Operational Humid $\amalg W$ Disposal Site . . . . . . . 3

3 Reference $\amalg W$ Disposal Site Layout . . . . . . . . . 4

4 Reference $\amalg W$ Disposal Trench . . . . . . . . . 6

5 Reference $\amalg W$ Disposal Site Access Building . . . . . 7

6 ALARA Organizational Structure . . . . . . . . 11

7 Exposure Control Organizational Structure . . . . . 34

8 Unloading Platform Located at Top of Trench . . • • • 37

9 Unloading Platform Located Within Trench . . . . . 38

10 Shielding of Emplaced $\amalg W$ Containers . . . • . . 40

11 Shielded Fork Lift . . . . . . . . . . . 40

12 Chair Counting System Using Multiple Detectors . • . . 50

13 Thyroid Counting System . . . . . . . . . 51

14 Examples of Respiratory Protection Used at $\Perp W$ Disposal Sites . 60

15 Radiological Survey of Transport Vehicle and Shipping Cask . . 71

16 Radiological Survey of Truck Cab . • • • • • • 71

17 Radiological Survey at Trench Edge . • • • . . . 72

18 Fixed Position Air Sampling Station . • . . . . 78

19 Personnel Frisking Station . • • • • • • • 84

20 แW Container Inspection Facility with Overhead Fume Hood • • 87

21 Cask Preparation and Maintenance Facility . . . . 87

22 QA-Radiation Protection Organizational Structure . • • . 92

23 Variation of Waste Container Types . • • • • • • 110 
24 Use of Container Stacking for Radiation Shielding .

25 Prestacked Pallets of 55-Gallon Waste Drums . 112

26 Example of Currently Used Remote Handling Device . 113 


\section{TABLES}

1 Radiation Protection Training/Retraining Summary . . 28

2 Administrative Control Levels for External Exposure Control . . $\quad 35$

3 Administrative Control Levels for Internal Exposure Control . . 47

4 Unrestricted Release Limits for Tools and Equipment . 74

5 Unrestricted Release Limits for Transport Vehicles . 75

6 Contamination Release Limits for Exclusive-Use Transport Vehicles Being Returned to Service. . . . . . . 75

7 Personnel Release Limits. . . . . . . . . 76 


\section{I.G INTRODUCTION}

In July 1981, the Nuclear Regulatory Commission (NRC) published it s proposed rule (10 CR 61) on the disposal of low-level radioactive wastes by shallow land burial. While public comments on the rule were being received, the NRC undertook several studies to determine both the tools needed to implement $10 \mathrm{CFR} 61$ and the potential impact of the rule. This document relies heavily upon the information presented in two of these studies.

The first study was published as NUREG/CR-3125 (PNL-4372). Researchers from Pacific Northwest Laboratory (PNL) visited commercial Low-Level Waste (LLW) disposal sites to gather information on the current practices of waste disposal, especially the aspects affecting Radiation Protection and ALARA (As Low As Reasonably Achievable) programs. In addition, the most reliable dose data from the sites was collected and analyzed to determine any distinct trends associated with specific waste disposal operations or waste characteristics. Where appropriate, recommendations were provided to the NAC and licensees in areas that needed prompt attention.

The second study was an NRC staff-generated Draft Environmental Impact Statement (NUREG-0872) for shallow land burial of low-level waste, which was published in September 1981 . This document was primarily concerned with the offsite effects of implementing 10 CR 61 . With respect to safety, attention was focused on the offsite radiation dose effects while occupational dose effects were of secondary concern.

The purpose of this document is twofold. First, it presents the necessary and desirable elements of a good radiation protection program. Secondly, the impacts that 10 CFR 61 requirements are expected to have on site ALARA programs are discussed. Both of these discussions are based upon the findings of NUREG/CR-3125 and the subsequent application of good health physics practices. The present document provides a compilation of current ALARA practices at operating commercial $\amalg W$ disposal sites. This is not only intended to be a reference source for operations of these sites but should be considered as guidance in the development of radiation protection programs for future $\amalg W$ facilities. It should be recognized that the recommendations made in this document are only recommendations rather than requirements. Each facility is different and the recommendations given here need to be tailored to fit the needs. Using this approach licensees and workers may both benefit.

It is appropriate at this point to present a discussion of the characteristics, design and operation of a reference shallow land burial site.

\subsection{SHAШOW LAND BURIAL SITE}

The site characteristics in this study are based heavily upon the sites developed in NUREG-0782 and on those described in NUREG/CR-3125. 
NUREG-0782 discusses both humid and arid reference disposal site locations. A currently operating arid site is shown in Figure 1 and an operating humid site in Figure 2. The reference site chosen by this present study as assumed to be located in a humid Southeastern United States location for two reasons. First, the location of a site in a humid climate is a conservative assumption based on radiological migration. It is generally agreed that radionuclides are more likely to migrate in the presence of moisture than in the absence of moisture. Second, $75 \%$ of the waste generated over the next 20 years is projected to originate from sources in humid climates and is expected to be disposed of in the same region.

The NUREG-0782 reference site is described in three parts: statement of performance objective, general site description, and facility layout and design.

With respect to performance, the facility is projected to receive and dispose of 50,000 $\mathrm{m}^{3}$ of radioactive waste over it s 20-year operating life. This is equal to $25 \%$ of the anticipated total volume of waste generated nationally. The site is expected to dispose of waste by shallow land burial on a 150-acre plot. This land is to be owned by the state and leased to the licensee.

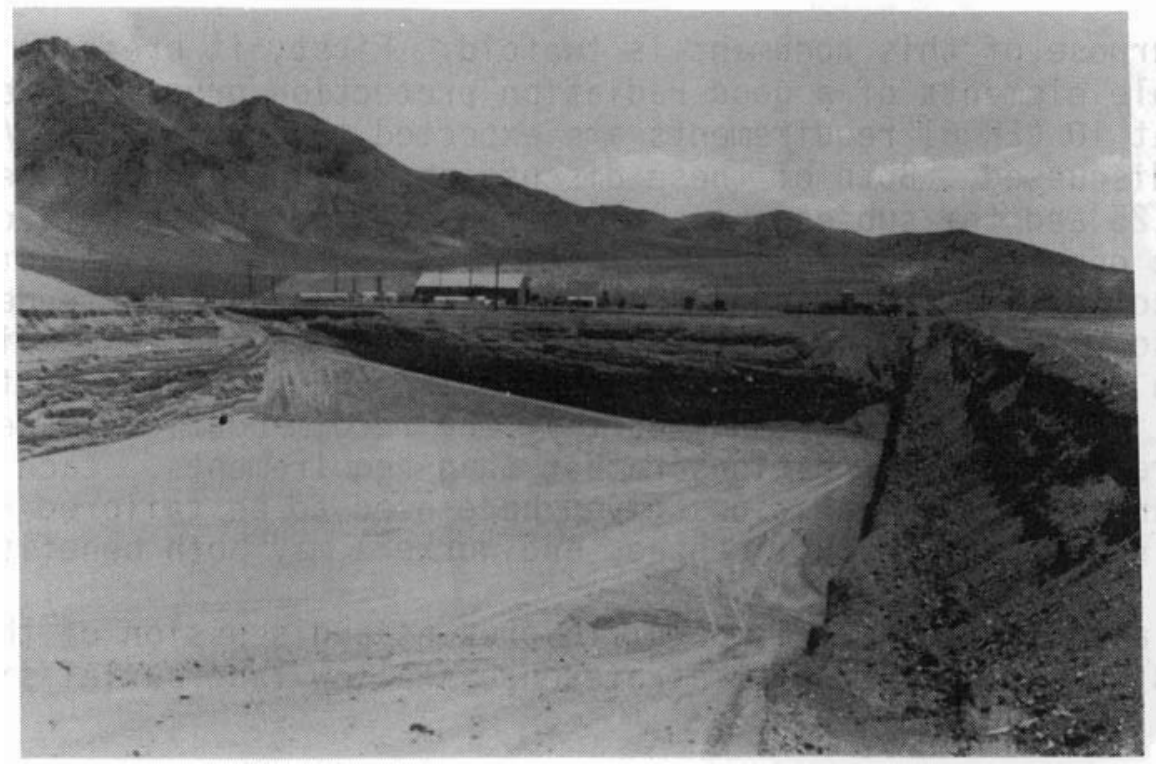

FIGURE 1. Operational Arid $\amalg W$ Disposal Site 


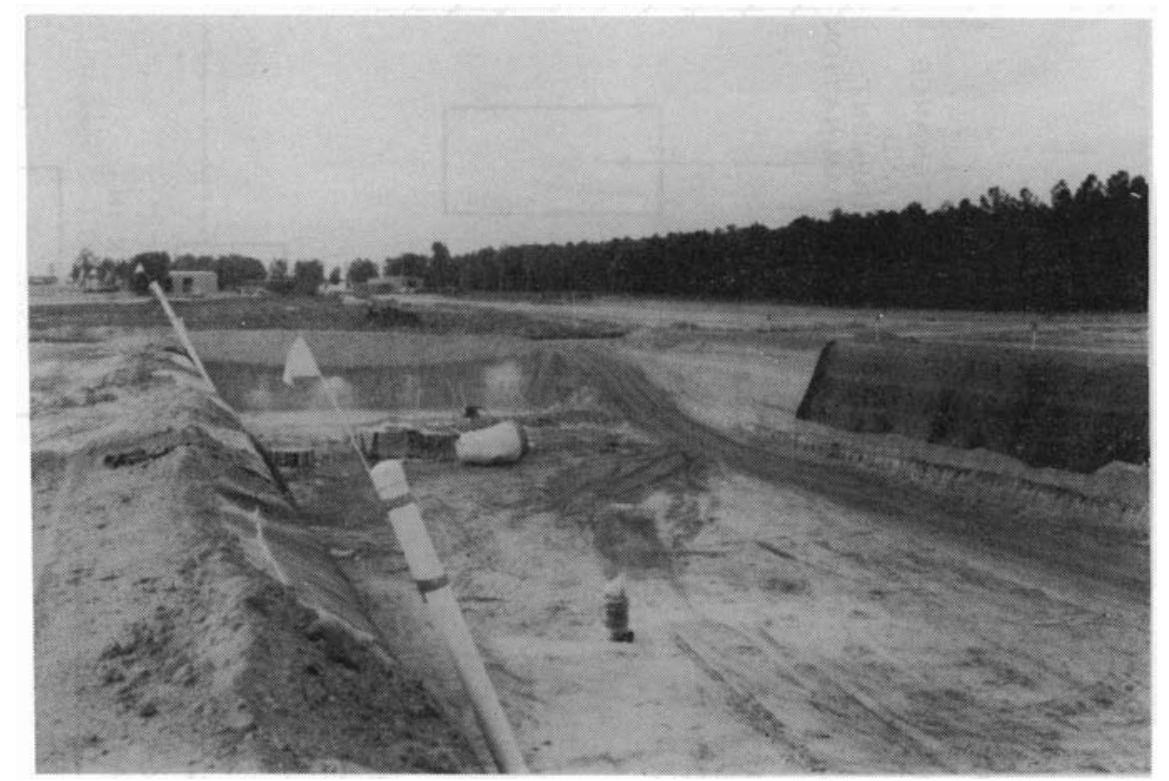

FIGURE 2. Operational Humid $\amalg W$ Disposal Site

The general site description includes hydrologic, geologic, and demographic characteristics of the site. Protection of the groundwater in the vicinity of the site is the primary reason for imposing restrictions on these characteristics. Towards this goal, the reference site fulfills the following requirements:

- Hydrology - Surface and subsurface water will not interfere with engineered barriers for the required design period. In addition, no streams, rivers, or sources of drinking water are in proximity to the site.

- Geology - Long term stability of the site is assurred. No cavernous media, steep slopes, or active faults are located near the site. There does exist a slight slope to the site that aids in surface water runoff.

- Demographic - The site is not located near any heavily populated areas, popular recreational areas, areas containing unique or endangered flora and fauna, or areas with the potential for natural resource development.

The site has a layout similar to that shown in Figure 3. A 2.4-meter high chain link fence runs the length of the site boundary and also divides the restricted and unrestricted areas. Disposal operations are carried on within the restricted area. 


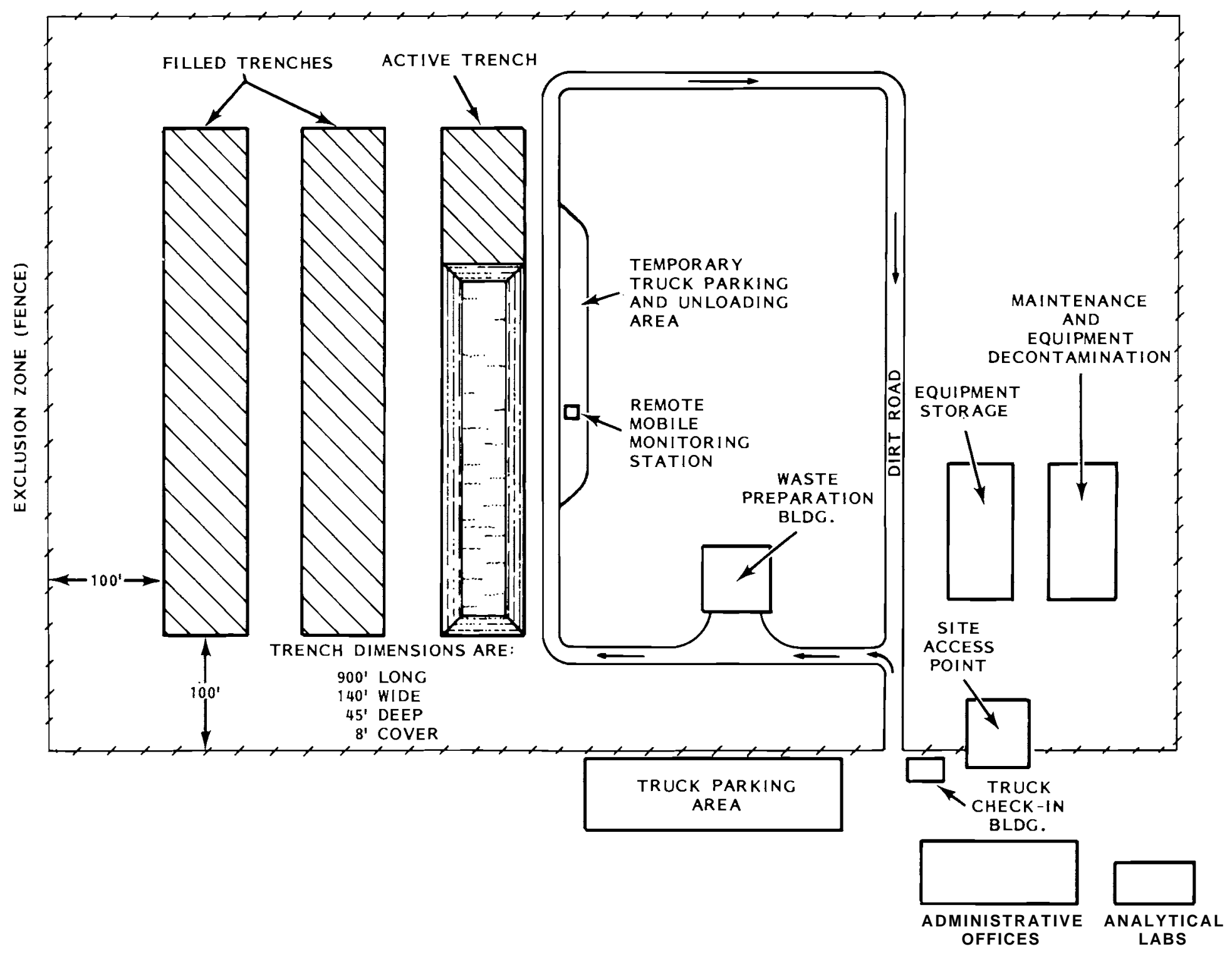

FIGURE 3. Reference $\amalg W$ Disposal Site Layout 
Not all of the 150 acres is assumed to be usable for disposal. If waste trenches are used with the dimensions as those in Figure 4 and if waste containers are randomly placed in the trench, the site will probably utilize 87 acres over its operational lifetime. This assumes the construction of 58 trenches for the reference disposal site. The land use rate is calculated to be 2.88 cubic meters of waste per square meter of land surface with these assumptions. The orderly placement of waste containers, as required by 10 CRR 61 , is assumed to require a land surface area less than the 87 acres. The remaining approximately 60 acres include the operational area and $100-f o o t$ buffer zones as well as any land devoted to roads, working areas, etc.

The trench walls slope at a 1:4 ratio (horizontal to vertical), but this may vary according to soil type. To decrease the likelihood of water collection, the trench has a 1 degree slope from end to end and from side to side. The slopes terminate in a gravel filled French drain which then drains into a gravel-filled sump. Several standpipes are located within the French drain system of each trench to allow periodic sampling of the drain system.

Facilities at the sites are generally the same as those discussed in NUREG/CR-3125. They include an Administration Building, a Site Access Building, a Maintenance and Decontamination Building, an Equipment Storage Building, and a Waste Preparation Building. A truck check-in station and an Analytical Laboratory are optional structures because those functions may be handled in another building. These facilities are described in the following list:

- Administration Building - Houses the site management and their support personnel (secretaries, clerks, etc.).

- Site Access Building - A multifunction building (See Figure 5) where site access is controlled, dosimetry is issued, Radiation Protection equipment and supplies are stored, and personnel exiting the restricted areas are surveyed. In addition, this area contains change rooms, personnel decontamination facilities, radiation protection offices and counting rooms.

- Maintenance and Decontamination Building - Structure which houses vehicle maintenance and general equipment repair. A separate section houses a variety of equipment decontamination apparatus.

- Equipment Storage Building - Where equipment and supplies are stored.

- Waste Preparation Facility - Building where tie-downs are removed and the waste is prepared for final removal from the truck and placement into the trench.

- Truck Check-in Building - Optional - A small structure primarily used for housing one or two persons, shipment records, and check-in equipment.

- Analytical Labs - Optional - Where onsite and offsite samples are analyzed - must be either well removed from site radioactive waste operations or well shielded from them. 


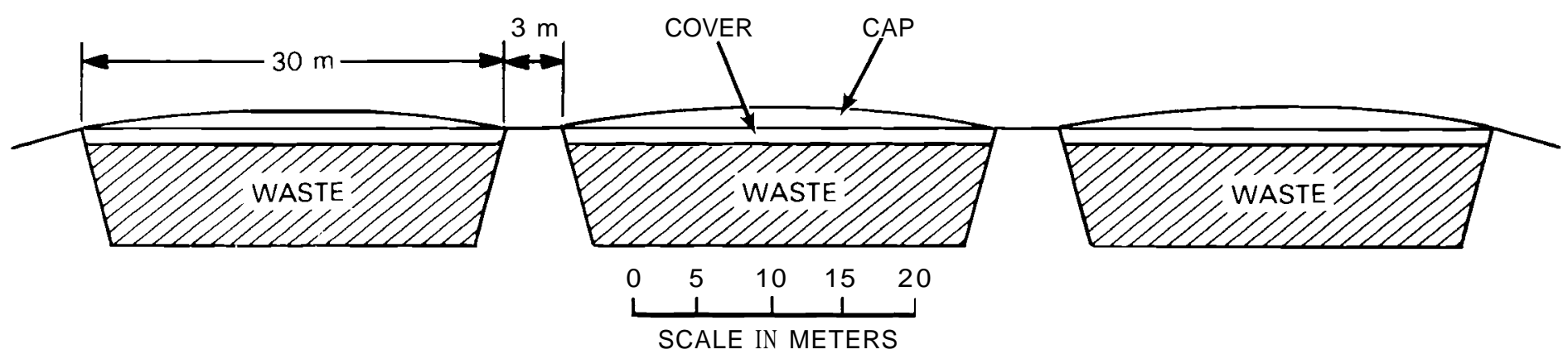

TYPICAL TRENCH CROSS-SECTION

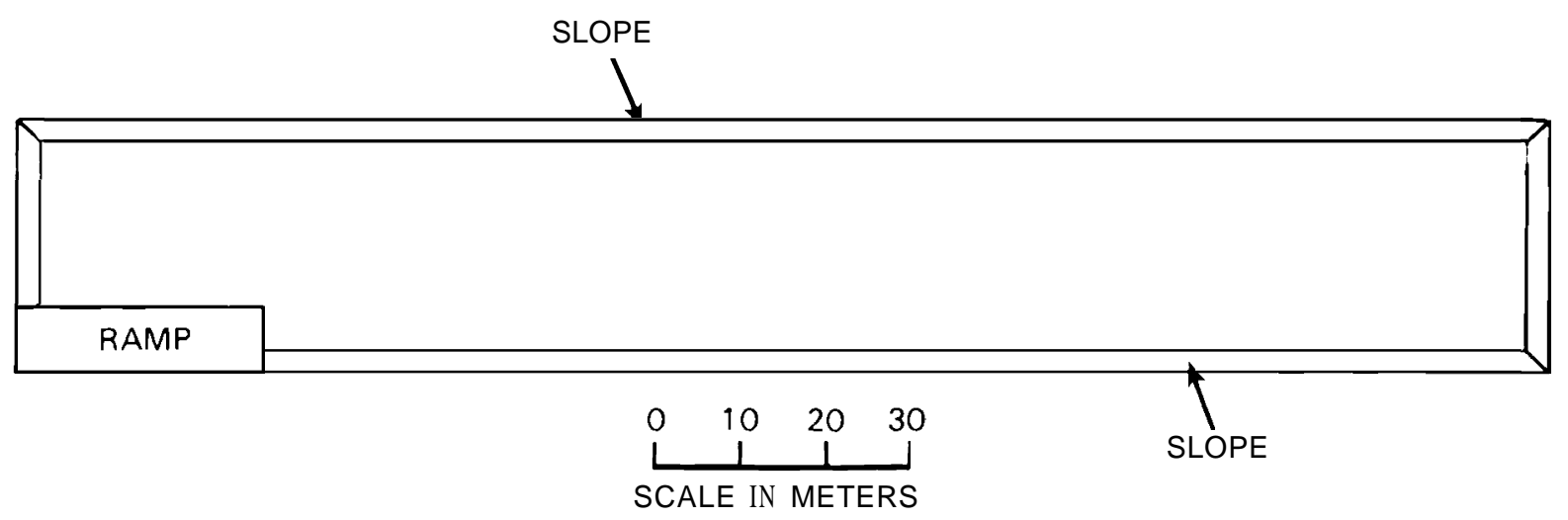

PLAN VIEW OF TYPICAL TRENCH

FIGURE 4. Reference LLW Disposal Trench 


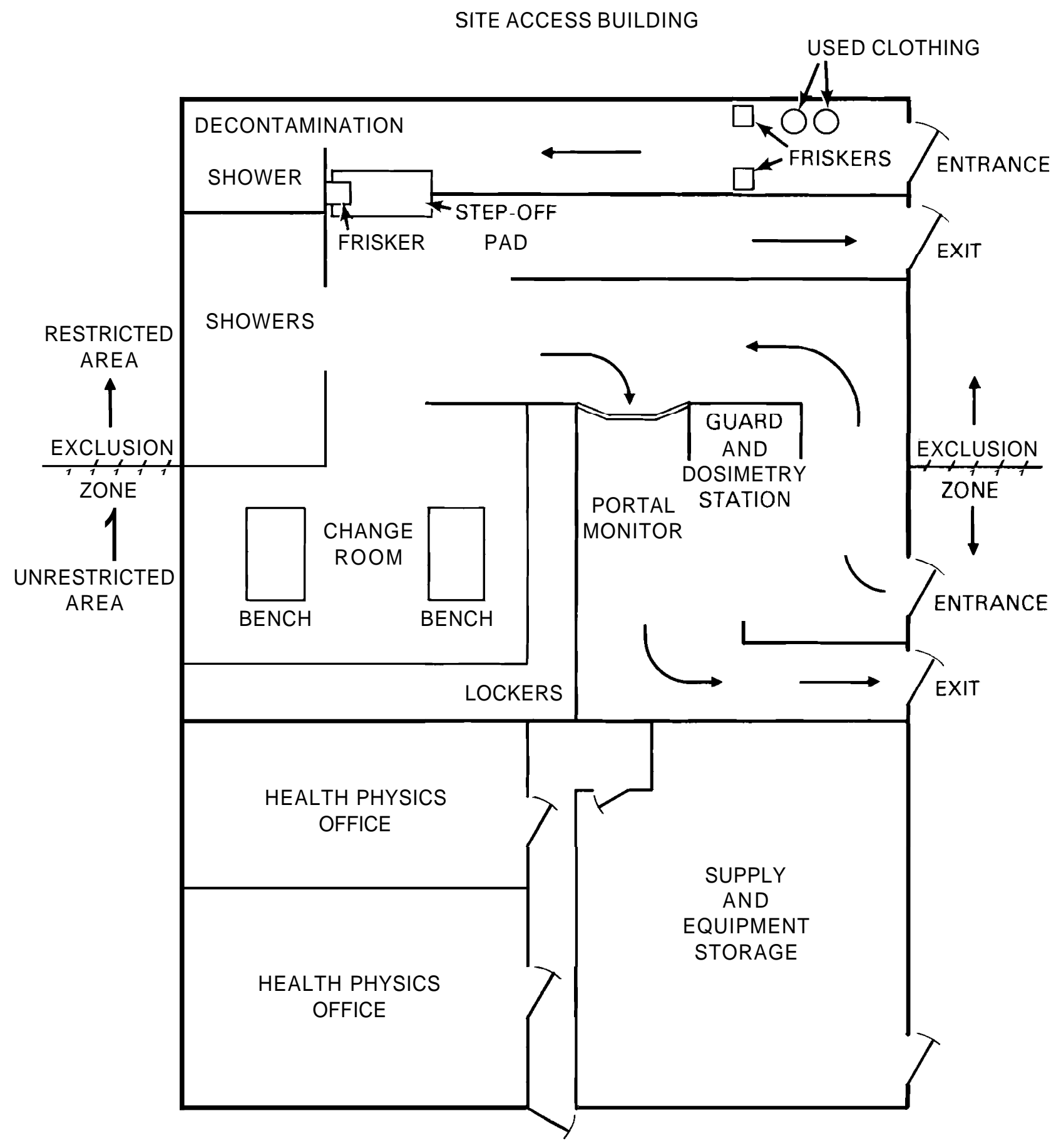

FIGURE 5. Reference LLW Disposal Site Access Building 
The discussion of the elements of an adequate radiation protection program for an $\amalg W$ disposal site and the impacts of $10 \mathrm{CFR} 61$ on that program are discussed in the following ten chapters. Chapters 2 through 4, entitled ALARA Program, Training Program, and External and Internal Exposure Control are based upon current practices at $\amalg W$ disposal sites. The next five chapters, Respiratory Protection, Surveillance, Contamination Control and Decontamination, Quality Assurance, and Procedures/Documentation are also based upon current-practices, but include significant recommendations for program improvement. The remaining chapter is a discussion of the anticipated onsite impacts of $10 \mathrm{CFR} 61$ and recommendations on what can be done to minimize the adverse impacts of this rule on occupational exposure levels.

It is recognized that ALARA is part of any radiation protection program and is used as a tool for that program. However, there are certain aspects of an ALARA philosophy tha't lend themselves to being formalized, such as an ALARA committee. Therefore, Chapter 2.0 is devoted to discussing these elements as part of a formalized ALARA program. Throughout the rest of this document, the use of the term ALARA or ALARA program is meant to be part of the radiation protection program as opposed to a separate entity.

Radiation protection procedures and documentation are very important both from a legal viewpoint and their everyday value. As a consequence, this document has included specific discussions of procedures and documentation in each chapter where applicable and in general in Chapter 9.0. Documentation discussions provide recommendations for radiation protection personnel on incidents, traceability, and trend analysis.

Following Chapter 10.0 is a Bibliography which is specific to each chapter. This method was chosen to minimize the time required to find additional information not outlined in this document. 


\subsection{ALARA PROGRAM}

Current occupational radiation exposure limits, for Low Level Waste (LLW) disposal sites, provide a very low risk of injury. However, it is prudent to keep exposure, thus risk, to "as low as is reasonably achievable" (ALARA) and to assure that this risk is assumed only if comparable benefit is achieved. Thus, the objective is to reduce occupational exposures to as far below the specified limits as is reasonably achievable by means of good radiation protection planning and practice, as well as by management commitment to ALARA policies. The ALARA concept is a part of the radiation protection effort, not a separate entity. While certain activities may be identified and conducted as ALARA actions, these same activities should also be part of a ncrmal comprehensive radiation protection program.

Maintaining radiation exposures, both external and internal, at or below the regulatory limits is not only good practice and legal protection, but an obligation to the $\amalg W$ disposal site employees. Therefore, establishing a common basis to compare the cost of reducing radiation exposure to the benefit of having done so is important. If the benefit equals or exceeds the cost, then the ALARA practice being evaluated should be implemented. However, costbenefit analysis is not the only tool to be used to evaluate exposure reduction methods and cannot be substituted for sound professional judgment. Those responsible for radiation protection in daily operations may need to rely on intuitive rather than quantitative evaluations. The emphasis of the present document towards ALARA will be directed to the use of professional judgment as opposed to a quantitative evaluation or mathematical formulation. The latter approach is commonly associated with the "optimization process" and has an objective of assigning an acceptable cost or dollar value per exposure unit.

The following discussion covers the areas of: (1) ALARA policy, (2) program reponsibility/authority, (3) training, (4) facility/equipment design, (5) procedures, '(6) controls, (7) preplanning/mock-ups, and (8) program effectiveness.

\subsection{ALARA POLICY}

Achieving a successful radiation protection program requires that the $\amalg W$ site management and personnel at all levels be cognizant of and committed to the ALARA pinciples and goals. In addition, a unified effort is essential for the functioning of the program.

An ALARA policy statement should be developed by corporate management and made available to all $\amalg W$ site personnel. This policy statement should be written to ensure that all personnel clearly understand that implementation of the ALARA concept is the desire and goal of management, is the responsibility of all individuals within the facility (regardless of their specific delegated responsibilities), and that all personnel will be evaluated and held accountable for performance according to the program criteria. The policy and 
commitment should be reflected in written administrative procedures and instructions for operations involving potential exposures of personnel to radiation and should be reflected in $\amalg W$ site design features. It should also describe the communications network from management to the staff and the feedback to management to promote full staff participation. minimum:

The ALARA policy statement should be based on the following criteria as a

- No practice should be adopted unless its introduction produces a positive net benefit.

- A?1 exposures should be kept as low as reasonably achievable; technological, economic and social factors being taken into account.

- The exposure to individuals should not exceed the limits recommended for the appropriate circumstances.

\subsection{PROGRAM RESPONSIBIL ITY/AUTHORITY}

The group responsible for coordinating the radiation protection program should be organizationally independent from the operational groups at an $\amalg W$ disposal site. If this is not accomplished a potential conflict of interest could arise between the operational and radiation protection functions. In addition, those responsible to coordinate the program must have a direct line of communication to the site manager. As a minimum, a specific individual should be assigned the responsibility for coordinating the program efforts. The staff member with overall responsibility for the program at an $\amalg W$ disposal site should be the Radiation Safety Officer (RSO) or Radiation Protection Manager depending upon site designation of title. A recommended organizational structure is outlined in Figure 6.

As can be seen in Figure 6, the RSO may share the ALARA responsibilities and functions with an ALARA committee. The responsibilities for this additional organizational component are discussed in Section 2.8.1 of this chapter. Even though one individual or group is responsible for coordinating the efforts, each $\amalg W$ site individual is responsible for understanding and carrying out the ALARA policies. It is especially important that first-line supervision of all radiation exposure user components recognize their responsibility and understand and practice the ALARA concepts.

The ALARA responsibilities at an $\amalg W$ disposal site may also be shared between the site manager and the RSO. Responsibilities of the site manager should include as a minimum:

- ensure support from all $\amalg W$ site personnel

- participation in the selection of ALARA goals and objectives

- provide support to the RSO for the ALARA policies. 


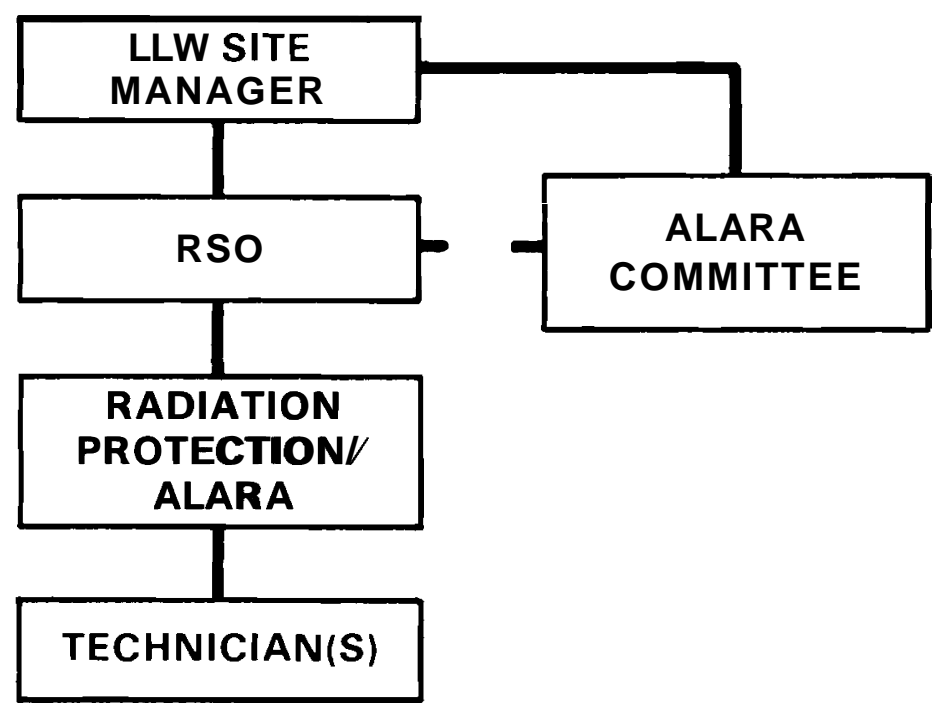

FIGURE 6. ALARA Organizational Structure

Responsibilities of the RSO should include as a minimum:

a implementation of internal and external exposure control programs

a operational, maintenance, and ALARA procedure development and review

a participation in development of training programs

a participation in design, redesign or modification reviews

a supervision of data collection, analysis and evaluation

a review of preplanning/mock-up activities.

\subsection{TRAINING}

Effective and successful implementation of an ALARA program requires knowledge and understanding of ALARA principles. Thus, training of $\square W$ dis posal site personnel in ALARA principles can be one of the most important elements in a radiation protection program. The training program should include instruction for all $\amalg W$ site personnel and should be given in conjunction with the radiation protection training. As a minimum, training should be given to personnel whose duties require: (1) working with radioactive materials, (2) entering radiation or contaminated areas, or (3) directing the activities of others who are categorized by (1) or (2) above. The overall radiation protection training program is discussed in detail in Chapter 3.0 of this document, with the portion specific to ALARA being covered in the following discussion.

ALARA training at $\amalg W$ sites. should be divided into: (1) general employee training, (2) radiation worker/management training, and (3) radiation protection staff training. These training programs are discussed in the following three sections. 


\subsubsection{General Employee}

General employees who may enter a radiation area should be provided specific training in ALARA. A radiation area is defined in 10 CFR 20.202(b)(2) and as used here is:

Any area, accessible to personnel, in which there exists radiation, originating in whole or in part within licensed material, at such levels that a major portion of the body could receive in any one hour a dose in excess of 5 millirem, or in any 5 consecutive days a dose in excess of $100 \mathrm{mi} 71$ irems.

This training should include as a minimum:

- UW site ALARA policy

- ALARA principles

a management commitnient and responsibilities

- radiation protection group responsibilities and authority

- individual's responsibilities.

\subsubsection{Radiation Worker/Management}

Personnel who frequent radiation areas are termed radiation workers. ALARA training for radiation worker's and management should include:

- ШW site ALARA policy

- ALARA principles

- management commitment and responsibilities

- radiation protection group responsibilities and authority

- greater emphasis on individual's responsibilities

- overview of ALARA program functions

- examples of ALARA techniques.

\subsubsection{Radiation Protection Staff}

A strong radiation protection organization is fundamental to radiation protection and effective exposure reduction to ALARA. Assisting in accomplishing radiation work with minimum exposure and maintaining personnel exposure as low as practicable has long been part of radiation protection. However, additional ALARA training should be provided to emphasize its importance. The degree of training provided will vary with the radiation protection staff members' level of experience, formal education, and assigned work functions. The training should include:

- $\amalg W$ site ALARA policy

- ALARA principles

a management commitment and responsibilities

a radiation protection group responsibilities and authority

a individual's responsibilities

- overview of ALARA functions

- examples of ALARA techniques 
- facility/equipment design techniques

- management system for ALARA implementation, goal development and measurement, and performance evaluation

- general exposure reduction techniques and site-specific practices

- periodic updates via short courses, etc.

\subsection{FACILITY/EQUIPMENT DESIGN}

The design of facilities and equipment necessary for the performance of work with radioactive materials provides an early opportunity to ensure radiation exposures are as low as reasonably achievable. The design process requires close coordination among many disciplines to accomplish the major objective of providing a usable facility or piece of equipment and to incorporate radiation protection and ALARA principles as well.

The design should be determined not only by the functional considerations of the facility, or equipment, but also by radiological factors. These factors include the type and quantity of radioactive material involved and the magnitude of the potential for internal and external radiation exposures to the $\amalg W$ site workers.

Personnel involved in the design of facilities should be trained in radiological design. General engineering or similar education may not be adequate to ensure recognition of radiological concerns. In addition, design personnel should be trained in ALARA principles. This training should include:

- LW site ALARA policy

- ALARA principles

- management commitment and responsibilities

- techniques and practices in designing for minimum radiation exposure use

- consideration of radiation exposure in selection and placement of equipment (reliability, maintenance, access)

- optimization techniques.

\subsection{PROCEDURES}

Procedures and the procedure development process should be used to ensure that ALARA considerations are included in work activities. Procedures should be reviewed and approved by those responsible for coodinating the radiation protection program prior to issue, when significant modifications occur, and periodically during use.

ALARA topic areas for which procedure development is recommended are:

- ALARA management, organization, and responsibilities

- ALARA committee responsibilities and functions. 
Procedure development is discussed in more detail in Chapter 9.0 of this document.

\subsection{CONTROLS}

The basic objective of a radiation protection program at an LLW disposal site is to reduce radiation exposures to workers to as low as reasonably achievable in order to reduce the level of risk. To ensure that this basic cbjective is met, administrative controls should be established at levels substantially below the regulatory limits. This will alert management of conditions so that actions can be taken to provide additional surveillance and control. These controls should not only be considered for external exposure from radiation fields but also for internal exposure from surface contamination and airborne radioactivity. Regulatory limits and recommended administrative control levels are discussed in detail in Chapters 4.0 and 6.0 of this document.

Exposures, meeting or exceeding the administrative control levels, should be investigated by qualified personnel from the LLW site radiation protection group. The results of the investigations and subsequent actions taken should be documented. The documentation should include the following information as a mininum:

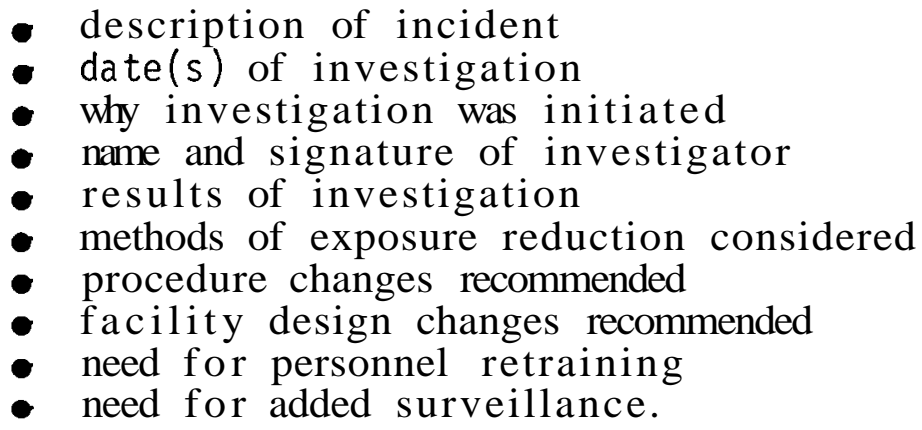

In addition to the administrative controls on exposure, it may be necessary to institute operational controls on certain tasks. The operational controls may i ncl ude:

- access control to radiation, contaminated or airborne radioactivity areas

- use of permanent or temporary shielding

- reduction of allowed exposure time

- increase of worker distance from exposure sources

- decontamination of area or equipment prior to commencing work

- use of protective clothing

- use of respiratory protection

- use of backfill over LLW in burial trenches

- remote handling of $\amalg W$ containers.

Operational controls are discussed in more detail in Chapters 5.0, 6.0, 7.0, and 10.0 of this document. 


\subsection{PREPLANNING/MOCK-UP TRAINING}

The effective use of planning before the job will provide one of the best opportunities to reduce personnel exposure. Preplanning allows time to determine the task to be accomplished, how it is best done, the resources necessary (including equipment, manpower and radiation exposure), the impact on surrounding activities and the impact of surrounding activities on the planned task.

In addition, preplanning allows assessnient of the training and skills necessary to do the work and, perhaps, the opportunity to use mock-ups to familiarize workers with the operation and practice sessions to sharpen skills, improve techniques and identify weaknesses in procedures.

Preplanning of work activities is particularly important in operations with high hazard potential, high radiation dose rates or potential airborne radionuclide concentrations, unusual or unique tasks, special maintenance tasks, recovery from accidents, or tasks with high cumulative exposure use.

The objective of preplanning is to execute tasks with minimum occupational exposure. In more practical terms, the objective of preplanning is to apply knowledge and past experience to the maximum extent possible to avoid repeating mistakes and to perfect the execution of the required task such that occupational exposure is ALARA. The preplanning stage involves four phases:

- documentation of existing $\amalg W$ site conditions that will affect execution of the designated tasks

- development of necessary procedures for the job at hand

- analysis of procedures to verify their validity

- practice of procedures to achieve the preset goal.

Practice of procedures can range from preoperational briefing for personnel who will perform services in a high-level radiation area to "dry runs" on mock-up equipment. Preoperational briefings can help ensure that personnel understand the tasks about to be performed, the information to be disseminated, and the special instructions to be presented. "Dry runs" can be useful for training personnel, identifying problems that can be encountered on the job, and selecting and qualifying special tools and procedures to reduce exposures. Mock-up equipment as defined here are any full-sized structural models built accurately to scale. They should be located in an area of the $\amalg W$ disposal site where the potential for exposure is minimal. This allows for extended study and practice with a minimum of exposure.

\subsection{PROGRAM EFFECTIVENESS}

The performance of the radiation protection program should be periodically reviewed by those directly responsible for its implementation and by management. The program should be evaluated based upon the objectives stated by 
management, its performance in meeting the goals established and its overall effectiveness in reducing exposure compared with the necessary work performed.

Care must be exercised in goal selection to ensure that the ultimate result is ALARA and not counter-productive. For example, some percentage reduction in radiation exposure for an $\amalg W$ operation may be established as a goal. However, if it is achieved by delaying or canceling needed maintenance or by reducing necessary surveillance activities, it may not be ALARA a t all. In addition, it should be recognized that exposure cannot be reduced year after year without end. After a period of time the exposures are going to reach a point (non-zero) for which further reduction is neither feasible nor warranted.

The following sections discuss three items that may be beneficial to evaluate the performance or effectiveness of the radiation protection programs at $\amalg W$ disposal sites. These are: (1) the ALARA committee, (2) trend analysis, and (3) program audits.

\subsubsection{ALARA Committee}

Essential to the success of any program is that management at the highest level be informed and apprised of the program's effectiveness and status. Normally, this can be accomplished via communication between the RSO and the $\amalg W$ site manager. However, this communication can be facilitated through an ALARA committee acting for and reporting directly to the site manager. The membership of this committee should include the RSO, the site manager, and one or more operating or support managers at a policy-making level. The ALARA committee is an extremely important management tool; therefore, it is suggested that it be structured to include the following personnel in addition to the RSO and the site manager:

a The various technical disciplines should be represented and chosen from departments other than the radiation protection department.

- The individuals chosen should be, as a minimum, senior personnel and recognized as expert in their respective disciplines.

Structured in this manner, the committee can not only make recommendations to those responsible for conducting the actual programs, but can also be effective in making recommendations that eventually become $\amalg W$ site policy. Additionally, the committee can be effective at resolving disputes. The committee should receive, as a minimum, the results of all reviews and audits, both internal and external, and should perform reviews of the overall radiation protection program.

To ensure that the ALARA committee accomplishes its goals, meetings are imperative and should be held every calendar quarter as a minimum. In addition, the ALARA committee should have the authority to ensure that an effective radiation protection program is in operation. 


\section{Trend Analysis}

Trend analysis is an important ALARA tool both for the radiation protection group and the ALARA committee. Trend analysis is especially useful for determining and anticipating the effects of actions that may, of themselves, appear to cause no noticeable change or cause changes that may be hidden within individual number fluctuations. Many radiological parameters, that are recorded as part of a routine radiation protection program, should be followed and analyzed for trends. Subjects of primary concern within the radiation protection program and to the ALARA committee and RSO are:

- mean individual exposure for the site

- mean individual exposure by job classification

- mean individual exposure by a particular task

- collective exposure for the site

- collective exposure by job classification

- collective exposure by a particular task

- contamination levels and areas

- airborne activity levels

- frequency of incidents.

\subsubsection{Program Audit}

As a minimum, the radiation protection program should be audited once per year and the results documented and transmitted to the $\amalg W$ site manager and corporate management. More frequent assessments may be desirable to inform management of program status or in operations where high exposure levels or significant potential hazards exist.

These program audits should be conducted by qualified personnel who are independent of those responsible for implementing the radiation protection program. In addition, the personnel assigned this function should be selected based on their technical knowledge of the operations being observed, and their technical competence and experience in radiation protection and ALARA. The independent assessment provides an objective evaluation to management, who should then provide redefinition of the program objectives and goals as feedback to those responsible for the radiation protection program implementation. This redefinition should include corrective actions for weaknesses identified. This feedback will ensure continual management attention and support for ALARA efforts. 


\subsection{TRAINING PROGRAM}

It is important for personnel working at $\amalg W$ disposal sites to be knowledgeable of the risks associated with radioactive material and how to minimize the risks. Thus, it is very important that the site personnel not only be trained but also be educated in minimizing risks. As defined here, education means imparting general or basic knowledge applicable to the job situation as a whole; it includes philosophical and theoretical bases, and permits understanding of the reasons for what takes place. Training, on the other hand, implies exercise or practice to gain a specific skill or proficiency and does not guarantee any understanding or knowledge of why the act is being performed. Therefore, training as used in this document is defined to include both training and educational aspects. In the final analysis, implementation of an effective radiation protection program not only depends upon the training program itself, but rests heavily on management support and the effort put forth by the workers. It is essential that the entire facility management and administrative support staff understand and support the effort to reduce radiation exposures to ALARA.

The following discussion covers the areas of: (1) program responsibility/authority, (2) personnel selection and qualification, (3) procedures/ lesson plans, (4) radiation protection (ALARA) training, (5) respiratory protection training, (6) female radiation worker training, (7) on-the-job training/mock-ups, (8) performance evaluation, and (9) training records, as they apply to the overall radiation protection training program.

\subsection{PROGRAM RESPONSIBILITY/AUTHORITY}

Radiation protection duties at $\amalg W$ disposal sites should be the responsibility of the radiation protection group. Typically this group is small and consists of a Radiation Safety Officer (RSO) and several radiation protection technicians. These individuals should have the responsibility for the radiation protection training outlined in this chapter. In a large organization, one or more of the staff member(s) may be exclusively assigned to the training program. To achieve an effective program, functional levels and assignment of responsibilities should be established for individuals that are part of the training organization.

The staff member with overall responsibility for the radiation protection training program should be the RSO or a delegated "training coordinator." Training responsibilities for this position should include as a minimum:

(1) training of upper management, (2) development of the overall training program, (3) training of radiation protection staff in the field, (4) evaluation of the training program's effectiveness and recommendations for improvement, and (5) guidance, assistance, and support to other staff members who have training responsibilities. The responsibilities, authority, and duties for staff members (RSO, instructors, administrative clerks, etc.) assigned to the training group should be outlined in formalized job descriptions which should be reviewed and updated periodically. Each staff member of an $\amalg W$ disposal site should be familiar with the contents of the job description that applies to them. 


\subsection{PERSONNEL SELECTION AND OUALIFICATION}

Radiation protection personnel at $\amalg W$ disposal sites should have a combination of training, experience, and skills commensurate with their functional level of responsibility. This will provide reasonable assurance that decisions and actions during normal and abnormal conditions will be such that the site is operated in a safe and efficient manner. Training can be satisfied by either academic training or related technical training. Academic training is defined to be the successful completion of college level work leading to a recognized degree in radiation protection. In contrast, related technical training is defined as formal radiation protection training beyond the high school level, such as required in training schools or programs conducted by the military, industry, vocational schools or others. Related technical training should count on a one-for-one time basis with academic training. Part of the experience requirement for radiation protection personnel may be acquired from non-LLW operations such as from military, civilian, government, or commercial nuclear facilities. However, observation of others performing radiation protection functions shall not be considered acceptable experience.

The following discussion outlines the recommended selection and qualification criteria for the: (1) RSO, (2) radiation protection technician, and (3) radiation protection training instructor.

\subsection{1 $\underline{\text { RSO }}$}

At the time of appointment to the RSO position, the responsible individual shall have experience in applied radiation protection at nuclear facilities dealing with radiation protection problems and programs similar to those at $\amalg W$ disposal sites. The individual should be familiar with the design features and operations of $\amalg W$ sites that affect the potential for exposures of site personnel to radiation. In addition, the RSO should have the technical competence to establish radiation protection programs and the supervisory capability to direct the work of radiation protection technicians.

The RSO should have a bachelor's degree in science or engineering (or its equivalent), including formal training in radiation protection. Minimum acceptable substitutes for a bachelor's degree are a high school diploma or it s equivalent and one of the following: (1) four years of formal schooling in science or engineering, (2) four years of applied experience at a nuclear facility in the area of radiation protection, or (3) any combination of the above totaling four years.

The RSO should have at least three years of experience in radiation protection, one year of which should be at a $\amalg W$ disposal site. If the RSO does not have a bachelor's degree, then a total of seven years experience is recommended. A master's degree and doctor's degree may be considered equivalent to one and two years experience, respectively, if the course work is related to radiation protection. 


\subsubsection{Radiation Protection Technician}

At the time of appointment, a senior radiation protection technician should have three years of working experience in radiation protection of which one year should be from an แW disposal site. The technician should possess a high degree of manual dexterity and ability, and should be capable of learning and applying basic skills.

Individuals in training or apprentice positions should not be considered technicians, but should be permitted to perform work for which qualification has been demonstrated. The classification of radiation protection technicians should be as follows:

in training (minimal experience) - apprentice technician

- 0-3 years experience - technician

- greater than 3 years experience - senior technician.

However, time alone is not enough. Any training and advancement program should also require technicians to pass written and oral examinations before advancing to different technician levels.

\subsubsection{Radiation Protection Training Instructor}

At the time of appointment to the instructor position, the responsible individual shall have experience in applied radiation protection at nuclear facilities dealing with radiation protection problems and programs similar to those at $\amalg W$ disposal sites. The individual should be familiar with the design features and operations of $\amalg W$ sites that affect the potential for exposure of site personnel to radiation.

The instructor should have an associate's degree in science or engineering (or its equivalent), including formal training in radiation protection. Minimum acceptable substitutes for an associate degree are a high school diploma or its equivalent and one of the following: (1) two years of formal schooling in science or engineering, (2) two years of applied experience at a nuclear facility in the area of radiation protection, or (3) any combination of the above totaling two years. The instructor should have one year of experience in radiation protection at an $\amalg W$ disposal site. If the instructor does not have an associate's degree, then a total of three years experience is recommended.

Personnel temporarily filling the RSO, technician, or instructor positions due to absences of the principal may not meet the requirements outlined above. Use of personnel to fill a position for which they do not meet the minimum requirements may be justified, but the duration of the assignment should not exceed three months.

The selection and qualification criteria for all three of the above positions should be fornialized in written procedures. The academic background and previous radiation protection experience for the selected personnel should be documented and kept in the staff member's training file. 


\subsection{PROCEDURES/LESSON PLANS}

Each $\amalg W$ disposal site should have a formalized written training program which is specific to radiation protection. The formalized training document should include as a minimum: a program policy statement; staff members responsibilities, authority and job descriptions; training procedures; and lesson plans. Training procedures should define:

a the extent and content of the program

- training and retraining frequency

- the records required

- student performance evaluation.

Radiation protection lesson plans may be in the form of or include:

- course outiines

- syllabuses

- brochures

- video tapes

- motion pictures

- texts

- tests.

Visual aids are generally an important part of any training program. In addition to motion pictures, video tapes can be used advantageously for radiation protection training. Video tapes are useful to record lectures and demonstrations that are to be used repeatedly for a certain type of training (i.e., general employee) but at different times. The use of video tapes allows a large number of personnel to view procedures, such as conducting radiological surveys or donning and removing protective equipment and clothing, that ordinarily could only be observed by a few staff members at one time. However, visual aids should not comprise the total training program. The program should include discussipns by the instructor. It is recommended that at least $50 \%$ of the training be classroom/lecture with instructor participation. This could promote valuable feedback from student to instructor and provide the opportunity for assessment of student comprehension.

In order to have effective training procedures and lesson plans, it is necessary that they be periodically reviewed and updated as necessary. The review process should be conducted not only by the person responsible for the program (RSO), but also by the personnel performing the training functions on a routine basis. Upon acceptance of the procedures and lesson plans, the RSO should sign and date them to indicate that they represent current training policy. It is recommended that the review and update process be performed at least annually. Procedure development is discussed in more detail in Chapter 9.0 of this document. Lesson plans specific to radiation protection training for the general employee, the radiation worker, and the radiation protection rtaff are outlined in Section 3.4. 


\section{$\underline{\text { RADIATION PROTECTION TRAINING }}$}

The objective of a training program should be to ensure the safe and efficient operation of a facility. To accomplish this, the organization should be fully qualified for the operational, maintenance, and technical aspects of the nuclear facility involved. The organization of a $\amalg W$ disposal site can be broken down into three main categories for radiation protection training. These groupings are: (1) general employees or all persons regularly employed at an $\amalg W$ site, (2) radiation workers, and (3) the radiation protection staff. Course content for these three types of training are outlined in the following three sections.

\subsubsection{General Employee}

Information on the $\amalg W$ site's radiation protection policy and program should be presented to all new employees during the general employee orientation training. The orientation training should consist of classroom instruction and may be supplemented by other training methods. Written material covering the basic topics of the training should be distributed to the new employees for future reference. Visitor and contractor personnel should be given the same training, if it is expected that they may encounter radioactive material or radiation levels above background. It is recommended that the classroom instruction phase of this training be at least one hour in length.

A recommended course outline/lesson plan for the radiation protection segment of the general employee training is given below.

\section{Radiation Protection-General Orientation Training}

\section{A. Technical}

1. Sources of radiation
a. Natural

b. Man made

2. Biological effects of radiation

3. External dosimetry

4. Time/distance/shielding

5. Internal dosimetry

6. Contamination control
a. Sources of contamination
b. Protective clothing
c. Respiratory protection
d. Controlled areas and exiting

7. Exposure of female workers 

8. Instrumentation
9. Personal Surveys.

B. Administrative

1. $\amalg W$ site radiation protection policy

2. Role of radiation protection organization

3. Authority of radiation protection organization

4. ALARA philosophy and practices

5. Regulatory and administrative limits

6. Radiological posting
a. $\amalg W$ disposal site
b. Regulatory (State/NRC/DOT)

7. Responsibilities of individuals

8. Radiological emergencies

9. Land burial of $\amalg W$.

Training for escorted visitors should include the required actions for emergency situations and any of the above mentioned technical or administrative topics as determined by the training coordinator or RSO.

\subsubsection{Radiation Worker}

Specialized radiation protection training should be given to all staff members who enter a radiation area, even if they do not work directly with radioactive material. A radiation area is defined in 10 CFR 20.202(b)(2) and, as used in this document, states:

Any area, accessible to personnel, in which there exists radiation, originating in whole or in part within licensed material, at such levels that a major portion of the body could receive in any one hour a dose in excess of 5 millirem, or in any 5 consecutive days a dose in excess of $100 \mathrm{mi} 11$ irems.

Personnel who work in a radiation area are termed radiation workers and their radiation worker training should be received prior to entering or beginning work in a radiation area. It is recommended that the classroom instruction phase of this training be at least four hours in length.

A recommended course outline/lesson plan for the radiation worker training is given below. 


\section{$\underline{\text { Radiation Worker Training }}$}

A. Technical

1. Sources of radiation
a. Natural

b. Man made

2. Basic atomic and nuclear physics

3. Types of radiation and their characteristics

4. Radiation units

5. Biological effects

6. Radiation measurement and survey instruments

7. External dosimetry

8. Time/distance/shielding

9. Internal dosimetry

a. Whole-body/lung counting

b. Urinalysis

c. Fecal analysis

10. Contamination control

a. Sources of contamination

b. Protective clothing

c. Controlled areas and exiting

d. Personal surveys

11. Personnel and equipment decontamination

12. Airborne radioactivity

13. Respiratory protection

14. Female radiation worker exposure

15. First aid considerations.

B. Administrative

1. LLW site radiation protection policy

2. Role of radiation protection organization

3. Authority of radiation protection organization 
4. ALARA philosophy and practices

5. Regulatory and administrative limits

6. Radiological posting

a. $\amalg W$ disposal site

b. Regulatory (State/NRC/DOT)

7. Radiological surveys, purposes and methods

8. Control and removal of contaminated equipment

9. Procedures for receipt and handling of $\amalg W$

10. Quality assurance

11. Investigation and reporting of abnormal exposures

12. Responsibilities of individuals

13. Radiological emergencies

14. Land burial of LLW.

\subsubsection{Radiation Protection Staff}

Radiation protection training should be given to all radiation protection technicians and professional health physicists/training instructor(s) by the RSO or a delegated radiation protection staff member. It is recommended that the training be an ongoing process, such as setting aside a certain amount of time each week or month to cover a different subject area. The classroom phase of this training should comprise about 40 hours annually with the handson training comprising an additional 20 hours as a minimum. Up to $50 \%$ of the classroom phase may take the form of continuing professional development through attendance and participation in scientific and technical meetings, academic courses, short courses, and other continuing education courses. A course outline/lesson plan for this training can be developed from the radiation worker course outline in Section 3.4.2 of this document. However, additional technical detail would need to be provided to the following subject areas:

- external dose calculations

- internal dose calculations

- shielding calculations, techniques

- counting statistics

- isotopic analysis methods.

Radiation protection training for the RSO should be performed by professional health physicists from corporate management. If qualified personnel do not exist in the corporate structure, then training should be provided by an outside group such as a university or consulting firm, or by attendance at 
short courses. The training should include technical aspects and state-of-theart technology. In conjunction with this formal training, the RSO (and other radiation protection staff members) should also read and review open iiterature articles. This training may also be satisfied in part through attendance and participation in selected scientific and technical meetings and academic courses. It is recommended that the RSO training be a continuing process. As a minimum, retraining for RSOs should be given on an annual basis. The duration of this training should be established by corporate management for each யW disposal site.

\subsubsection{Training/Retraining Frequency}

It is important that all $\amalg W$ disposal site personnel receive training for radiation protection. This should include initial training and retraining often enough and at appropriate times so that a high degree of proficiency is maintained. The recommended training and retraining requirements for general employees, radiation worker, and radiation protection staff training are summarized in Table 1. Training results should be documented and kept in individual training files for each staff member. Training documentation criteria are discussed in more detail in Section 3.9 of this chapter.

\subsection{RESPIRATORY PROTECTION TRAINING}

Personnel who may be required to wear respiratory protection should receive training in the proper wearing and use of all respiratory protection devices available at the $\amalg W$ disposal site. The training should include a description of how radioactive material enters into the human body and how the respirator minimizes this occurrence. Respirator training should be given to anyone whose job requires the wearing of respirators and to those who direct the work.

Training in the use of respiratory protection should be given by a qualified and experienced instructor. Preferably this instructor should be the RSO or a delegated staff member from the onsite radiation protection group. To be qualified, the instructor should be knowledgeable in the application and use of respiratory protection equipment and of the hazards associated with radioactive airborne contaminants. In addition, the instructor should have one year's experience in the practical selection and use of respirators for protec tion against airborne radioactivity. It is highly desirable that this individual be trained by one of the respirator manufacturers in the proper fitting, cleaning and repairing of respirators.

Personnel who are to use respirators should receive training prior to entering or beginning work in an airborne radioactivity area where respirators may be required. As defined here and in 10 CFR 20.203(d) an airborne radioactivity area is:

... any operating area in which airborne radioactive material coniposed wholly or partly of licensed material exists in concentrations which, 
TABLE 1. Radiation Protection Training/Retraining Summary

\begin{tabular}{|c|c|c|c|c|}
\hline $\begin{array}{c}\text { Type } \\
\text { of } \\
\text { Training } \\
\end{array}$ & $\begin{array}{c}\text { Employees } \\
\text { Receiving Training }\end{array}$ & $\begin{array}{l}\text { Completion } \\
\text { of Initial } \\
\text { Training } \\
\end{array}$ & $\begin{array}{l}\text { Minimum } \\
\text { Frequency } \\
\text { of } \\
\text { Retraining }\end{array}$ & $\begin{array}{l}\text { Minimum Duration of } \\
\text { Training/Retraining }\end{array}$ \\
\hline $\begin{array}{l}\text { General } \\
\text { Employee }\end{array}$ & $\begin{array}{l}\text { All site personnel, } \\
\text { visitors, and con- } \\
\text { tractors }\end{array}$ & $\begin{array}{l}\text { Within one } \\
\text { week of } \\
\text { employment }\end{array}$ & Annually & $1 \mathrm{hr}$ classroom \\
\hline $\begin{array}{l}\text { Radiation } \\
\text { Worker }\end{array}$ & $\begin{array}{l}\text { Staff members en- } \\
\text { tering radiation } \\
\text { areas }\end{array}$ & $\begin{array}{l}\text { Prior to } \\
\text { first } \\
\text { entry }\end{array}$ & Annually & $\begin{array}{l}4 \mathrm{hr} \text { classroom, } \\
\text { hands-on training } \\
\text { as needed }\end{array}$ \\
\hline \multirow{2}{*}{$\begin{array}{l}\text { Radiation } \\
\text { Protec- } \\
\text { tion } \\
\text { staff }\end{array}$} & $\begin{array}{l}\text { Technicians } \\
\text { assuming } \\
\text { responsi- } \\
\text { bility }\end{array}$ & Prior to & $\begin{array}{l}\text { Ongoing } \\
20 \mathrm{hr} \\
\text { hands-on }\end{array}$ & $40 \mathrm{hr}$ classroom, \\
\hline & $\begin{array}{l}\text { RSOs Prior to } \\
\text { assuming } \\
\text { responsi- } \\
\text { bility }\end{array}$ & $\begin{array}{l}\text { Ongoing } \\
\text { (annuall y } \\
\text { as a } \\
\text { minimum) }\end{array}$ & As needed & \\
\hline $\begin{array}{l}\text { Respira- } \\
\text { tory Pro- } \\
\text { tection }\end{array}$ & $\begin{array}{l}\text { Personnel required } \\
\text { to wear respirators } \\
\text { or supervise res- } \\
\text { pirator work }\end{array}$ & $\begin{array}{l}\text { Prior to } \\
\text { first } \\
\text { use }\end{array}$ & Annually & $\begin{array}{l}2 \mathrm{hr} \text { classroom, } \\
1 \mathrm{hr} \text { hands-on }\end{array}$ \\
\hline
\end{tabular}

which, averaged over the number of hours in any week during which individuals are in the area, exceed $25 \%$ of the amounts specified in Appendix B Table I, Column 1 of 10 CFR 20.

It is recommended that the classroom instruction phase of this training be at least two hours in length with an additional hour set aside for hands-on training such as donning, removing, and proper fitting of respirators.

A recommended course outline/lesson plan for the respiratory protection training is given below. 
$\underline{\text { Respiratory Protection Training }}$

A. Technical

1. Sources of airborne radioactivity

2. Airborne radioactive units

3. Biological pathways

4. Types of respirators

5. Types of filters

6. Respirator operation

7. Respirator Timitations

8. Respirator fitting

9. Proper use and maintenance

10. Action for respirator malfunction.

B. Administrative

1. $\amalg W$ site respiratory protection policy

2. Regulatory and administrative limits

3. Airborne radioactivity area posting

4. Responsibilities of individuals

5. Radiological emergencies.

The staff should be retrained often enough and at appropriate times so that a high degree of proficiency will be retained when respiratory protection equipment is actually used. As a minimum, it is recommended that retraining be performed on an annual basis.

\subsection{FEMALE RADIATION WOPKG TRAINING}

A special situation arises when an occupationally exposed woman is pregnant. Exposure of the woman's abdomen to penetrating radiation from either external or internal sources may also expose the embryo or fetus. A number of studies have indicated that the embryo or fetus is more radiosensitive than an adult, particularly during the first three months after conception, when a woman may be unaware of her pregnancy. Therefore, women should be encouraged to voluntarily inform the radiation protection group of their pregnancy. Every effort should be made to limit the dose to an embryo-fetus to 0.5 rem during the entire gestation period from occupational exposure of the mother. This exposure should be as uniformly distributed with time as is practicable.

All individuals who work at an $\amalg W$ disposal site should receive training in the risks associated with radiation exposure, including the risks to the unborn. Therefore, it is necessary to provide specialized training to the women onsite. Additionally, it is important that the men working alongside the women understand the risks involved and the reasons for the reduced occupational exposure limit during pregnancy. This training should be part of the general employee and radiation worker training curriculum both initially 
and during retraining. It is recommended that the following items be discussed during this segment of the training:

- reassignment to other work areas

- first three months of pregnancy are the most important

- risk to the unborn child

- ability to bear children

- administrative exposure limits.

In addition, copies of NRC Regulatory Guide 8.13, "Instruction Concerning Prenatal Radiation Exposure," should be made available to all students.

\subsection{ON-THE-JOB TRAINING/MOCK-UP TRAINING}

On-the-job training related to ALARA is essential for the $\amalg W$ disposal sites. This training should include demonstration, practice, and detailed descriptions of actions necessary for radiation protection. Two of the most effective on-the-job training mechanisms are hands-on training and the use of facility mock-ups.

Hands-on training should include instrument use, survey techniques, use of protective clothing and respiratory protection, and decontamination of equipment and personnel. Using equipment or facility mock-ups can also enhance training effectiveness. This allows individuals to practice procedures in a realistic setting before they enter areas where a potential for exposure to radioactive contamination exists. This type of training is especially valuable for repair and maintenance tasks that could result in high doses to personnel in relatively short periods of time.

\subsection{PERFORMANCE EVALUATION}

Each staff member's knowledge, competency, and understanding of radiation protection principles should be evaluated. The evaluation may consist of a written or oral test but should, in most cases, include an on-the-job performance test.

Testing criteria should be developed by each $\amalg W$ disposal site. However, it is recommended that written tests be developed using multiple choice questions. As a minimum, the general employee test should have 15 to 20 multiple choice questions. The test should be given immediately following the training with an allotted testing time of one-half hour. The radiation worker test should consist of 25 to 30 multiple choice questions with an allotted testing time of one hour. Passing grades on these two tests should be $70 \%$ or greater. If a student fails a test then it should be required that the course be retaken. Test questions should be changed periodically to ensure that the tests are not compromised. The questions asked, responses given, and test scores should be documented in each staff member's training file. Requalifi- cation testing should be conducted in conjunction with the designated retraining courses. 


\section{TRAINING RECORDS}

A separate training file should be established for each staff member at the $\amalg W$ disposal site. As a minimum, the file should contain the staff member's resume, including academic courses, copies of graded tests and instructor sign-off sheets. Additional required training records are discussed in detail in Chapter 9.0 of this document.

\subsection{RECOMMENDATIONS}

Personnel working at $\amalg W$ disposal sites should be trained regarding the risks associated with radioactive material and how to minimize the risks. This chapter has outlined the areas of personnel selection and qualification and specific training for various job classifications. The major recommendations made for program adequacy were:

- The ROO should have a Bachelor's Degree in Science or Engineering (or its equivalent) and 3 years of experience in radiation protection.

- General employee training should be given on an annual frequency for a one-hour duration.

- Radiation worker training should be given on an annual frequency for a four-hour duration.

- Female radiation worker training should be part of the radiation worker training curricul ums for general employee, radiation worker and radiation protection staff training. 


\subsection{EXTERNAL AND INTERNAL EXPOSURE CONTROL}

Minimizing external and internal exposure is the primary objective of a radiation protection program. In addition, the ALAKA philosophy must be considered in the development of the exposure controls for this program.

The following discussion covers the areas of: (1) external exposure control, and (2) internal exposure control.

\subsection{EXTERNAL EXPOSURE CONTROL}

External radiation exposure is defined as the exposure of the body to radiaticn emitted by materials outside of the body. One of the objectives of an ALARA program at an $\amalg W$ disposal site is to minimize the external exposure to occupational workers. To accomplish this objective, an external exposure control program must be established to enable the staff to predict exposure levels in addition to minimizing them.

The following sections contain information regarding: (1) program responsibility, (2) exposure sources, (3) administrative controls, (4) operational controls, and (5) dosimetry.

\subsubsection{Program Responsibility}

The organization having overall responsibility for radiation protection at an $\amalg W$ disposal site should also be responsible for the establishment of the exposure control program. An organizational structure for the exposure control program should be formally defined and documented. The staff member with overall responsibility for the program at an $\amalg W$ site should be the Radiation Safety Officer (RSO) or Radiation Protection Manager, depending upon site designation of title. A recommended organizational structure is outlined in Figure 7. The authority and duties of personnel and organizations responsible for exposure control should be documented in writing. The personnel should have sufficient authority and organizational freedom to identify problems; to initiate, recommend or provide solutions; and where necessary, to control or stop further work either in-house or by vendors.

\subsubsection{Exposure Sources}

Several factors may affect the external radiation exposure a worker receives from a radiation source. These factors include the activity level of the $\amalg W$ material handled, the duration of exposure to the $\amalg W$ material, and the type of radiation encountered.

The activity level of the material comprising $\amalg W$ is commonly termed the material's source strength and may be expressed in units of curies (or SI units of bacquerels). The exposure rate from this material is a direct linear function of the source strength, i.e., if the activity level is halved, then 


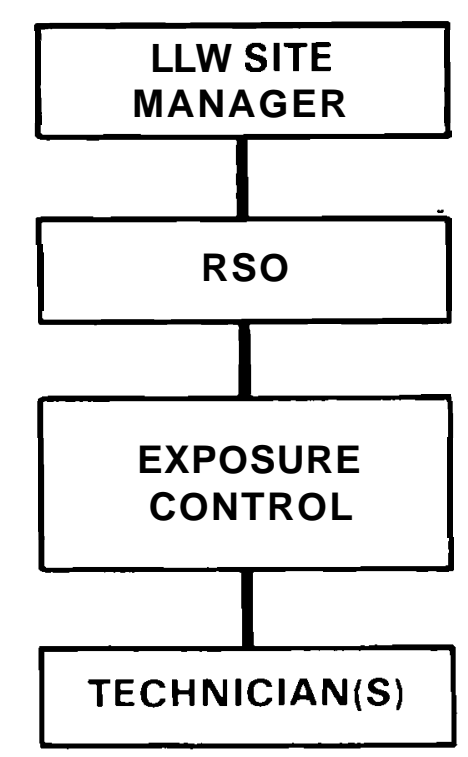

FIGURE 7. Exposure Control Organizational Structure

the exposure level is halved. In addition, the total exposure from the material is directly dependent upon the exposure time. That is, if the exposure time is halved then the total exposure is halved. This concept is discussed in detail in Section 4.1.4.1 of this document.

The three primary types of radiation that are most often encountered from commercial $\amalg W$ are: alpha, beta, and gamma. Of these, gamma rays (penetrating radiations), which can pass through the body and irradiate the internal organs, are considered to be more of an external hazard than the relatively nonpenetrating charged particles, such as alpha and beta radiation.

An alpha particle must have an energy of at least $7.5 \mathrm{MeV}$ to penetrate the $0.07-\mathrm{mm}$-thick protective layer of skin on the human body. The vast majorit y of known alpha-emitting radionuclides have alpha energies less than 7.5 MeV. In addition, the $\amalg W$ is packaged in wood or metal burial containers which provides sufficient shielding between the $\amalg W$ and the worker to completely attenuate the alpha particles. For these two reasons, alpha particles are not considered to present an appreciable external radiation hazard, and external exposure calculations should not be required. The attenuation of beta particles by air can be appreciable. This fact, in conjunction with the attenuation provided by the burial containers, indicates that beta particles from $\amalg W$ present a minimal external radiation hazard in most circumstances. However, it must be emphasized at this point that external beta particle exposure can be significant if the waste container's integrity is compromised. In addition, if the waste contains high energy beta-emitting isotopes, then these will contribute to the total exposure (including Bremsstrahlung) and the 
appropriate corrections must be made to the total exposure. The primary source of external radiation exposure to the $\amalg W$ disposal site staff member is from gamma rays emanating from the $\amalg W$ in the burial containers. Gamma measurements or calculations may be expressed in exposure units of roentgens (R) or in units of dose equivalent (rem).

In addition to the exposure from $\amalg W$ burial containers, workers may be subject to external exposure from radiological calibration sources, fixed surface contamination on transport vehicles, and background radiation. The discussion in the remainder of this chapter will deal only with the handling and disposal of LW; however, the principles may be applied to any source of external exposure.

\subsubsection{Administrative Controls}

The RSO, in conjunction with other site management, should control the activities of personnel at the $\amalg W$ site so that each individual's exposure does not exceed regulatory liniits and site administrative control levels, and is maintained ALARA.

External exposure may be categorized as: (1) whole body exposure, (2) skin exposure, or (3) extremity exposure. Whole body exposure, as defined here, is the exposure received by the trunk of the body, head, gonads, lens of the eye, red bone marrow, and active blood-forming organs. Exposure to unlimited areas of the skin excluding the hands and forearms, is categorized as skin exposure. The exposure received by hands, feet, and forearms comes under the category of extremity exposure. In the majority of the cases at an LW disposal site, the exposure to the whole body should be the rimiting factor and active control of whole body exposure will ensure that skin and extremity exposures are adequately controlled. If $\amalg W$ containers need to be manipulated by hand, all reasonable effort should be made to keep exposure to the forearms and hands to the general limit for the skin.

The regulatory limits for external dose equivalent based on 10 CFR 20.101 are: (1) during any calendar quarter, the total occupational dose equivalent to the whole body shall not exceed 3 rems, and (2) the dose equivalent to the whole body, when added to the accumulated occupational dose equivalent to the whole body, shall not exceed $5 \times(\mathrm{N}-18)$ rems where "N" equals the individual's age in years at his/her last birthday. Administrative control levels should be established to ensure that these regulatory limits are not exceeded and that the exposures are minimized to ALARA. Table 2 lists a set of recommended

TABLE 2. Administrative Control Levels for External Dose Control

\begin{tabular}{ccc} 
Type of Exposure & $\begin{array}{c}\text { Annual } \\
\text { (rem) }\end{array}$ & $\begin{array}{c}\text { Calendar } \\
\text { Quarter (rem) }\end{array}$ \\
\cline { 2 - 3 } Whole Body & 4 & 1.25 \\
Skin & 12 & 3 \\
Extremity & 12 & 3
\end{tabular}


administrative control levels for external dose equivalents at an LW disposal site. The recommended control level for the annual whole body dose equivalent was chosen to ensure that the limiting factor of $5 \times(\mathrm{N}-18)$ would not be exceeded or even approached. Additionally, the quarterly whole body level was chosen to be consistent with 10 CFR 20.101(a). Skin and extremity annual dose equivalent control levels were developed assuming that dose equivalent control levels should be reduced to 3 rem per calendar quarter to be consistent with 10 CFR 20.101(b)(1). Annual levels were then calculated by multiplying by four calendar quarters in a year.

Limiting the whole body exposure of pregnant females is also of primary concern in any radiation protection or external exposure control program. Methods for limiting exposure of pregnant females should be determined on an individual basis by the RSO and the involved staff member. Therefore, women should be encouraged to voluntarily inform the radiation protection group of their pregnancy. Every effort should be made to limit the dose equivalent to the embryo-fetus to 0.5 rem during the entire gestation period from occupational exposure of the mother. Female worker exposure and applicable training is discussed in more detail in Chapter 3.0 of this document.

\subsubsection{Operational Controls}

The external exposure control program can only be effective if operational controls are used in conjunction with administrative controls. Operational controls as defined here are those methodologies used in the field to reduce exposures to ALARA. The following discussion covers three primary factors that should be considered for the reduction of exposure to external radiation when planning work. These operational control factors are: (1) time, (2) distance, and (3) shielding.

\subsubsection{Time}

The influence of time on receipt of external (and internal) exposure is straight forward. The total exposure received at a given distance from a particular radioactive source is a linear function of the exposure time; that is, halving the exposure time will halve the total exposure. Time spent working in a radiation environment can be reduced by a number of methods; examples include training, time keeping, the use of power equipment such as forklifts, easy access to equipment, and modification of tasks or procedures to be performed.

Training can improve a worker's efficiency and thus reduce the amount of external exposure received. The training programs should include the actual performance of procedures with the exception that radioactivity and radiation are absent. Practice sessions should also include the use of protective clothing, survey instruments, etc. when applicable. Full-scale mock-ups can be very beneficial because they allow the workers to practice procedures and become more proficient and confident in their assigned tasks. Significant exposure savings can result when using mock-ups and training for handling casks carrying high activity LLW. 
Time spent in the radiation environment can also be controlled with the use of timekeepers. This practice requires that the exposure or dose equivalent rate in a given work area be known. The multiplication of exposure rate by elapsed time gives a total exposure value received. Using timekeepers ensures that personnel in the area do not exceed predetermined administrative control levels and that personnel do not linger in the area and receive unwarranted exposure. This should be accomplished by the timekeeper notifying the worker when the specified time has elapsed with the result that the worker leaves the area. Workers should be instructed - ave the area immediately and without question.

Time may also be reduced by ensuring ease of access to equipment and areas. This may be ensured when equipment or work areas are being designed and should be evaluated frequently to determine if new conditions warrant a redesign. For example, the construction of unloading platforms may reduce the time needed to remove $\amalg W$ containers from a transport vehicle. By being able to get a forklift onto or into the transport vehicle and closer to the $\amalg W$ containers a considerable savings of time and exposure can occur. Figures 8 and 9 show two types of unloading platforms currently used at $\amalg W$ disposal sites.

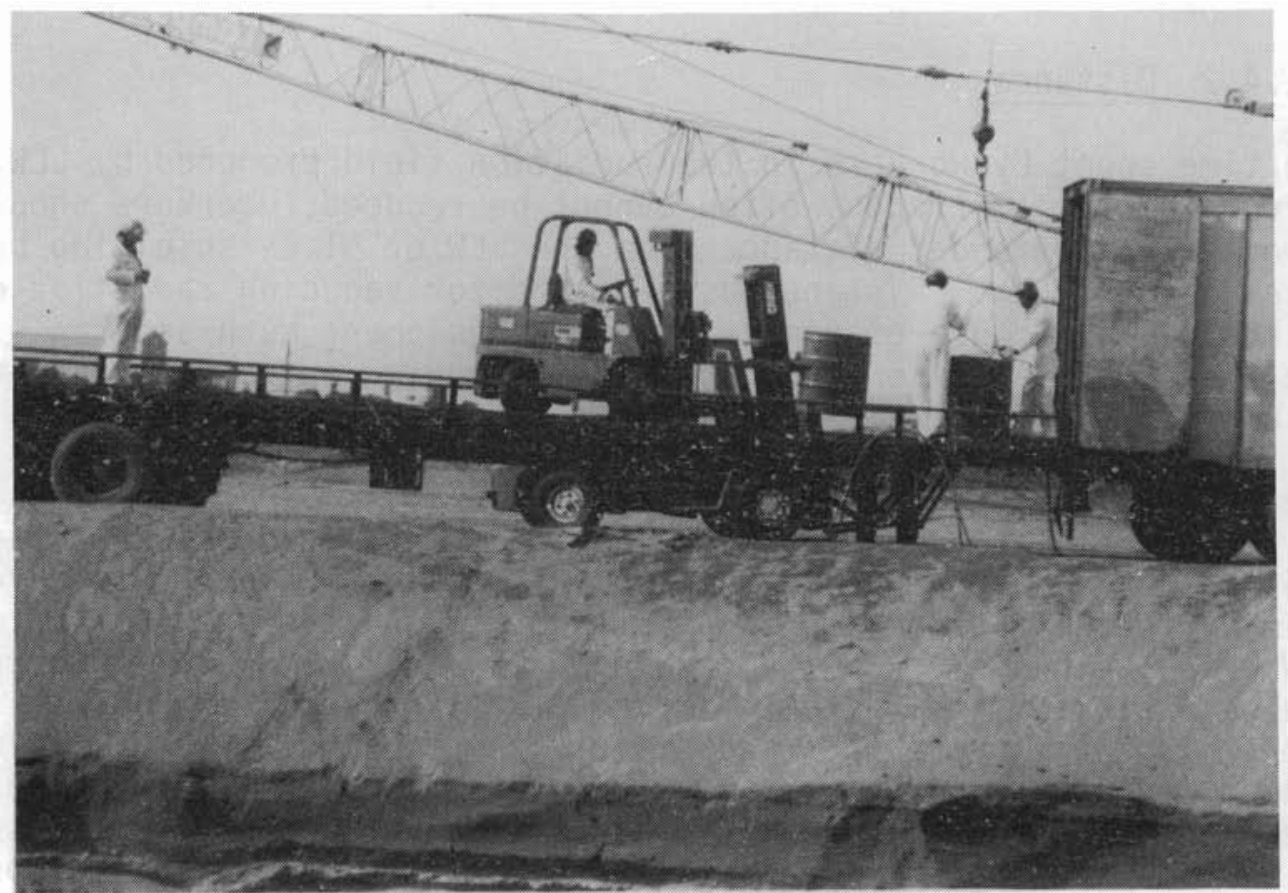

FIGURE 8. Unloading Platform Located at Top of Trench 


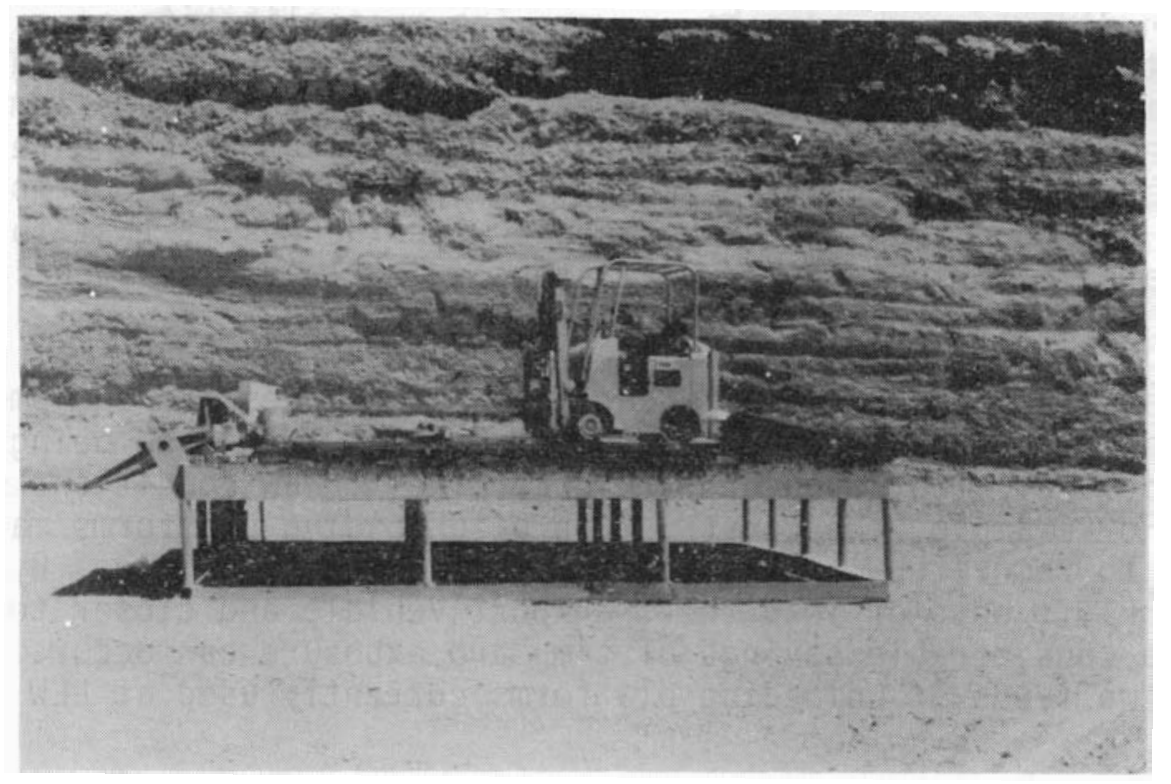

FIGURE 9. Unloading Platform Located Within Trench

\subsubsection{2 $\underline{\text { Distance }}$}

The time spent by workers in the radiation field produced by LLW, especially from the burial trench, often cannot be reduced. Workers should then either work at an extended distance from the $\amalg W$ or place shielding between themselves and the LLW. Distance as a method for reducing radiation exposure can include: (1) the use of remote handling equipment such as cranes, (2) moving work away from radiation sources, and (3) moving extraneous radiation sources away from the work area.

The $\amalg W$ burial containers are normally placed in the burial trenches using cranes. However, if stacking of containers becomes necessary as a result of 10 CFR 61 criteria, discussed in Chapter 10.0, then personnel may have to be in proximity to the $\amalg W$ for a period of time. When it is necessary to manipulate LLW with the hands, the work should be done quickly so that the radiation exposure will be minimized. Extremity dosimeters should be used for this operation. In addition to this operation, it must be noted that the use of remote handling equipment is not always the best method to reduce radiation exposure. Some manipulations are difficult when using handling tools and because time is an important factor in determining exposure, it is possible that the use of such tools may result in a greater exposure to the workers than doing the manipulation with the hands. Therefore, the use of remote handling equipment must be evaluated on a case-by-case basis for its exposure reduction value. 
Moving the work away from radiation sources can be very beneficial but is usually not very practical. Most $\amalg W$ operations involve unloading waste from transport vehicles and placing it in the burial trench which itself may be the primary source of radiation. However, if the $\amalg W$ containers are required to be secured to the vehicle during transport, such as spent resin casks, then the time required to remove the securing devices may become significant. In this case, it would be advantageous to perform this operation at a distance from the burial trench in order to be in a lower background radiation field. Another example would be if workers need to discuss a particular procedure, then they should move away from the radiation source, such as the transport vehicle or the burial trench, until they are ready to continue with the operation.

Moving extraneous radiation sources away from work areas may also help to reduce radiation exposure. One particular example for $\amalg W$ disposal sites is with the placement of loaded transport vehicles. It is recommended that there only be one vehicle at the burial trench at a time because of the increased background radiation levels that other vehicles may present. If this is not feasible, then it is recommended that vehicles be separated by a sufficient distance so that radiation levels from one vehicle do not significantly contribute to radiation levels at the vehicle being unloaded. In addition, the other loaded vehicles should be parked well away from normal personnel work locations and traffic routes and the drivers should not be in attendance.

\subsubsection{Shielding}

Shielding can be used to reduce radiation levels and thereby reduce personnel exposure. Shielding is provided by placing an absorber between a source and an individual to stop some fraction of the radiation. Alpha particles can be totally absorbed by a few centimeters of air or a few sheets of paper. Beta particles can be stopped by a few meters of air or a few millimeters of lead or plexiglass. Gamma radiation can penetrate even dense materials such as lead; however, the intensity of gamma radiation can be reduced to negligible levels by the use of shielding. The $\amalg W$ disposal containers shield out all the alpha and most of the beta radiation leaving only a gamma radiation field to consider.

The primary source of radiation at a $\amalg W$ disposal site is from the $\amalg W$ emplaced in the burial trench. One very effective method to shield the radiation emanating from the trench is to fill over the $\amalg W$ with backfill after the waste has been implaced. In addition, lower activity $\amalg W$ containers can be used to shield high activity LLW. Figure 10 shows both the use of backfill in the rear of the trench and the use of stacked waste containers as shielding in the foreground. Another source of radiation exposure is the $\amalg W$ container(s) as they are being moved by a forklift operator. A method to reduce exposure in this case may be to put shielding material on the front of the forklift between the $\amalg W$ and the operator. The height of this shielding must be restricted so that the operator has a clear view to unload and transport the LLW. Shielding material such as leaded glass can be used to provide optimum protection. This method is shown in Figure 11 where shielding material has been placed immediately behind the waste box. 


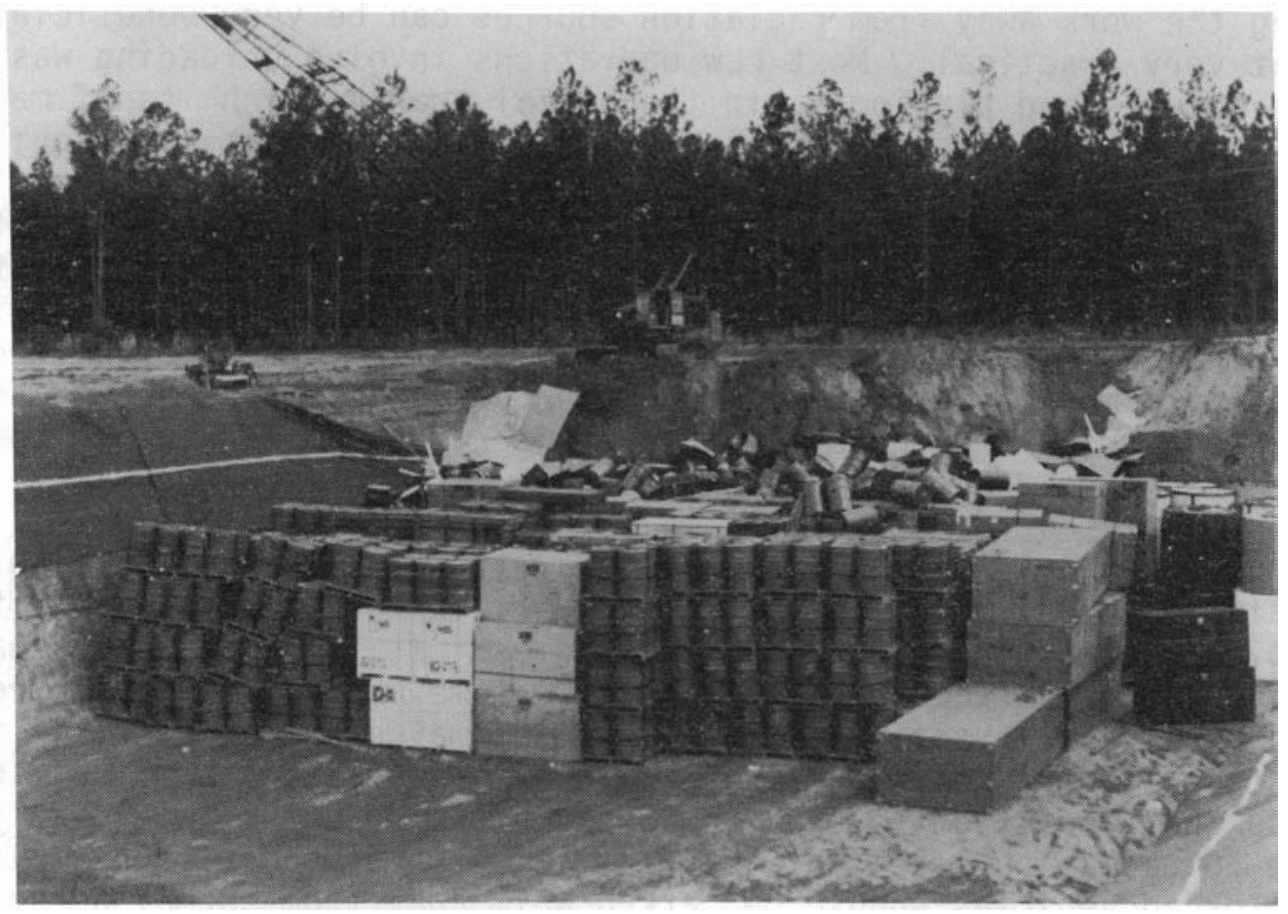

FIGURE 10. Shielding of Emplaced LLW Containers

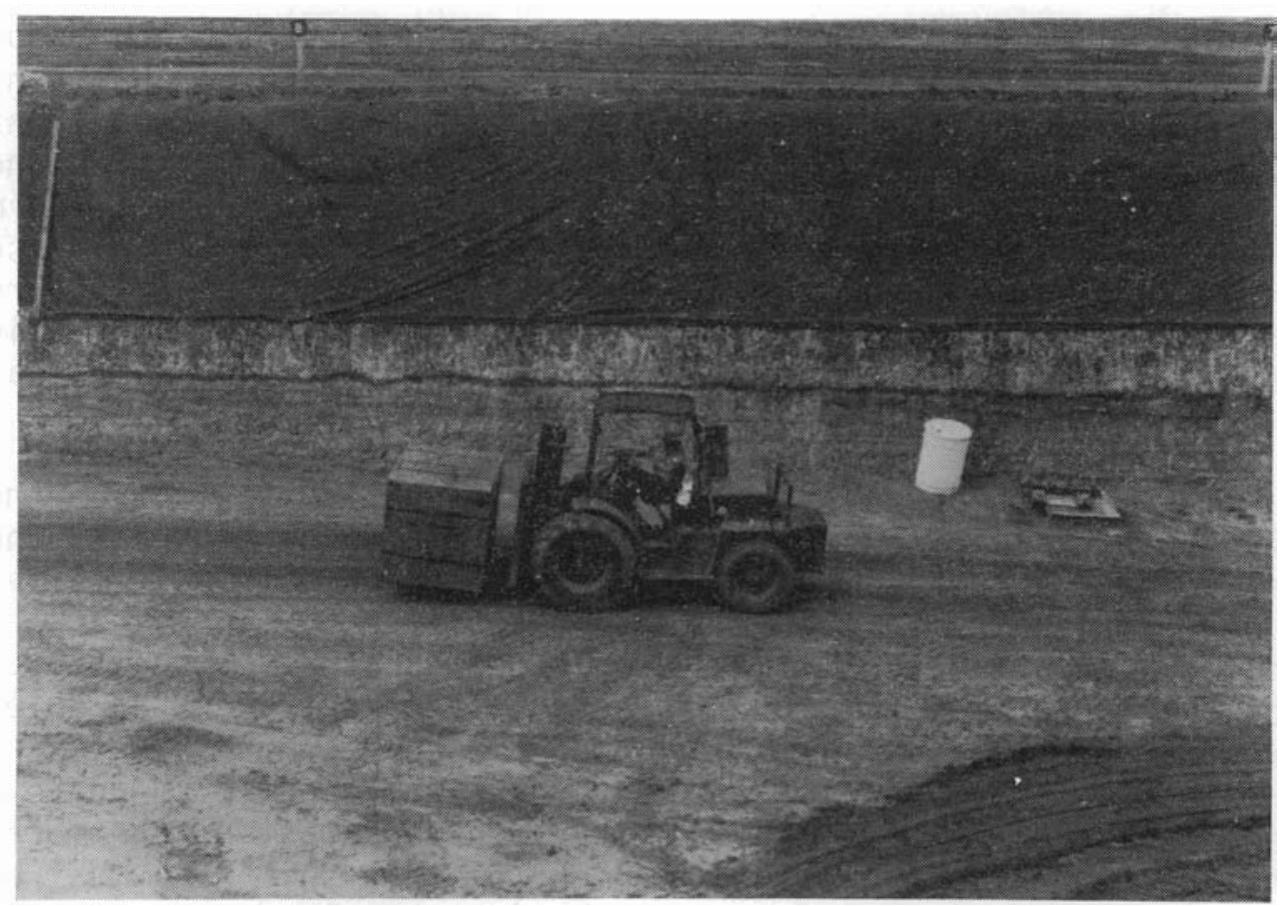

FIGURE 11. Shielded Fork Lift 


\subsubsection{Other}

Other operational methods to reduce exposure include:

- Minimizing the number of authorized radiation workers present by limiting the number of persons in an area at a given time.

- Radiological posting.

Radiological posting for external exposure control is defined as the use of signs, labels, barriers, and alarming devices to inform personnel of the potential radiation hazard that may be encountered upon entering or passing through (or nearby) a posted area, location, or piece of equipment. The posting applicable to external exposure control can be categorized into two types: radiation areas and high radiation areas. As defined in 10 CFR 20.202 (b), a radiation area is:

Any area accessible to personnel, in which there exists radiation originating in whole or in part within licensed material, at such levels that a major portion of the body could receive in any one hour a dose in excess of 5 millirem, or in any 5 consecutive days a dose in excess of 100 miliirem.

Radiation areas should be posted with signs bearing the radiation caution symbol and the words: caution, radiation area.

High radiation area is:

Any area accessible to personnel, in which there exists radiation originating in whole or in part within licensed material at such levels that a major portion of the body could receive in any one hour a dose in excess of 100 millirem.

High radiation area posting should bear the radiation caution symbol and the words: caution, high radiation area.

The radiological posting, both for radiation and high radiation areas, should contain enough additional information to aid individuals in minimizing exposure to radiation or to radioactive material. As a minimum the following information should be included in the posting of these two types of areas:

- average radiation level

- maximum expected level/hot spots

- date of survey

- special precautions.

The use of radiological posting can help to minimize external radiation exposure if used properly. However, if employees disregard or do not understand the posting then its effectiveness is diminshed. The work area should be surveyed every few months to ensure that the posting adequately describes the hazard associated with the area. The posting should indicate the actual 
hazard involved and should not be overposted. Habitual overstatement of radiation hazards may cause workers to ignore the warning signs. One method to overcome this problem is through the use of training on the need for posting, identification of posting types, and entry requirements. Another solution is to use barriers to prevent entry.

Additional controls for external exposure control include:

- Frequent radiation surveys shall be performed around radiation and/or high radiation areas to determine whether there is any deviation from the normal background levels.

- All containers used for radioactive materials shall be labeled in accordance with Regulatory Guidance. Radioactive warning labels, tape, signs, etc., shall not be used for purposes other than those for which they are intended.

- Work should be planned ahead, and whenever possible, a dummy run to test the procedure should be performed first.

- All items of equipment intended to provide features of safety shall be evaluated periodically to ensure that they provide the safety feature i ntended.

- Use a "buddy system" so that an individual never works alone in a radiation or high radiation area, particularly one that is locked.

- Use audible radiation dosimeters and/or radiation detection instrumentation with warning lights or audible alarms.

\subsubsection{Dosimetry}

Dosimetry is the measurement of the radiation dose. A radiation dosimeter, loosely defined, is any system capable of measuring radiation dose or dose equivalent. Dosimeters are typically used to provide a quantitative estimation of the radiation dose equivalent actually received by a worker. Their response should be reproducible, precise, and accurate, and they should be able to measure all ionizing radiation. The dosimeter should be simple and convenient to use, small, easy to handle, and low in cost. It should be stressed that a personnel dosimeter records only the dose it has received. Therefore, it is extremely important that personnel be trained in the proper use of the dosimeter.

The following sections describe the types of dosimetry recommended for uW disposal sites and their use. Types of dosimetry discussed are: (1) photographic film, (2) thermoluminescent dosimeters, and (3) pocket ionization chambers.

\subsubsection{Photographic Film}

Photographic fil m is measurably darkened by radiation and therefore can provide a useful estimation of personnel dose equivalent. The response of 
photographic film depends on the type and energy of the incident radiation and is also proportional to the amount of radiation incident on the film. Photographic films are incorporated into a device called a film badge or dosimeter. The film badge is designed so that radiation can reach the film either directly through an open window, or through filters. The filters are discs made of metals, such as lead, tin, copper, cadmium, silver, or aluminum, and are used to help compensate for the different response of the film to different types and energy of radiation. Most film wrappers will stop beta particles with energy less than $150 \mathrm{keV}$. Thus, film should not be used to monitor radiation exposures from low energy emitters such as tritium, carbon-14, or sulfur-35.

If a film is processed without being exposed, it will still show a slight positive reading. This effect is known as the base fog. The magnitude of this effect is a function of the type of emulsion, the age of the film, and the manufacturing processes, as well as the film storage conditions and development time. To correct for the base-fog effect, control films should be processed along with the individual worker's films. The control films should be from the same batch as the other films and stored under the same conditions. Then, if all are processed in the same way, the base fog on the control films allows identification of extraneous effects as well as normal fog. The basefog values can then be subtracted from the readings of the individual films to give corrected values. Care must be taken to properly store the film so that environmental effects from temperature, light, and humidity are minimized.

Photographic film dosimeters are not absolute devices and therefore must be calibrated against a known radiological source in order to relate the film's reading to the exposure delivered. The calibration of dosimeters should be performed under very carefully controlled laboratory situations using sources traceable to the National Bureau of Standards (NBS).

One of the major advantages of $\mathrm{film}$ dosimeters is that once they have been processed the information is not lost. This allows the film dosimeters to be retained as a permanent record. The major disadvantage of film dosimeters is their sensitivity to environmental effects.

\subsubsection{Thermoluminescent Dosimeters}

As a result of irradiation, some solid substances undergo changes in some of their physical properties. These changes amount to a storage of energy, and this forms the basis of using these solids for dosimetry. Thermoluminescence is defined as that property of a crystalline material which causes the emission of light when the substance is heated after being exposed to ionizing radiation. Because the amount of light released from a heated crystal is proportional to the energy or radiation exposure absorbed within the crystal, the phenomenon of thermoluminescence can be used in radiation dosimetry. Thermoluminescent ( $T L$ ) material in the form of small wafers are incorporated into a device called a thermoluminescent dosimeter (TLD). The construction of this device allows radiation to reach the $\mathrm{TL}$ material either directly through an open window, or through filters. The filters are used to help distinguish between types and energy levels of radiation and may be metal disks made of 
such materials as lead, tin, copper, cadmium, sitver, or aluminum. Materials most commonly used for TLDs are: (1) lithium fluoride, (2) calcium fluoride, (3) calcium sulfate, (4) lithium borate, and (5) aluminum oxide.

A device called a TLD reader, which has a controlled heating element, is used to heat the TL material and then determine how much light is emitted during the heating process. Once a TLD has been irradiated and read on a TLD reader, it can be annealed. Annealing is a slow heating process that restores the crystal to its original state. This allows the TLDs to be reused in contrast to the one time use of film dosimeters.

Thermoluminenscent dosimeters can be applied in any situation where film dosimeters are currently being used. They are preferred to film for extremity dosimeters (e.g., ring and wrist badges), for personnel monitoring at energies below approximately $100 \mathrm{keV}$, and for environmental monitoring. However, TLDs do not provide a permanent record of exposure as film dosimeters do. Advantages of the TLDs are that they are very small, quite rugged, essentially unaffected by environmental variables such as temperature and humidity, and are relatively insensitive to their orientation ${ }_{5}$ in a radiation field. The TLD has a wide exposure-reponse range (1 mrad to $10^{5}$ rad) and has a very low energy dependence. The most popular TL material, LiF, has an effective atomic number very close to that of human muscle tissue. Thus, it is considered to respond much as tissue would and should be considered "tissue equivalent."

\subsubsection{Pocket Ionization Chambers}

Pocket ionization chambers are dosimetry devices which are used for $x$ and gamma radiation detection. They are designed to be carried in the worker's pocket or clipped to protective clothing. They may have visual, mechanical, or electronic readouts and may include alarm functions. The pocket dosimeters can be either of the self-reading type or read on a separate device.

The primary advantage of pocket dosimeters over fil m and TL dosimeters is the accessibility to the exposure data. This allows the radiation protection personnel and individual workers in the field to keep current on the personnel exposure status as jobs progress. These devices should be used only for approximate dosimetric evaluations and should always be used in conjunction with TLDs or film dosimeters.

\subsubsection{Dosimetry Use}

When using dosimetry devices to measure and control external dose, the following items should be considered.

- Dosimeters must be appropriately worn on the person in order to effectively measure the exposure:

For whole body dose measurements, the dosimeter should be worn on the trunk of the body between the waist and neck with the beta window facing away from the body. 
- For extremity dose measurements, wrist or finger ring dosimeters should be worn. The dosimeters should be positioned so that they face towards the radiation source.

- Additional dosimetry should be considered for the head and groin areas when applicable.

- When practical, several dosimeters should be worn together to allow for a redundancy or backup of data. As a minimum, pocket dosimeters (such as pencil dosimeters) should be worn in conjunction with TLDs or film dosimeters when measuring whole body exposure at $\amalg W$ disposal sites. However the TL or film dosimeter's data is to be used for the legal record.

\subsubsection{Quality Assurance}

The use of properly calibrated instruments is critical to a good radiation protection program, and $\mathbf{i t}$ is the responsibility of the radiation protection group to ensure that only properly calibrated instruments and dosimeters are used. External dosimetry devices may be supplied to $\amalg W$ disposal sites by vendors. After use, the vendors process the dosimeters and supply exposure reports to the sites. In order to ensure that the exposure data is reliable, the site should perform quality assurance (QA) checks on the vendor data. The method involved in these checks is discussed in detail in Section 8.4.2.2 of this document. In addition, dosimeters should be calibrated not by the persons using them but rather by someone who has an unbiased viewpoint. A small radiation protection office should procure the services provided by a commercial calibration company. Calibration companies must maintain their traceability to NBS through a periodic direct intercomparison.

\subsection{INTERNAL EXPOSURE CONTROL}

Internal radiation exposure is defined as the exposure of the body to radiation released by materials deposited inside the body. Radioactive materials can enter the body through inhalation of radioactive dusts, mists, and fumes and also by ingestion of contaminated food or water, or occasionally by absorption through the skin or a wound.

One of the primary objectives of a radiation protection program at an $\amalg W$ disposal site is to minimize the internal exposure to occupational workers. To accomplish this objective, an internal exposure control program must be established and it must be capable of predicting exposure levels in addition to minimizing exposures.

The following sections contain information regarding: (1) program responsibility, (2) administrative controls, (3) operational controls, and (4) biosurvei 1 lance. 


\section{Program Responsibility}

Internal exposure control program duties at $\amalg W$ disposal sites should be the responsibility of the radiation protection group with the RSO having overal1 responsibjility for the program's effectiveness. An organizational structure should be formally defined and documented. A recommended organizational structure is shown in Figure 7. The authority and duties of personnel and organizations responsible for internal exposure Control should be documented in writing. The personnel should have sufficient authority and organizational freedom to identify problems; to initiate, recommend or provide solutions; and where nececessary, to control or stop further work either in-house or by vendors.

\subsubsection{Administrative controls}

The RSO in conjunction with other site management shall control activities of personnel at the $\amalg W$ site so that each individual's internal dose does not exceed regulatory limits and site administrative control levels. Therefore, evaluations should be performed to ensure that physical containment of $\amalg W$, a ir sampling and monitoring programs, and other operational controls are sufficiently effective in the control of internal exposures. The evaluation of operational controls should be part of an administrative control program. The program can be facilitated by the use of biosurveillance which should be:

- performed routinely at a specified frequency to identify unfavorable trends or to check the effectiveness of other internal exposure control methods

- temporarily performed more frequently to verify the adequacy of new or modified equipment and procedures used to control exposures

- temporarily performed more frequently during an investigation of an unexpected upward trend of monitoring results such as may be indicated by smears or a ir samples

- performed at a high frequency during tasks which involve exposure to high concentrations of airborne radioactive material.

Biosurveillance techniques and recommended frequencies are discussed in detail in Section 4.2 .4 of this document.

The most common method for occupationally exposed individuals to receive exposure is through inhalation. After inhalation, the radioactive material may be gradually or immediately transferred to the blood, depending upon the solubility of the material. The material may then be excreted from or retained by the body, depending upon the characteristics of the material. The applicable regulatory I imit for internal inhalation exposure of individuals to concentrations of radioactive materials in air, based on 10 CF 20.103(a)(1), is: 
- the amount of radioactive material inhaled in any period of one calendar quarter shall be less than the quantity which would result from inhalation for 40 hours per week for 13 weeks at uniform concentrations of radioactive material in air specified in Appendix B, Table I, Column 1.

The Table I values (10 CFR, Appendix B) are referred to as the MPC (Maximum Permissible Concentration) values. Therefore, the regulatory limit for inhalation of airborne radioactive material is that exposures do not exceed 40 MPC-hours per week. As defined here MPC-hours are obtained by multiplying the exposure time (in hours) in a work area by the relative MPC value. The relative MPC value is obtained from the ratio between the actual airborne radioactivity concentration and the values given in Appendix B, Table I, Column 1. Administrative control levels should be established to ensure that the regulatory limits are not exceeded and that the exposures are minimized to ALARA. Table 3 lists a set of recommended administrative control levels for internal exposure at an $\amalg W$ disposal site, that are a result of the regulatory limits on inhalation of radioactive material.

TABLE 3. Administrative Control Levels for Internal Exposure Control

\begin{tabular}{|c|c|}
\hline Organ & Control Level \\
\hline Gonads & $4 \mathrm{rem} /$ year \\
\hline Skeleton & $30 \mathrm{rem} /$ year \\
\hline Thyroid & $30 \mathrm{rem} /$ year \\
\hline Others & $\begin{array}{l}4 \mathrm{rem} / 13 \text { week or } \\
15 \mathrm{rem} / \text { year }\end{array}$ \\
\hline
\end{tabular}

Limiting the exposure of pregnant remales is also of primary concern in the internal exposure control program. Every effort should be made to limit the dose equivalent to the embryo-fetus to 0.5 rem during the entire gestation period from occupational exposure of the mother. Prenatal exposure and applicable training is discussed in more detail in Chapter 3.0 of this document.

\subsubsection{Operational Controls}

External radiation exposures can be minimized by controlling exposure time, increasing the working distance from sources, or by placing shielding between the individual and the sources. tiowever, once radioactive material has entered the body, there is usually no highly effective method to reduce the radiation exposure. Therefore, considerable effort should be expended to prevent any intake of radioactive material.

The internal exposure control program can only be effective if operational controls are used in conjunction with administrative controls. Operational 
controls as defined here are those procedures, techniques, or guidelines used in the field to reduce exposures to ALARA. The following items should be considered when instituting operational controls:

- Hoods and gloveboxes should be used when $\amalg W$ containers need to be opened.

- Smoking, eating, and drinking should not be allowed in contaminated areas or at the burial trench during unloading/burial of LLW.

a Upon completion of work with radioactive material and intermittently during the work, each individual should survey their hands, shoes, and other areas of the body or clothing that may have come into contact with the equipment or items being worked on.

a Equipment that has come in contact with radioactive materials should not be used for other purposes until it is demonstrated that contamination levels are below the release limits set forth in Table 4, Chapter 6.0.

- Work should be planned ahead and when deemed necessary, a practice run be performed to test procedures.

- Frequent radiation surveys should be performed around radiation and/or contamination areas to determine whether there is any deviation from the normal background levels.

- All containers used for $\amalg W$ should be labeled in accordance with regulatory guidance. Radioactive warning labels, tape, signs, etc., should not be used for purposes other than those for which they are intended.

- $\amalg W$ should be stored in such a manner that unauthorized individuals are not likely to accidentially handle or otherwise come in contact with it.

The following discussion covers operational controls as they apply to: surface contamination, (2) airborne radioactivity, and (3) protective clothing/equipment. These three subjects should be considered to have the greatest impact on internal exposure control.

\subsubsection{Surface Contamination}

Contamination is radioactive material in any place where it is not desired, and particularly in any place where its presence may be harmful. This contamination may be either fixed or removable. Fixed contamination is radioactive material that has become firmly bound to an object. The hazard presented by fixed contamination is an external hazard related to the type of radiation emitted. Removable or surface contamination, on the other hand, is radioactive material that is readily removed from a surface by wiping. Removable contamination can pose both an external hazard and, more important, an internal hazard if the contamination is inhaled or ingested. 
Surveys for surface contamination should be conducted routinely as part of the operational control program. Personnel surveys should be conducted periodically during the course of work and as each person leaves the work area. The purpose of contaniination surveillance is to locate and isolate contamination problem areas before they spread to uncontrolled areas or cause unnecessary radiation exposures. The primary methods of surveillance are wipe testing and instrument surveys for contamination on tools and equipment, and frisking for personnel contamination. However, the key to contaniination control, and thus internal exposure control, is prevention. Operational controls must ensure that contamination is minimized by the use of routine surveys and decontaminations. Contamination control is discussed in more detail in Chapter 7.0 of this document.

\subsubsection{Airborne Radioactivity}

Radioactive material may become suspended in air as a dust, mist, or fume. This release into the air may come as a consequence of normal work procedures, suspension or resuspension of surface contamination, or by release from a ruptured $\amalg W$ container. Once airborne, these materials may be inhaled by workers, resulting in an internal radiation exposure. An effective operational control, which is used for monitoring airborne radioactivity, is an a ir sampling program. This program has two major objectives:

1. to detect the presence of radioactive dusts, mists, fumes, etc. in the a ir

2. to quantify the amount and type of radioactive material in the air.

Continuous monitoring or sampling for airborne radioactivity should be conducted as part of the operational control program. This should be performed whenever staff members have a significant potential for airborne exposure because of radiological conditions in the area. Air samples should be taken in all potentially contaminated work locations that are not continuously monitored. These samples should be analyzed to ensure that personnel are not knowingly exposed to airborne radioactivity concentrations higher than the levels given in 10 CRR 20, Appendix B, Table I unless they are wearing the proper protective apparel. Airborne radioactivity control is discussed in detail in Chapter 6.0 of this document.

\subsubsection{Protective Clothing/Equipment}

The purpose of protective clothing/equipment is to place a barrier between radioactive material and the worker. The protective barrier has negligible shielding characteristics but its main purpose is to prevent contamination of the skin of personnel and inhalation of airborne radioactive materials. Two classes of protective apparel are commonly used: (1) protective clothing, which minimizes the contamination of an individual's skin; and (2) respirators, which minimize the inhalation of airborne radioactive material. Protective apparel should not be substituted for either good ALARA or good engineering/ design principles. Operational controls applicable to respiratory protection and protective clothing are discussed in Chapters 5.0 and 7.0, respectively. 


\subsubsection{Biosurveillance}

A biosurveillance program has two objectives: the first is to indicate whether an intake of radioactive material has occurred; the second is to determine the body or organ content of the radionuclides and to estimate the radiation dose from the intake. Two bioassay methods are used to estimate the amount of radioactive material taken into the body: (1) radioanalysis, and (2) in vivo counting. Radioanalysis is the measurement of radioactivity in urine, feces, secretions (such as nasal swabs) and other body samples, such as blood and other tissues. In vivo counting is the measurement of the radiation emitted from the body, using an external detector. The most common biosurvei ?lance methods used at $\amalg W$ disposal sites should be: (1) whole body counting as an in vivo method, (2) thyroid counting as in in vivo method, and (3) urinalysis as a radioanalysis method. Figure 12 shows a chair counting system with multiple detectors for in vive counting. Figure 13 depicts a thyroid counting system. Both systems are currently in use at $\amalg W$ disposal sites.

The following discussions cover the areas of: (1) biosurveillance frequency, and (2) biosurveillance actions following an incident.

\subsubsection{Biosurveillance Frequency}

All $\amalg W$ site personnel, when assigned to the site, should have a baseline bioassay performed as soon as is practicable following assignment. The baseline bioassays should include a whole body count and urinalysis as a minimum. These evaluations are performed to determine the nature and extent of any prior

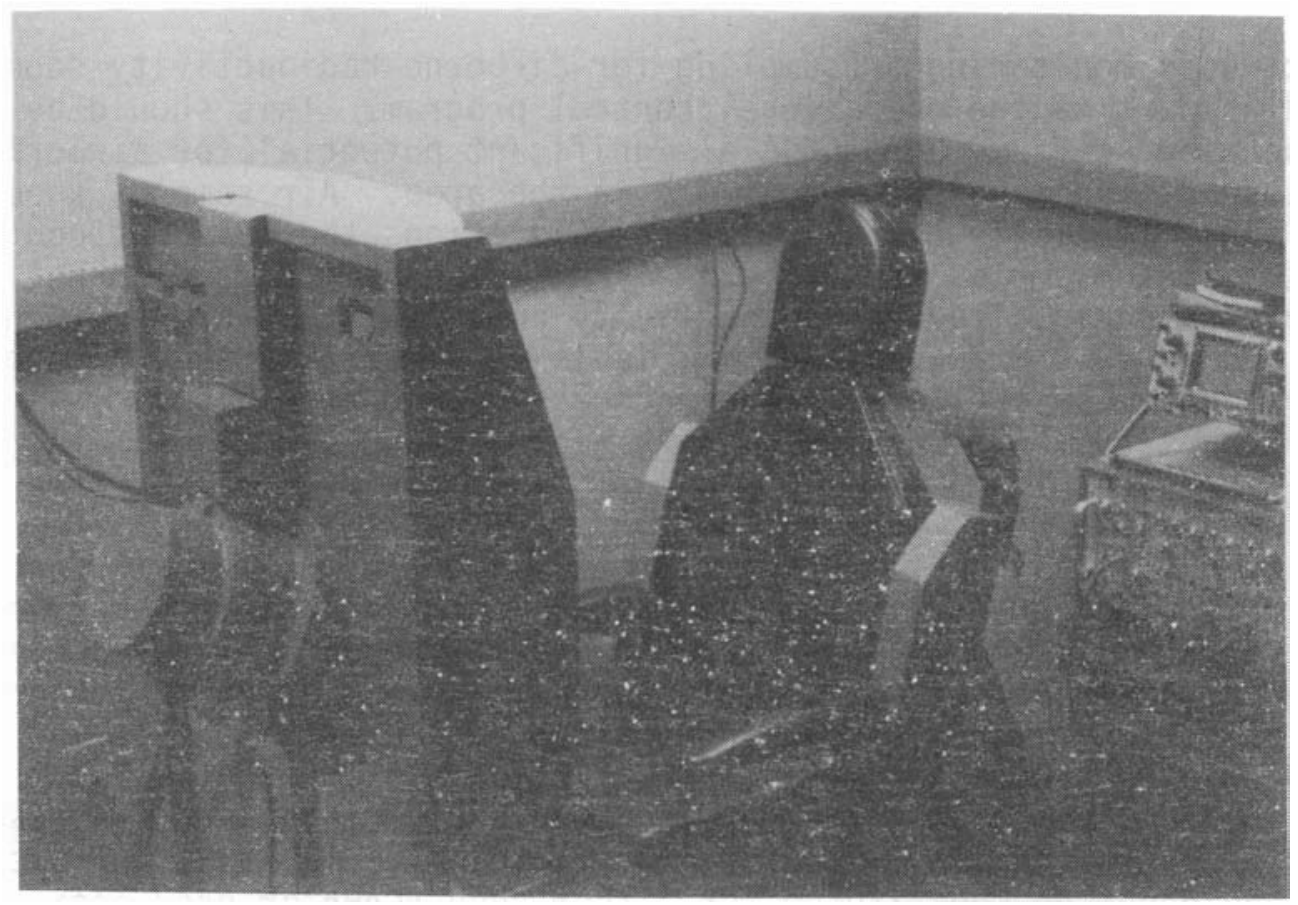

FIGURE 12. Chair Counting System Using Multiple Detectors 


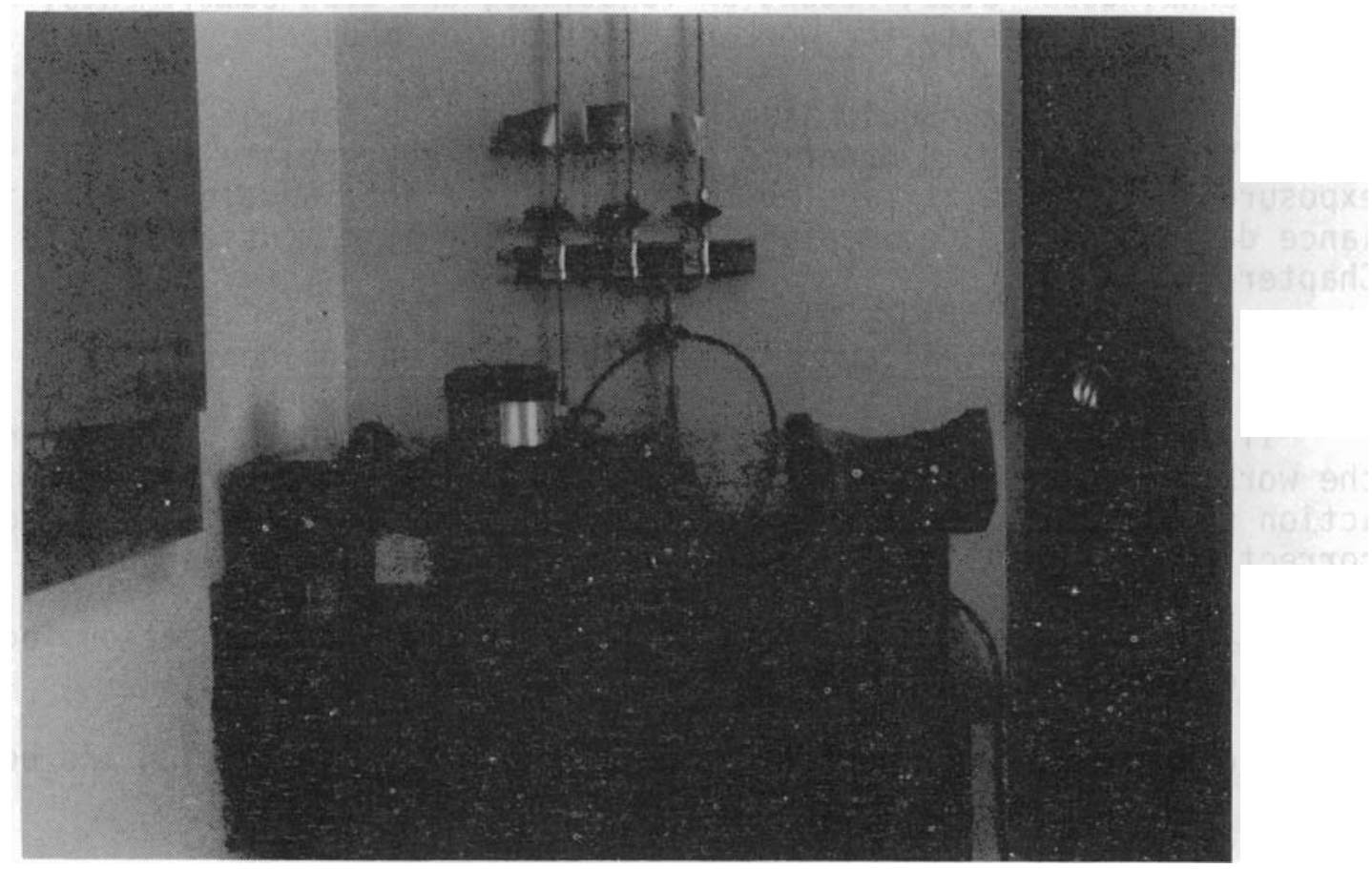

FIGURE 13. Thyroid Counting System

exposu, e that could affect an individual's availability for job assignments. These baseline studies can also be used to establish previous exposures which should not be credited to the present working environment.

All $\amalg W$ site personnel who routinely enter radiation areas, contaminated areas, or handle radioactive materials should have whole body counts at least annually. In addition, bioassays should be performed periodically to ensure the adequacy of physical containment and contamination control measures. The frequency of evaluations should be sufficient to identify unfavorable exposure trends. An increased frequency may be required whenever new processes, procedures, controls, or equipment are added, to verify that protective measures are adequate. An increased frequency should be considered whenever surface or a ir contamination is detected. Additionally, whole body counting should be performed when, in the judgment of the RSO, conditions during a job were such that significant internal exposure may have occurred. As a minimum, urinalysis should be used to provide backup information to the whole body counting program. It is recommended that urinalysis be performed on a quarterly basis if whole body counting is only performed annually.

If biosurveillance indicates a result greater than $10 \%$ of the maximum permissible organ burden as defined in the regulatory guidance, followup measurements should be conducted. The frequency and number of subsequent counts should be determined by the RSO. The data obtained is necessary to estimate 
the internal dose rates, retention functions, and dose commitments; and to determine the necessity for work restrictions or medical evaluations.

Biosurveillance should also be performed as a part of the formal personnel termination sequence in order to determine the appropriate level of internal exposure that may be attributed to the worker's job function. All biosurveillance data should be documented. Recordkeeping is discussed in more detail in Chapter 9.0.

\subsubsection{Biosurveillance Actions Following an Incident}

If an intake of radionuclides is suspected, immediate decontamination of the worker is necessary to prevent additional exposure. In addition, prompt action should be taken to estimate the magnitude of the intake and to determine corrective actions. The following biosurveillance actions should be taken:

Retrieve samples from any air samplers operating in locations occupied by the individual and measure the activity present.

- Check for external contamination of the person's clothing and body.

- Take nasal smears and measure activity.

- Estimate the probable duration of exposure. This, together with airborne concentration and nasal smear activity level, may be the only immediately available indicator of the probable deposition.

- Collect bioassay samples, including urine, feces, and/or blood as appropriate (see ANSI N343).

- Perform in vivo examinations, including whole body counts and/or counts of selected body areas such as thyroid or wounds.

- With wounds involving radioactive material, examine the wound to determine the presence of contamination, then clean it and ensure that all or most of the contaminant has been removed.

- Identify the radionuclide(s) involved to assist in evaluation of internal exposure.

- Determine the chemical form of the radionuclide(s) and its solubility in body fluids.

- Determine the physical characteristics of the material, including particle size measurements. 


\subsection{RECOMMENDATIONS}

This chapter has outlined methods to minimize external and internal exposure. The major recommendations made for program adequacy were:

- The use of unloading platforms to reduce the time needed to remove $\amalg W$ containers from transport vehicles.

- The use of remote handling equipment to provide distance between the workers and the LLW containers when unloading transport vehicles.

- The use of backfill to shield $\amalg W$ already emplaced in trenches.

- Performance of baseline bioassays. 


\subsection{RESPIRATORY PROTECTION}

At facilities where radionuclides are present, it is necessary to identify all potential sources of exposure to personnel from ionizing radiation and establish dose reduction methodologies to minimize that potential. External exposure control methods may include such basic dose reduction techniques as the use of time, distance, and shielding. Internal exposure, which may result from the uptake of radionuclides into the human body through inhalation or ingestion pathways, can be effectively reduced by the use of respiratory protection. There exists a potential for the uptake of respirable radioactive materials by some workers at Low-Level Waste (LLW) disposal sites from such unanticipated events as waste container rupture or from planned actions such as opening containers for inspection. Because of this potential, a respiratory protection program is necessary at these sites if an adequate radiation protection program is to be achieved. Therefore, a respiratory protection program should be established and implemented at all existing and potential $\amalg W$ disposal sites.

The following chapter discusses recommended practices for the use of respiratory protection at $\amalg W$ disposal sites. Additional information can be found in NUREG-0041, "Manual of Respiratory Protection Against Airborne Radioactive Materials."

\subsection{PROGRAM ESTABLISHMENT}

The magnitude of a respiratory protection program should be keyed to the needs of a specific facility or activity, and should be intensified or relaxed as conditions dictate. The respiratory protection program should be established as an integral part of the overall radiation protection program and should follow the guidelines set forth in formalized written procedures. These procedures should be developed, approved, and supported by upper management as well as by the operations and radiation protection department managers. Where general procedures governing multi-site operations are generated by corporate level management, it is necessary that these procedures offer flexibility for site specifics.

Procedures should offer guidance in:

- program objectives

- delegation of responsibility

- action levels for respirator use

- wearer requirements (prerequisites)

- training

- respirator fitting

- proper selection of respirators

- capabilities and limitations of respirators

- maintenance and disposition of used respirators

- emergency actions

- documentation and reporting

- evaluation of program effectiveness. 
Program design should also consider management structure as an important factor for allowing an effective operation. For example, at $\amalg W$ sites it is necessary for operations and radiation protection personnel to work together very closely in performing many tasks; however, these groups should remain separate entities in order to avoid situations where radiation protection may be compromised for increased production.

\subsection{RESPIRATORY PROTECTION PROGRAM GUIDANCE FOR LOW-LEVEL DISPOSAL SITES}

The use of respirators must be based on a written policy statement issued from a high management level. This management backing is considered essential to an adequate respiratory protection program. Information in this section provides guidance which may be used to achieve an adequate respiratory protection program at LLW disposal sites assuming management backing.

\subsubsection{Program Objectives}

The major objective of a respiratory protection program at $\amalg W$ disposal sites is to aid in maintaining internal exposure to personnel ALARA. The required use of adequate respiratory protection by personnel, when airborne radionuclides are potentially present, is the basic exposure reduction technique. It should be noted that inhalation and ingestion are the pathways of uptake affected by respirator wear. Internal exposure resulting from penetrating radiations of external origin is a separate problem which must be dealt with in a different manner.

\subsubsection{Deleaation of Responsibilities}

NUREG-0041 specifies that the ultimate responsibility for a respiratory protection program be vested in one individual. A health physicist, industrial hygienist, safety engineer, or other similarly qualified person may direct the program. The responsible person in charge "must have the ability, training, and experience to:

- evaluate the total hazard and the job

- recommend engineering controls, if appropriate

- specify respiratory protection if control cannot be otherwise obtained

- forbid the use of respirators if conditions warrant.

The responsible person should have, in addition to his other qualifications, at least one year's field experience in the use of respirators."

\subsubsection{Action Levels for Respirator Wear}

Normal operating conditions at low-level waste disposal sites do not require the constant wearing of respirators, even for workers engaged in unloading operations. Airborne concentrations of radionuclides, which might 
result from the rupture of a waste container, would not be expected to remain at "maximum permissible concentration" (MPC) levels (as 1isted in 10 CFR, Part 20, Appendix B, Table 1, Column 1) for a significant period of time. This judgment is based on parameters such as the anticipated rapid dispersal of respirable particulates and gases in an open air environment, and further, upon the capability available at the sites to quickly cover ruptured containers with fill dirt. The covering operation does not require that workers be in proximity to the container.

When a known potential exists for the presence of airborne radionuclides, however, the proper use of respiratory protection equipment can reduce internal doses significantly. The effectiveness of the program depends upon either knowing in advance that a potential hazard exists, or through the ability of personnel to quickly recognize and react to problems resulting from inadvertent happenings.

Action levels for respirator wear should be significantly conservative so as to not allow personnel to enter areas without respiratory protection where the airborne concentration values listed in 10 CFR, Part 20, Appendix B, Table 1, Column 1 have been exceeded. To maintain exposure ALARA, however, respirators should be worn by personnel when entering areas or performing tasks which have historically yielded airborne concentrations in excess of $25 \%$ of the MPC as specified in Appendix B, Table 1, Column 1 of 10 CFR 20, averaged over the number of hours in any week during which individuals occupy the area (10 CFR, Part 20.203).

Historical data provide indicators which may dictate the need for respirator wear. After-the-fact indicators such as air sample alarms, high air sample analysis data, or survey results showing loose contamination resulting from performance of tasks where respirators were not worn, may require that internal dose estimations be calculated from follow-up biosurveillance data. It is not a sound ALARA practice to rely on after-the-fact indicators.

Some tasks, such as the sandblasting of contaminated equipment, welding contaminated equipment, or the opening of $\amalg W$ containers for any purpose should, by the nature of the task, require respirator wear.

Personnel, entering an area of suspected or known high surface or airborne contamination, should always wear respiratory protection (e.g., re-entering the burial trench after a container rupture has occurred). Respirators should be worn when entering or accessing transport vans or trailers where damaged or leaking containers are evident. Respirator wear should be considered when entering areas where gross removable surface contamination levels exceed a few thousand (2000-5000) disintegrations per minute. This is a recommended "rule of thumb," if entry into an area is necessary before air sample results can be obtained. It should be kept in mind that the potential hazard may vary with different radionuclides, but radioisotope identification data may not be rapidly available. Additionally, radiation protection personnel should always be given the authority to require respirator wear as is deemed necessary. 


\subsubsection{Wearer Requirements}

Prerequisites for respirator use by an employee are:

- A medical examination from a company-approved physician or physician's assistant with an emphasis on key body functions (e.g., proper pulmonary function) which may be effected by respirator wear. The physician must supply a certificate of health stating that the examinee's physical condition is such that respirator wear is approved. Any restrictions on the types of respirators which are approved must be included. An annual re-examination is necessary.

- Training in the proper issue of respirators, use and post-use disposition techniques for each respirator type and model approved for use.

- Respirator fit test to ensure a proper seal for each respirator type and model to be worn; such factors as abnormal facial structure and facial hair which may hinder a proper seal should receive special attention.

- A performance evaluation while wearing respirators under work conditions.

- Notice that he may leave the controlled area at any time in the event of equipment (respirator) malfunction, physical or psychological distress or other conditions of stress as stated in NUREG-0041, Section 2.2.

\subsubsection{Training}

Personnel who may be required to wear respiratory protection must receive thorough instruction in the proper use of respiratory protection devices available for use at that specific site. Retraining should be done on an annual basis; especially where respirators are infrequently used. More information concerning training is supplied in Section 3.0.

\subsubsection{Respirator Fitting}

Normal operations at low-level disposal sites do not normally present a significant problem from airborne radioactive materials. However, a respirator fit test must be performed to ensure protection of the workers when respiratory protection is required. NUREG-0041, Chapter 8.5 defines a minimum qualitative fitting program as one employing a challenge atmosphere of stannic chloride, isoamyl acetate (banana oil), or titanium tetrachloride to determine which models of masks give each wearer the best protection. Preferrably, these tests should be administered with the wearer inside of a test booth or chamber. If the wearer can detect the odor from the banana oil or is irritated by the smoke, the fit is not satisfactory. A repeat of the test must then be done after the mask has been re-adjusted. Air concentrations of 100 parts per million (ppm) and 1000 ppm isoamyl acetate are recommended for fit testing halfmasks and full-face masks, respectively. Half-masks should be fit tested before each use because of the added difficulty in achieving a proper seal. Full-face masks may be fit tested less frequently, but at least once or twice 
per year assuming that negative or positive pressure tests are conducted before each use.

Negative pressure tests may be performed by closing the respirator's air inlet by placing the palm of the hand over it and inhaling gently. If a proper seal is achieved, the face-piece will remain sightly collapsed for a period of 10 seconds. Positive pressure tests may require that the exhalation value cover be'removed and the valve be closed off with the palm of the hand. Gentle exhalation should produce a positive pressure inside of the mask. If the pressure cannot be maintained, a leak is indicated and a proper fit has not been achieved. These tests are to be used with air purifying respirators; not with supplied-air models.

\subsubsection{Proper Selection of Respirators}

All respirator models to be used must be approved by the National Institute for Occupational Safety (NIOSH). Three types of respirator, each to be used for different conditions, should provide adequate respiratory protection to workers at the $\amalg W$ disposal sites under all foreseeable conditions. These are:

- half-face masks; air purifying

- full-face masks; air purifying

- full-face masks; self contained breathing apparatus (SCBA).

Air purifying models protect the wearer by removing specific contaminants from the inhaled air by means of a filter cartridge or canister. These canisters contain materials which effectively remove a specified particulate from the air. Therefore, it is of the utmost importance that the appropriate canister be attached as the collection media is not effective for all ambient atmospheres. The full-face air purifying and half-mask air purifying respirators, currently being used at $\amalg W$ disposal sites, are shown in Figure 14.

Air purifying models should not be selected for use in confined areas where high airborne particulates or radioactive gases are present, because there are maximum concentrations above which these models do not adequately protect the wearer. Supplied-air models should be selected for use in such atmospheres. In addition, air-purifying half-or full-face masks should not be used in oxygen deficient atmospheres.

Self-contained breathing apparatus (SCBA) models supply air to the wearer from a supply tank, carried by the wearer. These units supply breathable air regardless of the ambient environment. They should be selected for use in atmospheres where high concentrations of airborne radioactive particulates gases, or oxygen deficient atmospheres are anticipated, (i.e., for radiation related fire-fighting or entering areas where a ruptured or open container presents a high airborne potential). The demand for SCBA use at $\amalg W$ disposal sites is low; however, a few units should be made available for use under abnormal or emergency situations. 


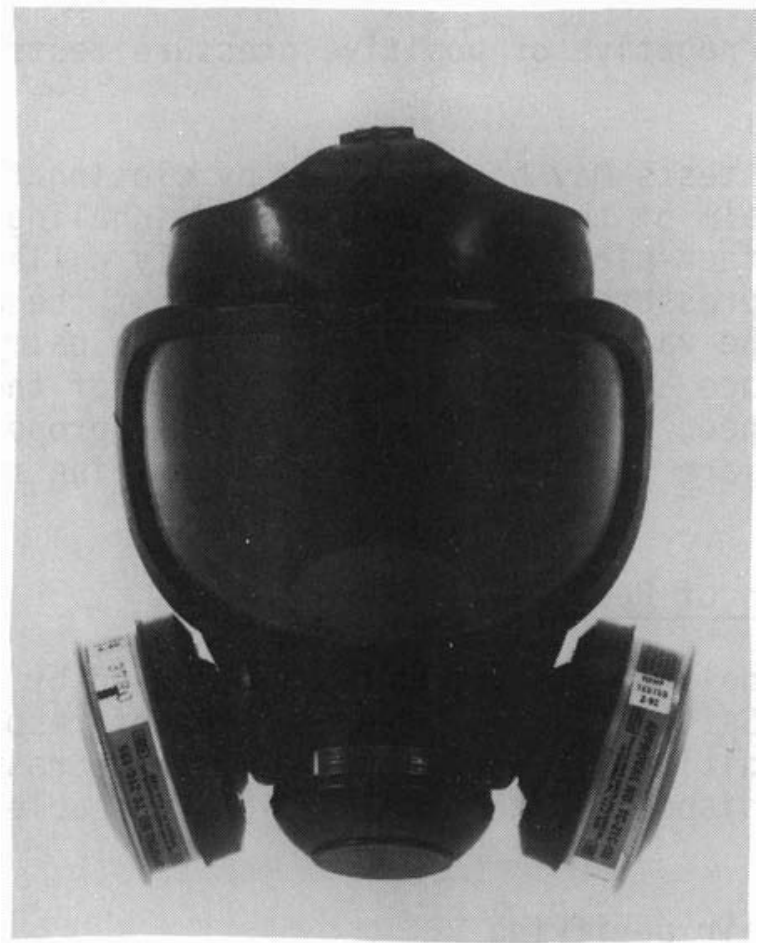

Full-Face Respi rator

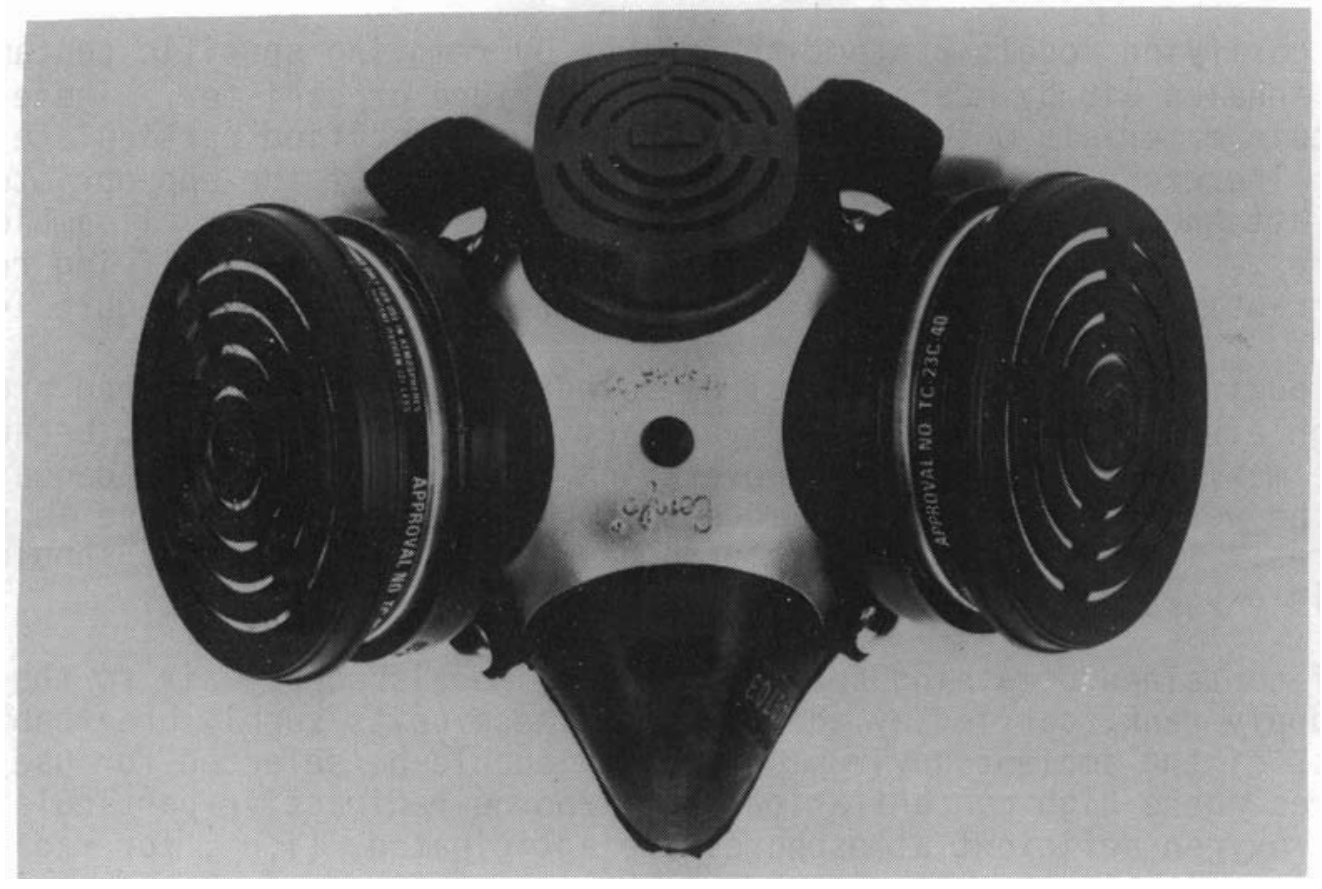

Half-Mask

FIGURE 14. Examples of Respiratory Protection Used at LLW Disposal Sites 


\subsubsection{Capabilities and Limitations of Respirators}

It is important that personnel who may be required to wear respiratory protection be thoroughly trained in their proper use. This training should also make workers aware that certain limitations are associated with these devices. With this knowledge, the appropriate respirator can be chosen for each task. Section 5.2.5 of this document suggests the use of three basic types of respirators at $\amalg W$ sites.

Half-masks are capable of removing particulates from breathing a ir under ideal circumstances. The effectiveness of this device is highly dependent on the ability to achieve and maintain a good facial seal. A limited number of straps are available for securing the half-mask in place. Further, because the face-piece covers only part of the face, these units are prone to leak around the mask's perimeter. Additionally, they do not offer protection to the eyes from beta radiation as do full face respirators. Therefore, it is recommended that half-masks only be selected for use under very low hazard conditions. Training sessions should stress the limitations of half-mask models. Quarter masks should not be used.

The nature of the contaminant (i.e., the physical and chemical state) must be considered in the proper canister selection. Both half-and full-face air-purifying respirators rely on the canister being appropriate for the hazardous atmosphere. Canisters designed to collect particulates do not offer protection against radioactive gases or vapors. Certain canisters are approved by NIOSH for removal of specific gases and vapors. Extreme care must be exercised in their use to ensure that their limitations are not exceeded. Therefore, air purifying half-or full-face respirators should not be used for protection against radionuclides that decay from particulates to gases or from gases to particulates. Neither, should they be worn in very high airborne concentration atmospheres.

Supplied-air respirators offer protection against gaseous and/or particulate atmospheres. The major limitations of these devices can be attributed to the limited air supply contained in the tank and their additional weight and bulk. These restrictors are not major problems for low-level waste site applications. For operations requiring respirator wear at low-level waste sites, the full-face air purifying models with appropriate canister(s) attached are generally the most desirable. Half-mask usage should be 1 imited and SCBA models should be available for use in high hazard situations.

\subsubsection{Maintenance and Disposition of Used Respirators}

This section discusses maintenance and disposition of used respirators. However, new equipment should also be inspected to prevent the use of defective equipment. The inspection process, except for radiation surveys, should be the same whether the respirators are new or used.

All respirators should be carefully removed after use to avoid the potential transfer of radioactive contamination from the respirator to personnel. 
Respirators should not be removed until the wearer is safely out of the hazard area. Then, each respirator should receive a radiation survey to determine its proper disposition. Respirators that are found to be contaminated should be decontaminated until there is no detectable removable activity, using standard swipes. ANSI Standard Z88.2-1980, "Practices for Respiratory Protection" states that allowable levels of fixed contamination should not exceed 100 disintegrations per minute per $100 \mathrm{~cm}^{2}$ fixed alpha and $0.2 \mathrm{mrad} / \mathrm{hr}$ of beta-gamma above background at contact.

Respirator facepieces that are below the above contamination levels may be reused by the same person on the same working day. Beyond that working day, they should not be reused before cleaning, sanitizing and inspection has been done.

Respirators should not be cleaned and sanitized before they have received a radiological survey and are found to be within release limits. "Cleaned," as referred to here, does not imply radiological decontamination. Cleaning, disinfection, and inspection for faulty or deteriorated components must be performed periodically. Facepieces, with the canisters removed, may be washed in warm water using a good detergent. Electric dishwashers may be adapted to clean facepieces. After washing, they should be rinsed and dried; extreme heat $\left(>140^{\circ} \mathrm{F}\right)$ or agitation should be avoided.

The sanitizing agent may be added to the cleaning solution or applied to the facepiece directly. Care should be taken to thoroughly rinse the unit to remove the sanitizer solution. Commercial cleaner-sanitizers are available, or a suitable compound such as a hypochlorite solution with 50 ppm chlorine, may be used.

Inspection of half-masks and full-face air-purifying respirators should ensure the integrity of:

- strap

- facepiece

- valves and valve seal

- cartridge mounts and gaskets

- Iens or eyepiece

- clamps and connections

- speaking diaphram (where applicable).

Self-contained breathing appratus models are more complicated because of the larger number and intricacy of the component parts. Therefore, it is recommended that a factory certified person perform or oversee the inspection and maintenance of these units.

Units found to be defective at any time should be removed from service until defective parts have been repaired or replaced. 


\subsubsection{Emergency Actions}

The potential for a major airborne contamination problem from radionuclides at $\amalg W$ disposal sites is low. It is difficult to envision air concentrations at these sites which would require the simultaneous use of more than a few SCBA units, except for a fire. Procedures should be in place, however, which would offer guidance for actions to be taken by personnel if such an occurrence should arise.

\subsubsection{Documentation and Reporting}

Certain information pertinent to the respiratory protection program should be documented. These records may be valuable to identify potential problems and to determine program effectiveness through the correlation of historical data.

It is advisable, where practical, to record information on printed standard forms. This method allows for both consistency in reporting and rapid data retrieval. A record system should be established and should include information, such as:

a normal background air concentrations of radionuclides

a abnormal air concentration levels or potential hazardous atmospheres resulting from task performance

a respirator usage (normal and abnormal)

a a ir sampling results

a biosurveillance data keyed to hazardous atmospheres

a dose assignment

a respirator procurement data

- respirator maintenance data

a training and respirator fit test results.

Procedures should specify a reporting heirarchy to ensure that important information promptly reaches the desired people and/or organization.

\subsubsection{Proagram Effectiveness}

Because the purpose of a respiratory protection program is to aid in maintaining exposure ALARA, the program's effectiveness must be keyed to dose data over a period of time. The contribution of internal dose assignments to the total dose may reflect trends that indicate the adequacy of the program. Biosurveillance data can be plotted against waste volume processed, radionuclide and activity concentrations of waste processed, and internal to external dose 
ratios over time periods of interest as further indicators of program effectiveness. Prominently displayed plots which indicate such trends may also be helpful as a worker awareness tool.

\subsection{RECOMMENDATIONS}

This chapter has outlined recommended practices for the use of respiratory protection at $\amalg W$ disposal sites. The major recommendations made for program adequacy were:

a Support of site management for a respiratory protection program through a written policy statement.

a Performance of annual medical exams to determine ability to wear respiratory protection.

- Training in the proper use and care of respirators.

- Performance of respirator fit tests.

- Use of $\mathrm{NIOSH}$ approved respirators.

- Limited use of half-masks.

- Air-purifying respirators not to be used in atmospheres immediately hazardous to life or health. 


\subsection{SURVEILANCE}

Radiological surveillance at LLW disposal sites is a key factor to control radioactive contamination and maintaining exposure ALARA. Routine surveys provide information on the effectiveness of the contamination control program. Exposure rate measurements, taken prior to and during the performance of certain tasks, often provide the initial indicators for needed dose reduction actions. These actions may include revisions in job techniques, added shielding, or personnel placement to avoid high exposure rate areas. Radiation monitoring results ma be used to support dosimetry data. More importantly, radiation monitoring is often the only means to detect and document exposure to areas of the body which have no dosimeters and would therefore not be detected. Air sample results and biosurveillance data can be compared to determine the effectiveness of the respiratory protection program. These examples emphasize the importance of a radiological surveillance program at LLW sites.

\subsection{SCOPE}

The scope of the radiological surveillance program at LLW sites should be keyed to the needs of the specific site and/or operation. In general, all sites require surveillance in similar categories; although, the intensity or magnitude of the program may vary from site to site. This is because activities may be limited at some sites due to the low waste volume processed while others require a full work schedule in order to process the large volume of waste received.

Radiological surveillance programs should be formulated and implemented at each LLW site to adequately ensure the protection of personnel against radiological hazards and to optimize contamination control. The program should follow management approved, formalized written procedures covering each phase of the overall surveillance program. Although radiological hazards are relatively low at LLW sites, surveillance activities still need to provide radiological protection to occupational workers and to the general public. The surveillance activities of the program should include:

a perform continuous monitoring of radiological conditions throughout the facility

- use of radiation work procedures (permits)

a monitor the radiation dosimetry program

a make recommendatians for and ensure that adequate protective clothing and respiratory protection are being used

- perform contamination control surveys

a provide personnel monitoring services 
- survey incoming shipments and outgoing transport vehicles

- provide continuous monitoring of burial operations and other activities, as necessary

- perform release surveys of tools, equipment, vehicles and personnel

- monitor decontamination operations

- a ir sample collection, counting, and analysis

- correlate air sample results with biosurveillance data

- ensure compliance with state, federal, and internal regulations on radiation protection

- generate and maintain documentation of the above activities.

The following sections offer recommendations to perform the major surveillance activities.

\subsection{RADIOLOGICAL MONITORING OF FACILITIES}

The surveillance program must provide for an ongoing method to document radiological conditions throughout the facility. Surveys to provide this information are usually performed on a scheduled frequency keyed to the potential for change in conditions at a specific building or area of interest. Current practices at existing LLW disposal sites provide for frequent (e.g., weekly) surveys of buildings where there is a contamination potential, while buildings or areas where very little potential exists are typically surveyed on a monthly schedule. Routine surveys of facilities provide an excellent indication of the effectiveness of the contamination control program.

\subsection{RADIATION WOFK PROCEDURES}

Written procedures that offer instruction in radiation safety should be in place for specific tasks. These procedures, sometimes called radiation work permits, are intended to specify protective clothing and equipment requirements, and may offer insight into the types and quantities of radiation which may be encountered during task performance. Typically, these documents are approved and signed by managers or their delegated representatives from operations, radiation protection, and other departments associated with the specific task. All personnel working on the task must be familiar with the procedure. Where practical, it is a good practice to post a copy of the radiation work procedure in a conspicuous location at the job site. 


\subsection{PERSONNH DOSMEIRY}

The present method to collect personnel dose data is through the wearing of personnel dosimeters. Personnel dosimeters, as referred to here, contain either thermol uminescence (TL) materials or photographic film as the exposure response media. A dosimetry program should be in place at each LLW disposal site designed to fit the needs of that specific site. In general, all LLW disposal sites have similar dosimetry needs; however, dosimeter selection, replacement frequency, and program administration may vary somewhat. TL and film dosimeters each offer advantages in certain areas, but it is generally accepted that the advantages of TL dosimeters outweigh those offered by film dosimeters for most applications.. It is also important that dosimeters be worn in the manner which they were designed to be worn. The response of the dosimeter may be highly dependent upon its close attachment to the central trunk area of the upper body and orientation of the dosimeter to the source of radiation. It may be important, for correct dosimeter response, that the front of the dosimeter is aimed away from the body, not toward it. Personnel dosimetry is discussed in detail in Section 4.1.5 of Chapter 4.0.

\subsection{PERSONNEL MONITORING}

Constant monitoring of radiological conditions should be aimed toward limiting personnel exposure and controlling the spread of contamination. Workers should heed the advice of radiation protection personnel and cooperate fully in efforts to maintain exposure ALARA. It should be anticipated by all workers that changing conditions in operations may cause radiological conditions to change as well. Radiation measurements should be taken immediately upon any obvious change in physical conditions related to the job.

Self-monitoring may be desirable when exposure rates or contamination levels are low. As the hazard potential increases, personnel monitoring should be performed by highly skilled individuals. LLW disposal sites presently require that radiation protection personnel receive intensive training in personnel monitoring techniques to develop a high degree of competency.

\subsubsection{Instrumentation Types}

In order to detect and quantify radiation from radioactive materials it is necessary to select the proper instrument or device. Each type of radiation (i.e., alpha, beta, and gamma) has different physical characteristics. These different physical characteristics require different designs of detection and measurement devices to adequately detect, measure and/or differentiate the three types of radiations. Additional differences may be required by the intended application of the device, e.g., portability, detection of more than one type of radiation, etc.

Some detectors are capable of measuring more than one type of radiation. When such detectors are used, the versatility of the instrument must be recognized and the contribution of each radiation to the total measured value 
must be identified. Coversely, it is often necessary to use more than one instrument in order to detect and measure all radiations present.

as:

Radiation detection instruments at $\amalg W$ disposal sites may be categorized

- portable instruments

- fixed and movable instruments

- personnel monitoring instruments.

These categories define the manner in which the instrument or device is typically used. Portable instruments are those designed to be hand carried to the measurement location. Fixed and movable instruments are those with either limited portability or permanently installed in a fixed location. Personnel instruments are those used for personal surveys, whether portable such as a frisker, fixed such as a portal monitor, or a personnel dosimeter such as a fil m dosimeter.

Portable radiation protection instruments may employ ionization chambers, Geiger-Mueller tubes, scintillation material, or gas/air proportional detectors as part of the instrument package.

Ionization chamber type instruments are usually used to measure exposure or dose rates. The typical instrument consists of an ion chamber, an electrometer, and a meter readout. Batteries supply the voltage. Radiation entering the chamber causes ionization in the fill gas (fill gas is normally air). The rate of ionization occurring in the chamber from radiation can be read on the meter of the instrument. By proper calibration of the instrument, the reading on the meter may be directly related to the rate that radiation energy is absorbed by the air in the ionization chamber. Portable ionization instruments (dose rate meters) are normally calibrated to read directly in roentgen (R) per unit of time.

Geiger-Mueller (GM) type detection instruments are used primarily for detecting beta and gamma radiations. GM detectors are essentially gas-filled ionization chambers designed to operate in a pulse mode. In the pulse mode, the tube is operated at a voltage potential such that a single ionizing event initiates a cascade which ionizes all the gas in the tube. This cascade produces a pulse which is recorded on the meter of the instrument.

Thin window GM tubes, commonly called pancake probes, have a very thin window $\left(1.5 \mathrm{mg} / \mathrm{cm}^{2}\right)$ which permits detection of a wider spectrum of radiation energies. Because of this increased capability, thin window GM tubes are recommended for beta-gamma personnel surveys and material release surveys.

In selecting the correct instrument for performing a radiation survey, the following factors must be considered.

- the type and energy of the radiation measured

- whether detection, quantification, or differential is required

- the range of response required. 
The two most common types of radiation encountered at an LLW disposal site are beta and gamma. A radiation survey will almost always require an instrument capable of measuring beta-gamma radiation.

\subsubsection{Instrument Calibration}

Instruments used for the detection and measurement of radiation and contamination levels and determination of air concentrations must be calibrated in accordance with written procedures established by current standards. Each instrument should be calibrated at least annually and perhaps more often depending upon use and handling. The documentation of the calibration should contain such data as energy dependence, angular dependence, geotropism, detection limits, linearity, ambient environmental condition during calibration, reproducibility, sensitivity, overload response, and any other factor which may cause instrument readings to be inaccurate. From this information, correction factors can be developed to minimize measurement errors. Upon satisfactory completion of the calibration, a sticker should be attached to the instrument stating the instrument number, the calibration expiration date, and the name of the individual performing the calibration. All radiation sources used in the calibration must be traceable to the National Bureau of Standards (NBS).

Preoperational checks should be performed before each use to verify that the instrument is operating properly. Preoperational checks should include:

- verification of current calibration

- examination of the physical condition of the instrument

- adequacy of battery condition

- instrument response to radiation sources

- proper zero

- time response.

\subsubsection{Instrument Selection for Personnel Monitoring}

Exposure rates cannot be accurately assessed unless the measurement device is capable of and calibrated to measure the radionuclides of interest. It is important to know the energy response capabilities of a specific instrument in order to apply the proper correction factors to the indicated meter readings. Although there is presently no known portable field instrument which responds correctly to the entire spectrum of radiation energies, ionization chamber type instruments are generally acceptable. Typically, portable ionization chamber instruments are capable of measuring beta (nonpenetrating) radiation energies above $70 \mathrm{keV}$ and gamma or x-ray energies above $8 \mathrm{keV}$. Low energy correction factors are usually required for gamma and $x$-ray energies below about $30 \mathrm{keV}$. Many such instruments measure radiation intensities from 0-5000 $\mathrm{mR} / \mathrm{hr}$, while others are available that are capable of measuring much higher fields of beta, gamma and $x$-rays.

Thin window (pancake) GM detectors are recommended as beta-gamma survey instruments. Although these detectors are more fragile than conventional GM 
detectors, whey are capable of lower energy detection capabilities. Typically, thin window GM detectors respond to beta energies as low as $0.15 \mathrm{MeV}$ ( $\mathrm{E}_{\max }$ ) at an efficiency of approximately 10\%; efficiency increases as a function of the increasing energy of the radiation being measured. A gamma sensitivity to ${ }^{137} \mathrm{Cs}$ of approximately $3000-4000 \mathrm{cpm} / \mathrm{mR} / \mathrm{hr}$ can be expected. Intensity ranges are usually $0-100,000 \mathrm{cpm}$.

Scintillation or gas flow proportional detectors are suitable alpha detectors for $\amalg W$ disposal sites. Efficiency and sensitivity vary substantially, as a function of window thickness, and detector to source size ratios. Minimum efficiencies of about $18 \%$ for scintillation detectors and approximately $35 \%$ for gas flow proportional detectors can be anticipated from small (about 1 in. dia) $239 \mathrm{pu}$ sources in a $2 \pi$ geometry. Maximum intensity levels which can be measured depend on the electronics package (count rate meter) selected.

\subsection{INCOMING SHIPMENT SURVEYS}

Each incoming shipment should receive a radiological survey to document radiation and contamination levels associated with that shipment. A visual inspection for physical damage to the vehicle and the waste containers should be performed simultaneously with the radiological survey. If physical damage is noted, a more extensive contamination survey should be performed. A survey of an incoming transport vehicle is shown in Figure 15.

Radiation measurements should be taken to establish exposure rates at a distance of six feet and at the surface around the perimeter of "closed transport vehicles." A closed transport vehicle is defined in 49 CFR, Part 173.389, as "a vehicle equipped with a securely attached exterior enclosure, which during normal transport, restricts the access of unauthorized persons to the cargo space containing the radioactive materials." Positions in the cab which are normally occupied should also be surveyed to establish exposure rates to the occupants. This survey is shown in Figure 16.

Closed transport vehicles should also receive an internal survey including both exposure rate and contamination measurements. Contamination measurements should be obtained by means of smear (or swipe) samples and counted remotely. All transport vehicles should receive an external "spot check" for smearable contamination in addition to exposure rate surveys upon arrival at the site.

\subsection{BURIAL TRENCH SURVEILLANCE}

Radiation monitoring coverage should be provided when personnel are present at the burial trenches. Surveillance activities should be directed toward monitoring existing radiological conditions and toward providing information from which dose reduction measures can be determined. This may include pointing out high exposure areas and waste containers which may require special 


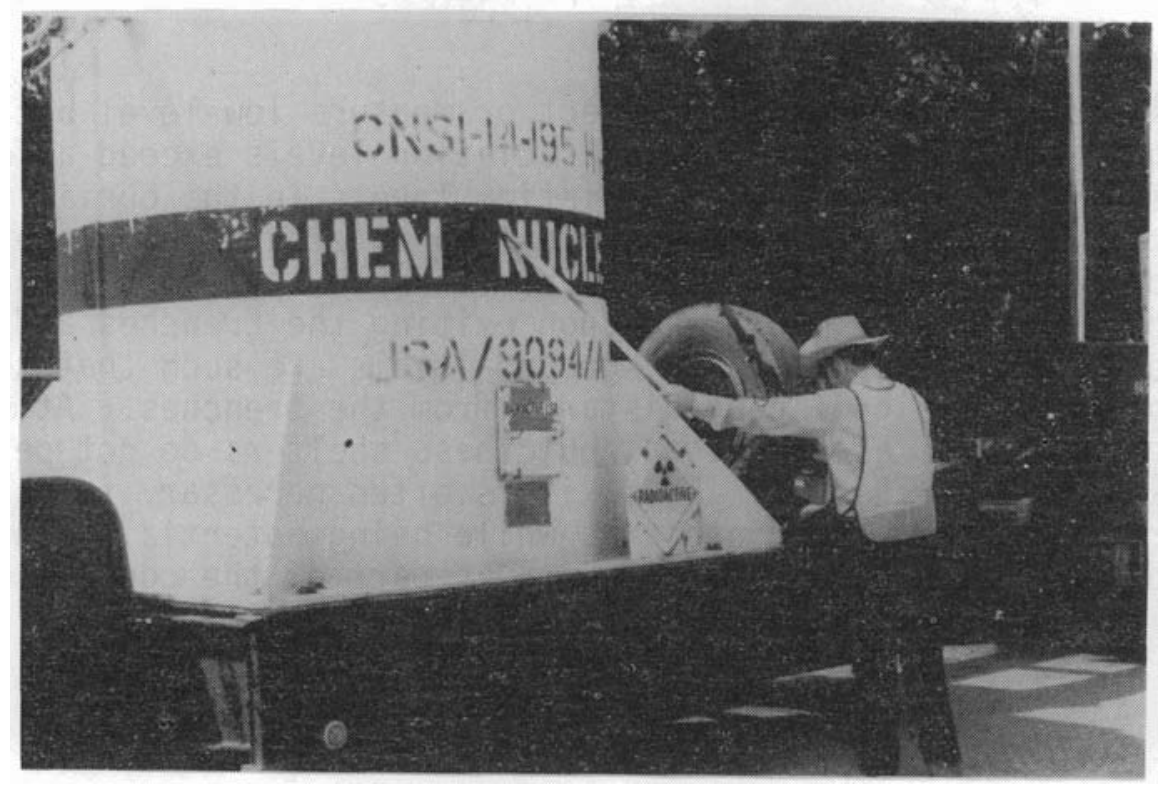

FIGURE 15. Radiological Survey of Transport Vehicle and Shipping Cask

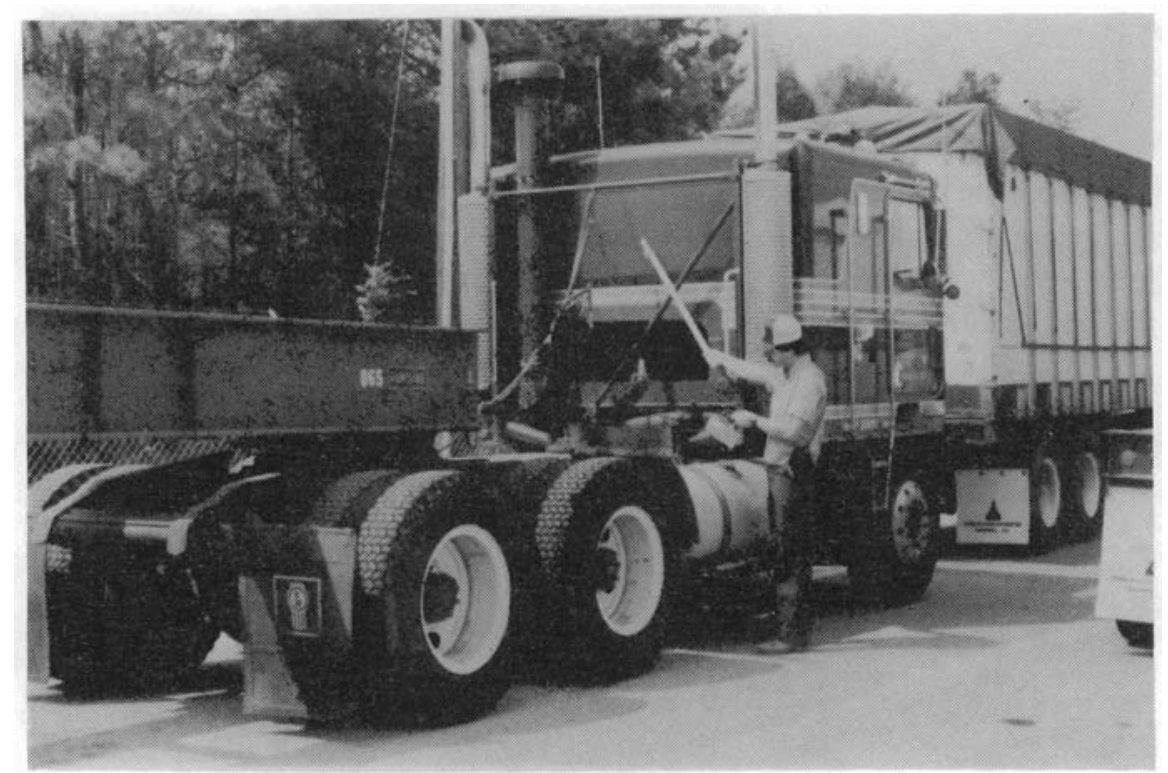

FIGURE 16. Radiological Survey of Truck Cab 
handling or immediate earth cover to minimize personnel exposure. Figure 17 shows a radiation protection technician performing a survey along the edge of a trench.

It is difficult to effectively detect or measure low-level beta-gamma contamination in areas where background radiation levels exceed a few hundred counts per minute. Therefore, when radiation levels in the burial trenches do not allow for a direct contamination survey, an alternate survey method must be used to monitor loose contamination. For example, personnel, tools, and equipment should be closely monitored upon exiting the trenches and/or the associated work area. Typically, background levels are such that these surveys must be conducted at a significant distance from the trenches. At some sites shielded survey hutments are provided, but these shelters do not permit surveys of large equipment and vehicles. Thus, it is often necessary for an unsurveyed vehicle to traverse an intermediate area while being potentially contaminated. This intermediate area should be maintained as part of the controlled zone from which a radiation release survey is required.

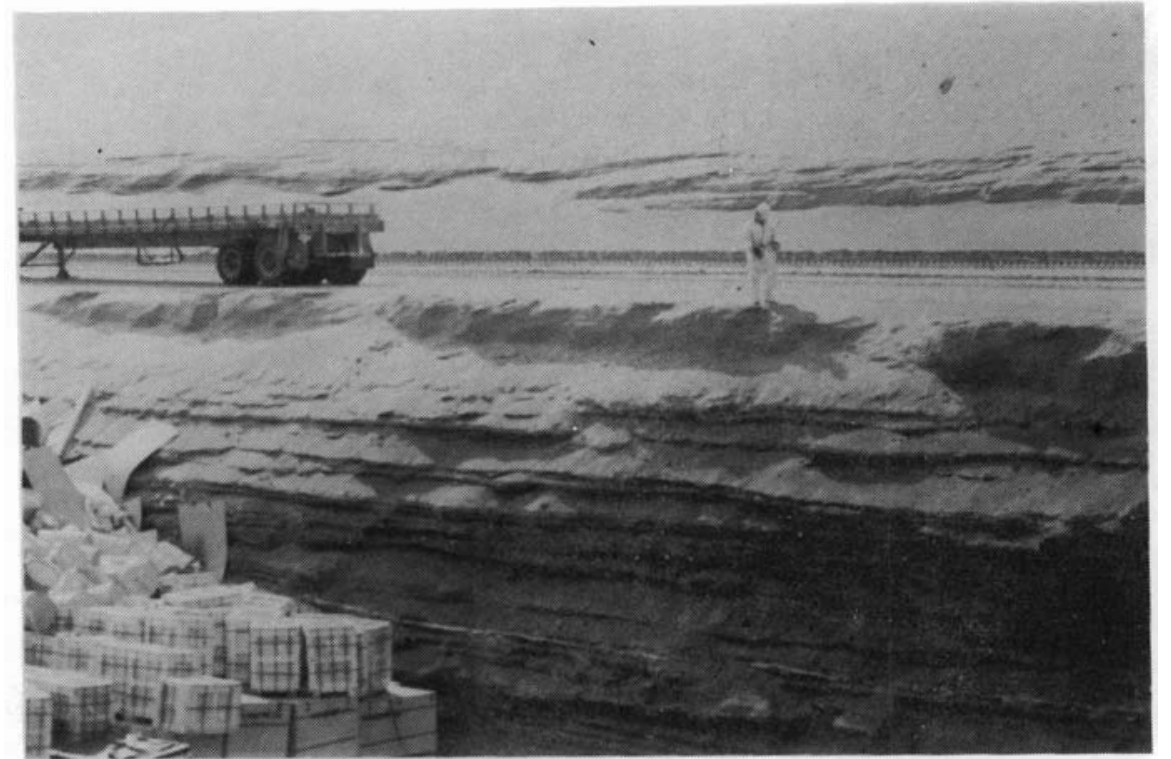

FIGURE 17. Radiological Survey at Trench Edge 


\subsection{RADIATION RELEASE CRITERIA}

All property or personnel exiting a controlled area, where a potential for radioactive contamination exists, must receive a radiation release survey. Suitable radiation detection instruments (see Section 6.5) and survey techniques must be used in the performance of these surveys. Consideration should be given to whether an item is being unconditionally released (uncontrolled) for radiation protection purposes or if certain restrictions are to be associated with the release (controlled). Some potentially contaminated items such as pipes, ductwork, and vacuum pumps do not permit an adequate survey of internal surfaces. A radiological evaluation should be made of such items on a case by case basis, considering such factors as historical information and potential for internal contamination. Covering or coating a contaminated item in order to "seal" the contamination and/or attenuate the intensity of the emission is not a suitable substitute for decontamination. Property which is found to be contaminated should be cleaned to less than the release limits or retained in a restricted status.

All release surveys should be documented and filed as permanent records. Special attention should be given to ensure full documentation of all follow-up actions in event of personnel contamination. A quality assurance program to verify the adequacy of release survey measurements should also be considered.

\subsection{RADIATION RELEASE SURVEYS}

Radiation release surveys at low-level waste sites include three general categories. These are:

- equipment, tools, and miscellaneous items

- transport vehicles

- personnel.

Each of these categories are discussed separately in this chapter and recommended release $1 \mathrm{im}$ it values are listed.

\subsubsection{Equipment, Tools, and Miscellaneous Items}

Radiation release surveys of equipment, tools, and other miscellaneous items should be performed on each item being removed from a controlled area. If the item is to be released for unrestricted use, it is necessary that contamination levels be very low. Recommended maximum contamination levels are listed in Table 4.

It may be practical to allow an item with radiation levels in excess of the fixed contamination limits listed above to be temporarily released from the controlled zone. For example, sites utilizing company-owned tractors (trucks) to pull transport trailers between the waiting compound and the burial trenches may wish to use tractors having low levels of fixed contamination. Under such circumstances, a "restricted" or controlled release may be 
TABLE 4. Unrestricted Release Limits for Tools and Equipment Contaminant

\begin{tabular}{cc} 
Maximum $_{\text {Removable }}(a)$ & $\begin{array}{c}\text { Permissible Level } \\
\text { Total (Fixed } \\
\text { Plus Removable) }\end{array}$ \\
\hline
\end{tabular}

Natural or depleted uranium and natural thorium:

beta-gamma

a) pha

$2200 \mathrm{dpm} / \mathrm{cm}^{2}$

$220 \mathrm{dpm} / \mathrm{cm}^{2}$

All other beta-gamma emitting radionuclides $220 \mathrm{dpm} / \mathrm{cm}^{2} \quad$ Nondetectable

All other alpha emitting radionuclides

$22 \mathrm{dpm} / \mathrm{cm}^{2} \quad$ Nondetectable

(a) Maximum permissible removable levels averaged over $300 \mathrm{~cm}^{2}$.

granted as long as the vehicle or item does not constitute a radiological

hazard. The following guidelines should be followed for restricted releases:

- removable contamination should not exceed unrestricted limits

- the radiation protection group should ensure that the restricted release item does not present a radiological hazard

- the restricted release item should not go outside of the plant boundary.

\subsubsection{Transport Vehicle Release Surveys}

Transport vehicle release surveys must be keyed to the Department of Transportation classification (49 CFR) of the specific vehicle. Exclusive-use vehicles and unrestricted vehicles are regulated by different release limits. Some sites are regulated by limits that have been established by state agencies. These limits may coincide with federal regulatory limits, or they may be more restrictive. However, state- or site-specific radiation release limits may not be less restrictive than the federal limits. The contamination limits listed in Table 5 should not be exceeded on transport vehicles being released for unrestricted use.

The contamination limits listed in Table 6 should not be exceeded on exclusive-use transport vehicles. 
TABLE 5. Unrestricted Release Limits for Transport Vehicles

Contaminant

Maximum Permissible Level Removable $\quad$ Fixed

Natural or depleted uranium and natural thori um:

beta-gamma

al pha

All other beta-gamma emitting radi onucl ides

All other alpha emitting radionuclides

$$
\begin{array}{rl}
2200 \mathrm{dpm} / \mathrm{cm}^{2} & 0.5 \mathrm{mR} / \mathrm{hr}(\mathrm{b}) \\
220 \mathrm{dpm} / \mathrm{cm}^{2} & \text { Nondetectable } \\
220 \mathrm{dpm} / \mathrm{cm}^{2} & 0.1 \mathrm{mR} / \mathrm{hr}(\mathrm{b})
\end{array}
$$

$22 \mathrm{dpm} / \mathrm{cm}^{2} \quad$ Nondetectable

(a) Maximum permissible levels averaged over $300 \mathrm{~cm}^{2}$.

(b) At any accessible surface.

TABLE 6. Contaniination Release Limits for Excl usive-Use Transport Vehicles Being Returned to Service

\section{Contaminant}

Natural or depleted uranium and natural thori um:

beta-gamma

alpha

All other beta-gamma emitting radionuclides

All other alpha emitting radionuclides
Maximum Permissible Level Removable Fixed

(a) Maximum permissible levels averaged over $300 \mathrm{~cm}^{2}$.

(b) At any accessible surface.

\subsubsection{Personnel Release Surveys}

All personnel exiting a controlled zone should receive a radiation survey. Portal monitors and/or frisking stations should be provided to ensure an adequate survey capability. Hand and shoe counters used in conjunction with friskers provide an excellent personnel survey facility. Care should be taken to not rely totally on portal monitors or hand and shoe counters for releasing personnel. While these units, when operating properly, provide an effective, fast survey, some less sensitive units are limited by geometrical considerations and frisking should be done as a supplemental survey. 
Personnel surveys can be performed by each individual; however, if contamination is indicated by the survey, radiation safety personnel should be notified immediately to determine what followup action is necessary. Release limits for personnel should not exceed the levels listed in Table 7.

\section{TABLE 7. Personnel Release Limits}

\begin{tabular}{|c|c|c|}
\hline \multirow[b]{2}{*}{ Contaminant } & \multicolumn{2}{|c|}{ Maximum Permissible Levels } \\
\hline & Removable & Fixed \\
\hline $\begin{array}{l}\text { Alpha } \\
\text { Beta-gamma }\end{array}$ & $\begin{array}{l}\text { Nondetectable } \\
\text { Nondetectable }\end{array}$ & $\begin{array}{l}\text { Nondetectable }(a) \\
\text { Nondetectabl e }(a, b)\end{array}$ \\
\hline
\end{tabular}

(a) If contamination is still present after repeated decontamination attempts, medical assistance may be required.

(b) "Nondetectable" can be considered as levels not exceeding approximately 100 counts per minute above natural background (beta-gamma) as measured with a thin window pancake type GM counter.

\subsubsection{Instrument Selection for Release Surveys}

Radiation release surveys must be performed with appropriate instruments of ,known efficiency. Gas proportional and scintillation detectors are suitable for alpha monitoring. Thin window pancake type GM detectors are recommended for beta-gamma surveys (see Section 6.5.1).

Energy response characteristics for each instrument should be known and response time should be sufficiently fast to ensure the detection of contaminants on a nonuniformly contaminated item. The counting efficiency should be sufficiently high to provide for a reasonably accurate measurement of the radionuclides present. American National Standards Institute Document N13.12, 1978 "Draft American National Standard Control of Radioactive Surface Contamination on Materials, Equipment, and Facilities to be Released for Uncontrolled Use," suggests an accuracy of $\pm 50 \%$ at the $90 \%$ confidence level in a counting time of less than five minutes.

The requirements of ANSI N13.4-1971, "American National Standard Specification of Portable X- or Gamma Radiation Survey Instruments" should be met and instrument tests and calibrations should follow the guidelines of ANSI N323-1977, "American National Standard for Radiation Protection Instrumentation Test and Calibration."

If portable instruments do not exhibit sufficient detection efficiency, laboratory analysis of smear samples should be performed before items are released for uncontrolled use. 


\subsection{MONITORING DECONTAMINATION OPERATIONS}

The extent of contamination on an item dictates the degree of radiation monitoring which is needed for the decontamination effort. Radiation safety (radiation control) personnel who detect contaminated items should direct or advise the decontamination process and ultimately release or deny release of the item based upon survey results. Protective clothing and respiratory requirements for the job should be prescribed in the radiation work procedure; however, radiation protection personnel should have the authority to alter the requirements as conditions warrant. A survey of the work area and of personnel involved in the decontamination task should be performed upon completion of the job to document existing radiological conditions and to ensure the safety of the personnel involved.

\subsection{AIR SAMPLING/MONITORING}

In zones where a potential hazard exists from breathing airborne radioactive materials, the concentration of radionuclides in air must be determined and compared to applicable regulations. $10 \mathrm{CFR}$, Part 20, Appendix B, Table 1 lists maximum permissible air concentration limits for radiation workers.

These limits vary for different radionuclides. Thus, it is necessary to identify the radionuclides which are present by performing an analysis.

The primary objective of an air sampling/monitoring program at $\amalg W$ dis posal sites is to minimize personnel exposure to airborne radioactive materials. When airborne radionuclides are present, respiratory protection may be required to reduce worker exposure. By accurately assessing existing conditions, the proper respiratory protection may be selected to adequately protect the workers.

The open air environment, which is prevelant for major burial operations, offer advantages in that rapid dispersion of airborne particulates is likely. In case of a ruptured container, all sites should have the capability to quickly reduce the hazard by covering the container with fill-dirt.

Effective air sampling can be realized by following certain principles. The sample should be representative of worker breathing zone air. Although possible, it may not be practical to sample air at the most ideal sampling point (i.e., near the workers nostrils or mouth). Acceptable alternate sampling locations should be chosen. Fixed position sampling equipment is suitable at most sites, but it is necessary to relocate the sampling equipment as the burial operation moves in the trench. A commonly used fixed position air sampling system is shown in Figure 18. 


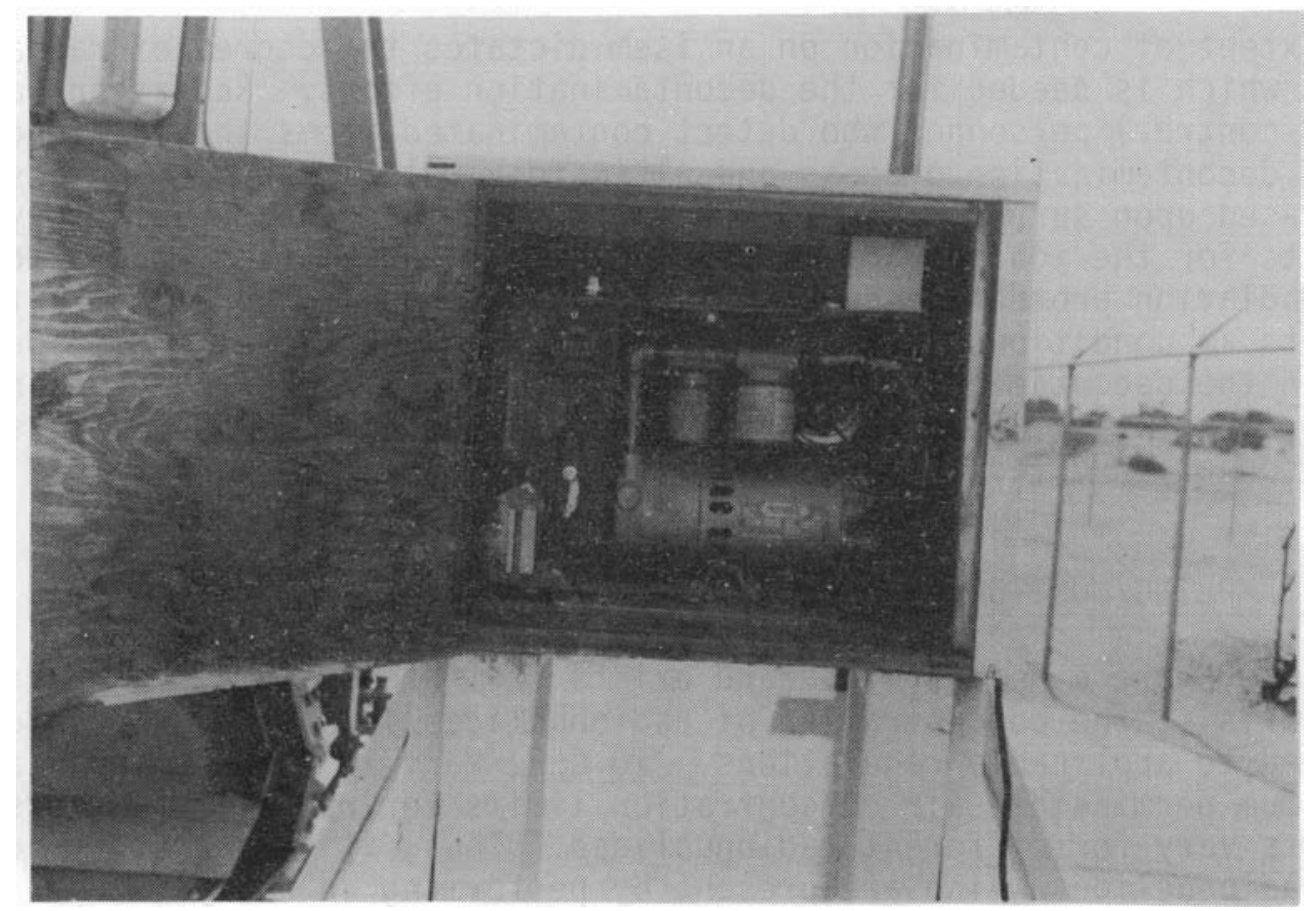

FIGURE 18. Fixed Position Air Sampling Station

It is recommended that a ir samplers be positioned in the trench and on the trench lip. Samples should be as representative of the breathing zones of workers as practical without interfering with the worker or the task being performed. Consideration should be given to installing $A C$ to $D C$ convertors on the fork lifts that are used in the trench for disposal operations to power a ir samplers. Sample collection media should be positioned in free-air (i.e., away from air-flow altering obstructions) at a height of 5 to 6 feet above work area ground surfaces. Sampled a ir should not be carried to the collection media through delivery lines which may remove particulates from the air; but rather, the sample media should be open to the ambient atmosphere. If this is not feasible then the sampling lines should be as short and as straight as possible to avoid plating out along the walls of the sample line. The sampling head should be sufficiently removed from the last bend, opening, or obstruction to avoid the effects of excessive turbulance in the air flow pattern.

The choice of a filter media is very important to the effectiveness of an air sampling program. A wide choice of filters are available and there is one suitable for almost any purpose. Commonly used types include cellulose and membrane. Among the characteristics that influence a choice of a filter are its collection efficiency, flow resistance, and mechanical strength. Collection efficiency cannot be tied to a single variable but is a function of particle size and density, flow velocity, filter pore size, fiber diamter, filter 
loading, and the electrostatic charge and chemical characteristics of the airborne material being sampled. The collection efficiency should be determined on a case-by-case basis for different sampling situations. Air filters used for particulate sampling should provide greater than 99\%collection efficiency for 0.3 micron particulates. When alpha counting is required the selfabsorption of the filter must be taken into account. Membrane filters offer advantages here; however, they are somewhat brittle and must be well supported during collection and carefully handled. Moreover, they exhibit a rather high pressure drop (flow resistance) to accompany their good collection efficiency and 1 ow selfabsor tioncharacteristics.

Air sampling should be conducted during burial operations, decontamination operations, and waste inspections. Changes in air sample characteristics should be anticipated with changes in operations. Air-flow rates through the sampling system should approximate the breathing rate of a "standard man" while working (i.e., approximately 20-30 liters per minute, ICRP 23, 1970). Flow measuring devices, such as "rotometers," and a variable-orifice are suitable to determine the air flow rate. These meters should be installed on the downstream side of the collector. A control valve that is installed in the line between the air pump and the collection media is suitable to control the flow rate. If the sampling system does not offer automatic flow rate adjustments as materials buildup on the filter, periodic hand adjustments may be necessary.

The minimum amount of air which must be sampled in order to provide valid results is dependent upon the sensitivity and accuracy of the analytical or counting system to be used.

Information relevant to each sample should be documented. Information should include flow rates, sample duration, total vol ume sampled, the operation being monitored, and counting or analysis results. After a data base is established, the effectiveness of the program can be keyed to biosurveillance data.

There are two types of sample collection involved in an air sampling program: 1) grab samples, and 2) integrated samples. A grab sample is defined as a single saniple taken at a point in time and space. Many such samples would need to be taken to adequately describe conditions in a large area. An integrated sample provides for an average of the air concentration over the collection time and does not allow for identification of specific events. Samples of either type may be taken for both gases and particulates.

Choosing a sampler involves choosing a method of analysis as well. A less sensitive method of analysis requires a larger or more concentrated sample, such as a larger volume for a grab saniple or a higher sample collection flow rate for an integrated sample. The choice of sampler also depends upon the type of inforniation desired. If immediate readout is needed, collection and analysis are done at the same time such as with a continuous air monitor. If not, analysis is often conducted at a laboratory facility such as with the collection media from fixed or lapel samplers. 
The most commonly used types of a ir samplers are:

- filter collection media samplers

- grab samplers

- continuous air samplers.

Filter collection media samplers operate by drawing a sample at a known flow rate through a filter for a known length of time, thus yielding an integrated sample. These samplers can either be fixed location samplers or lapel samplers. Fixed samplers may indeed be portable but remain in a fixed location during the sampling period. They employ pumps which draw air through the filter media at flow rates up to about $60 \mathrm{~m} /$ hour. Filter sizes can range from about 1 inch in diameter up to 7-8 inches in diameter and may be circular or rectangular in shape. Power for the pumps is supplied by 110 volts A.C. or greater, or they may be gasoline powered. In contrast, lapel samplers operate on rechargeable batteries and sample the breathing zone of an individual who is moving about. A filter holder 1-2 inches in diameter is positioned near the breathing zone and is connected by tubing to a small portable pump. Flow rates for lapel samplers range up to about $1 \mathrm{~m} /$ hour. The filters from fixed or lapel samplers are then sent to a laboratory for chemical or radioanalysis.

Grab samples are obtained by replacing the gaseous contents of a chamber with an air sample. This can be accomplished by one of two methods. The first is achieved by evacuating the chamber using a vaccum pump and allowing it to refill in the work area of interest. The second is to draw a sample through the chamber (using a pump) at the area of interest until a representative sample is obtained within the chamber. Both methods require that the that the sample chamber have the capability of being isolated after the sample has been collected. The chamber contents can then be analyzed by a laboratory using a radioanalysis method.

Continuous air samplers are used to monitor the airborne radioactivity levels in the area as a function of time. They may also be fitted with an alarm function (set to alarm at a preset value) and may be capable of grab sample or filter sample collection. One system design possibility would be to utilize a flow-through ionization chamber to monitor radioactive gases, while an end-window G-M tube monitors particulates which collected up on a filter.

Other types of air samplers include:

condensation devices.

(1) adsorbers, (2) impingers, and

In order to accurately assess the air concentration of radioactive materials in a given location, the volume of air sampled as well as the quantity of contaminant in the air sample must be determined. Accurate determination of the volume of air sampled requires standard, reproducible, and frequent calibration of the flow rate meters which are used with the air samplers. A calibration of air flow rate and/or volume meters should be performed at least once every six months. In addition, calibrations should be performed at any time there is reason to believe that the operating characteristics of the meter have changed, by repair or alteration, or whenever system performance is observed to have changed significantly. The calibrations should be performed 
using a primary or secondary calibration standard that is traceable to the National Bureau of Standards. A ir sampler flow rate or volume meter devices are considered to have been calibrated successfully, if the error between the primary standard value and the actual meter value is less than $20 \%$. Detailed information relevant to each calibration should be documented (i.e., the primary or secondary standard used, calibration method employed, and accuracy of the calibrated meters including calibration curves or correction factors). In addition to calibration, routine instrument maintenance should be performed as recommended by the manufacturer.

\subsection{RECOMMENDATIONS}

This chapter has outlined recommended practices for radiological surveillance at $\amalg W$ disposal sites. The major recommendations made for program adequacy were:

- Use of ionization chamber type survey instruments to establish dose rates for personnel monitoring.

- Use of radiation release criteria from Tables 4, 5, 6, and 7 .

- Use of either gas proportional or scintillation detector instrumentation for alpha monitoring.

- Positioning of an air sampler on fork lift(s) being used to unload waste containers from closed transport vehicles. 


\subsection{CONTAMINATION CONTROL AND DECONTAMINATION}

An $\amalg W$ disposal site operator should establish and maintain a program to minimize the occurrence and spread of radioactive contamination. The proper use of radiological controls and decontamination facilities lessens the probability that contamination will be spread to areas and persons outside the controlled area.

This section covers four major factors in contamination control and decontamination. They are contamination control (preventative measures), equipment decontamination, personnel decontamination, and decontamination procedures.

\subsection{CONTAMINATION CONTROL}

Several methods are available to prevent or minimize the spread of contamination. Three of the most effective are considered here.

\subsubsection{Protective Clothing}

The use of various articles of clothing, both disposable and nondisposable, can minimize the possibility of contaminants contacting the skin of a worker. Coveralls, gloves, boots, and head covers are examples of protective clothing which are currently available. In jobs where the possibility of contamination is high, these items should be impervious to liquid contaminants. Gloves and shoe covers should be sufficiently sturdy to remain intact during work tasks.

Clothing must be available in sufficient quantities for both normal and abnormal work situations. Usually, a 30 day supply is sufficient. Protective clothing should be stored in an easily accessible location.

Respiratory protection, which is normally included under the topic of protective clothing, is discussed in Chapter 5.0.

\subsubsection{Contamination Surveillance}

The purpose of contamination surveillance is to locate and isolate contamination before it can spread to uncontrolled areas or cause unnecessary radiation exposures. The primary methods of surveillance are wipe testing for area contamination and frisking for personnel contamination.

\section{Wipe Testing}

This survey method establishes the amount of removable radioactivity on the surfaces sampled. Usually, a standard-sized pad is used to rub a standard-sized area $\left(100 \mathrm{~cm}^{2}\right)$ to, determine the level of removable contamination per unit area of surface. Areas that should be considered for periodic 
survey are those which are in proximity to potential sources such as workplaces, changerooms, and other occupied areas within the controlled area.

\section{Personnel Contamination Monitorina}

Personnel frisking stations should be available near work locations so workers may periodically survey themselves. However, the station should be far enough away from radiation sources to ensure that a low radiation background environment exists for the contamination survey (frisk). If this is not practical then shielding may be used to help minimize the background levels. It is recommended that the background levels be less than 100 counts per minute when using a Geiger-Mueller (GM) survey instrument equipped with a thin window pancake detector probe. Figure 19 shows an example of a worker performing a "frisk" with a pancake-detector probe inside a frisking booth. Contamination surveys should be performed with the detector window facing towards the area to be surveyed and within close proximity to that area

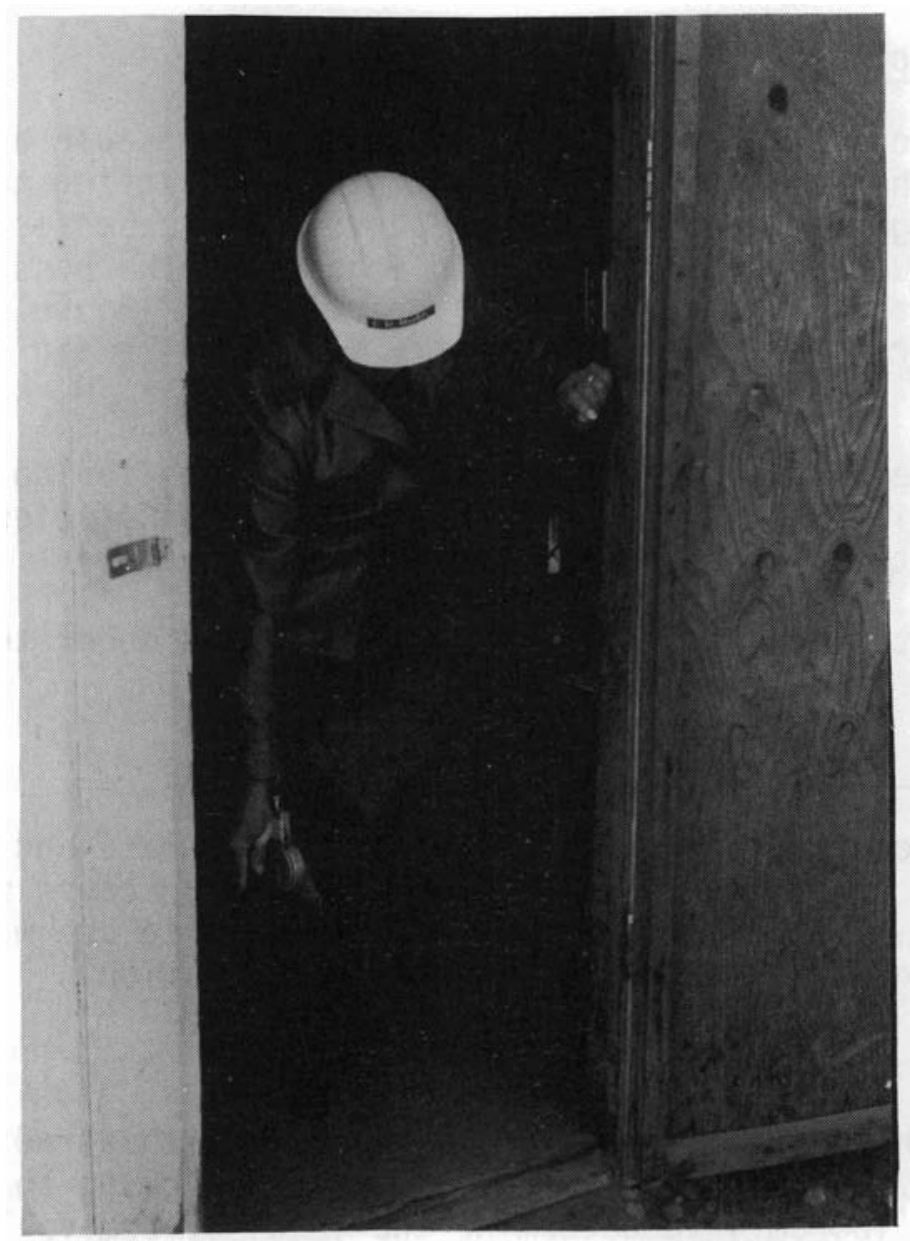

FIGURE 19. Personnel Frisking Station 
(1/4-1/2 inch). It is recommended that the survey scanning speed be less than 4-5 inches per second to ensure that the survey instrument has an adequate time to respond to any radiation fields that are present in the path of the survey. In addition, a frisker station should be available in the employee changeroom area and a portal monitor should be located at the controlled area exit point. The portal monitor should have a very low limit of detectability and should be positioned so no employee can exit without being monitored. Monitors at the personnel frisking stations should be capable of providing a thorough survey in a minimal amount of time so employee impatience with the task does not cause a lessening in survey effectiveness. All instrumentation used for personnel contamination surveys should be equipped with thin-window detectors to ensure that they are sensitive enough to detect beta particles and low-energy gamma rays.

\subsubsection{Site and Facility Design}

Control and isolation of contamination should be considered in the design and construction of an $\amalg W$ disposal site and supporting facilities. A well planned and constructed site can aid in contamination control by minimizing human and equipment contact with the waste once it is onsite.

Buildings should be arranged to permit efficient waste disposal operations. For example, the truck check-in station should be near the truck parking lot and the site access gate. The site design should provide for one personnel access point and one waste entry point. Limiting the entry locations reduces the area which must be monitored for material and contamination control of the site. This minimizes the probability of materials or contamination leaving the site.

Individual facilities should be designed to minimize the spread of contamination. The site access building, as shown in Figure 5 , is designed to control and isolate contaminated persons and equipment leaving the site by use of barriers and alarmed monitor points.

\subsection{EQUIPMENT DECONTAMINATION}

Control of contamination on tools and equipment is discussed in this section.

\subsubsection{Facility Requirements}

Control of contamination on tools and equipment aids in the control of personnel contamination and personnel exposures. Each site should maintain a building or separate facility dedicated to equipment decontamination. The facility should be large enough to accommodate all sizes of potentially contaminated items, from hand tools to heavy equipment.

Provisions for the required personnel protection should be in place and operable. Walls, floors, and furnishings in the decontamination area 
should be constructed or protected to facilitate removal of contaminants generated in decontamination operations.

Several methods are currently available for equipment decontamination. Examples of destructive and nondestructive methods are given below. These methods have proven effective in reducing contamination levels on both large and small items:

- scrubbing with a solvent and water

- high pressure water and steam spray

- hydrolasing

- abrasive blasing (wet and dry)

- grinding and destructive removal

- vibratory finishing

- ultrasonic cleaning.

There are distinct differences in the effectiveness and cost of these methods. Each site should study the available methods or combination of methods to determine those best suited to its needs and economic situation.

Enclosed facilities which contain loose radioactive materials (e.g., contaminated equipment) should be provided with a ventilation system. Ventilation systems may assist in controlling the concentration of radioactive contaminants in the building atmosphere. This reduces the probability that airborne radioactive material will be spread inside the building or released outside the building. Specifically, an effective ventilation system will eliminate building releases to the atmosphere and will help decrease personnel exposure, respiratory protection requirements, and contamination spread inside the facility. This is particularly important when waste containers need to be opened for inspection or when decontamination of highly contaminated equipment is required. It may then be necessary to supplement the ventilation system with a more localized exhaust duct or hood. Figure 20 shows an overhead fume hood system that is capable of being moved up or down over waste containers for the purpose of waste and/or container inspection.

In certain instances, it may become necessary to decontaminate large pieces of equipment such as reusable shipping casks. It may then be appropriate to have facilities designed to act as a whole to control contamination spread. An example of this may be a cask preparation and equipment decontamination facility as shown in Figure 21. This facility allows the truck, with loaded cask, to be driven into the building and any needed unrigging or decontamination of the cask performed.

Decontamination processes generate contaminated solid, liquid, or gaseous waste. Waste collection and containment systems must be in place and operable at each facility. The method of collection depends upon the decontamination method chosen. For example, a sump with a holding tank may be used to collect contaminated water that is generated in scrubbing or hydrolasing operations; vacuum equipment may be used to collect contaminated sand during sandblasting operations; and 55-gallon drums may be used to collect other solids. 


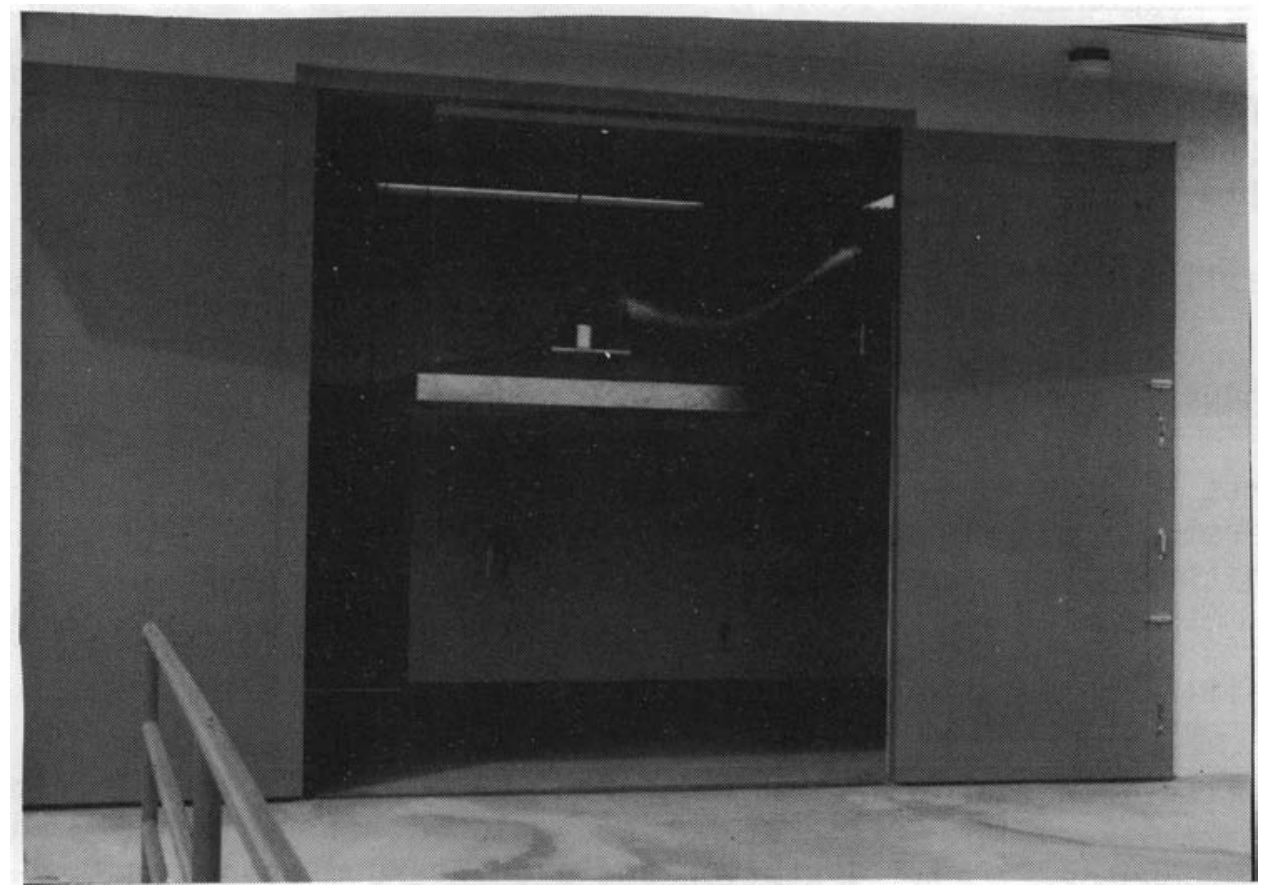

FIGURE 20. $\amalg$ W Container Inspection Facility With Overhead Fume Ha

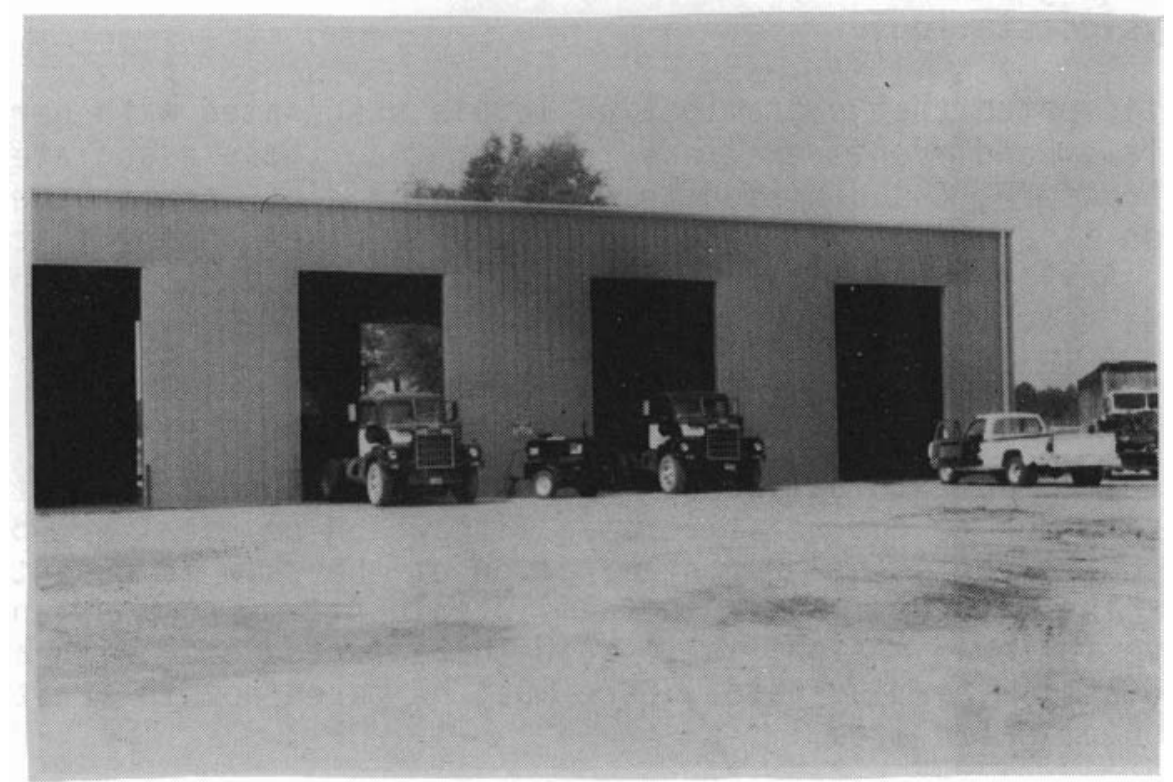

FIGURE 21. Cask Preparation and Maintenance Facility 


\subsubsection{Release Limits}

Each disposal site must establish contamination limits for equipment released for use in both the controlled and uncontrolled areas. Enforcement of these limits ensures that decontamination or disposal actions are taken when the limits are exceeded.

These limits are discussed in more detail in Chapter 6.0 of this document.

\subsection{PERSONNEL DECONTAMINATION}

Efforts to control personnel contamination greatly aid the efforts to control personnel exposures and contamination spread. Access control and personnel monitoring for contamination has been discussed previously in this chapter. The methods and equipment available for this task will now be discussed.

\subsubsection{Facility Requirements}

Each site should maintain a "dedicated" personnel decontamination area as a separate part of some facility. For convenience, it is strongly recommended that an area near a first aid station and a changeroom be designated as the decontamination area (see Figure 3). In designating an area, attention should be paid to the proximity of the area with respect to other functional facilities. For example, the decontamination facility should be located within the controlled area of the site. Contaminated personnel should not be required to walk a long distance through any building to reach the decontamination area. It is also advantageous to locate the decontamination area near the showers and Health Physics station.

It is anticipated that contamination levels associated with personnel are somewhat lower and events are less frequent than those associated with equipment. Therefore, the decision to install a holding tank for personnel decontamination is a borderline case and should be based on specific site requirements. Any shower dedicated to personnel decontamination should drain into a separate retention tank.

\subsubsection{Release Limits}

Methods to remove external contamination from personnel are rather limited. This is due to the relative ease with which physical and biological damage can occur to the skin. Decontamination of the skin is essentially limited to washing with warm water and a mild solvent. A common, and sometimes effective followup action, is to wash the affected area with a dilute solution of potassium permanganate. Care must be taken not to irritate the skin in the contaminated area.

Probably, the only other action site personnel can take is to "sweat out" the contaminated area. For example, if no further material can be removed 
from a contaminated hand, a rubberized glove may be placed on the hand and sealed with tape. This causes a large portion of the materials to be released from the pores in the perspiration process.

Release limits for contamination on personnel are given in Table 7 . If radiation levels remain high (greater than tens of $\mathrm{mR} / \mathrm{hr}$ ) after repeated decontaminations, professional medical help may be required to assist in removing the contamination. It should be remembered that medical treatment should take precedence over personnel decontamination when responding to contaminated/ injured personnel.

\subsection{DECONTAMINATION PROCEDURES}

Formal written procedures should be developed for equipment and personnel decontamination. Procedures help ensure that decontamination will be carried out in a safe, efficient, and approved manner.

Procedures should assign the responsibility for decontamination to a specific individual. This responsibility should be assigned to the site RSO by the site manager.

Procedures should designate the equipnient and supplies to be used for decontaniination operations. Procedures should be specific and detailed to avoid any confusion or misunderstanding. They should include an inventory list and the assigned location of decontamination supplies and equipment.

Procedures should identify contamination levels and actions to be initiated when those levels are reached. They should specify the records required and the information to be included.

\subsection{RECOMMENDATIONS}

This chapter has outlined methods to minimize the occurrence and spread of radioactive contamination including decontamination considerations. The major recommendations made for program adequacy were:

- The use of frisking stations in low radiation background areas.

- The use of localized exhaust ducts and hoods to handle highly contaminated items.

- The establishment of a "dedicated" personnel decontamination area.

- The establishment of equipment and personnel decontamination procedures. 


\subsection{QUALITY ASSURANCE}

The following chapter describes the quality assurance elements recommended for the radiation protection programs at Low-Level Waste (LLW) disposal sites. "Quality Assurance" is defined as all the planned and systematic actions necessary to provide confidence that an item or a facility will perform satisfactorily in service. As described here, quality assurance is a planned program to verify that each part of the ALARA program is being accomplished adequately and that the intended purpose, to ensure the health and safety of the worker and the general public, is met. "Quality Control" (QC), as used in this chapter, is defined as those quality assurance actions which provide a means to control and measure the characteristics of an item, process, or facility in accordance with predetermined requirements.

Establishment and implementation of a Quality Assurance (QA) program for radiation protection at $\amalg W$ disposal sites is essential. The extent of the program should be determined from a thorough evaluation of the activities to be conducted, their potential effect on the safety of the site personnel and the general public, and the requirements of applicable regulations, standards and Ticenses. Additionally, the extent of the program should be approved by the level of management responsible for the overall performance and safety of the facility.

The QA program should provide documented, verifiable evidence to support the reliability and effectiveness of the program, and compliance with regulatory and license requirements. The documentation should include verification that necessary corrective actions have been implemented.

The following discussion covers the areas of: program responsibility/ authority, (2) personnel selection, qualification and training, (3) procedures, (4) program elements, and (5) in-house audits.

\subsection{PROGRAM RESPONSIBILITY/AUTHORITY}

The organization having overall responsibility for safety at a nuclear facility should also be responsible for the development and implementation of the QA program as it applies to safety. At an $\amalg W$ disposal site the Radiation Protection Organization has the responsibility for the radiation protection program and, therefore, should also be responsible for the QA-radiation protection program. The Radiation Protection Organization may delegate to other organizations the work to develop and implement all, or a part of, the QAradiation protection program, but shall retain responsibility for the effectiveness of the overall program.

An organizational structure for the program should be formally defined and documented. The staff member with overall responsibility for the QAradiation protection program at an $\amalg W$ disposal site should be the Radiation Safety Officer (RSO) or Radiation Protection Manager depending upon site 
designation of title. A recommended organizational structure is outlined in Figure 22. It is important that the RSO report directly to the site manager both for radiation protection and QA functions. This is recommended to ensure that both the radiation protection and QA programs are organizationally independent from the site operating functions. If this is not accomplished, a potential conflict of interest could arise between the operational and safety functions. However, it must also be noted that a potential conflict of interest could also arise between the radiation protection and QA functions for in-house audits. This aspect is discussed in more detail in Section 8.6 of this document.

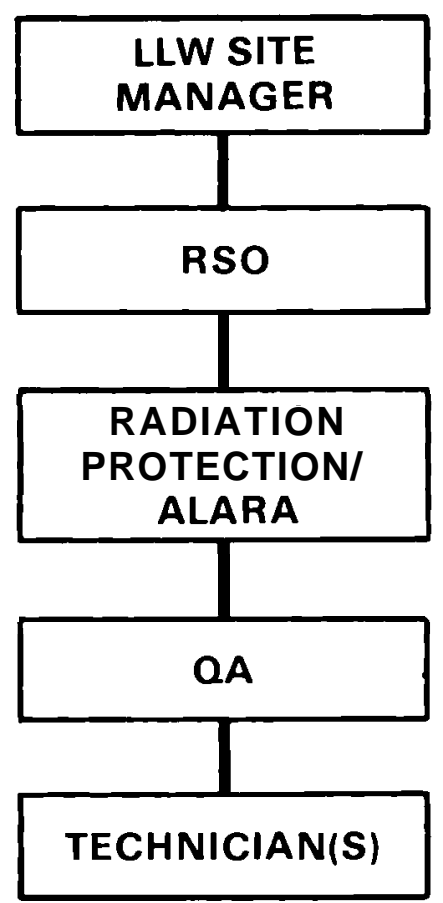

FIGURE 22. QA-Radiation Protection Organizational Structure

Where multiple organizational arrangements exist, the responsibility of each organization should be clearly established, and interfaces and coordination among the organizations should be ensured by formal mechanisms. The authority and duties of personnel and organizations responsible for QA performance and verification should be documented in writing. They should have sufficient authority and organizational freedom to identify QA problems; to initiate, recommend, or provide solutions; and where necessary, to control or stop further work either in-house or by vendors. This aspect is discussed in more detail in Sections 8.4.2 and 8.6. 


\subsection{PERSONNEL SELECTION, QUALIFICATION AND TRAINING}

The QA-radiation protection program should specify in writing the qualifications, training, and skills required of QA personnel. In addition, the $\amalg W$ disposal site operational schedule should be considered to allow adequate time to assign or select personnel and to perform the required QA training.

Al1 personnel responsible for performing $Q A^{\circ}$ activities should be qualified on the basis of the education, experience, and proficiency required to perform the specific assigned tasks,. As a minimum, the person responsible for the QA-radiation protection functions. should have three years of radiation protection experience, of which one year should be from an $\amalg W$ disposal site. The other two years of experience may be fulfilled by related technical or academic training.

Training and retraining programs and procedures should be established to ensure that suitable proficiency is achieved and maintained. The specifics of onsite training programs are given in Chapter 3.0 of this document.

\subsection{PROCEDURES}

Each $\amalg W$ disposal site should have a written QA program which is specific to radiation protection. The formalized $Q A$ document $(s)$ should include, as a minimum, a program policy statement, staff member responsibilities and authority, and QA procedures. In addition, the document(s) should define: (1) the extent and content of the program, (2) the records required, (3) acceptance criteria to determine that activities have been satisfactorily accomplished, and (4) audit functions required to verify implementation of the QA-ALARA program.

In order to have effective QA procedures, it is necessary that they be periodically reviewed and updated as necessary. The review process should be conducted not only by the person responsible for the program (RSO) but also by the personnel who perform the QA functions on a routine basis. Upon acceptance of the procedures, the RSO should sign and date them to indicate that they represent current QA policy. It is recommended that the review and update process be performed on a yearly basis as a minimum. Procedure development is discussed in more detail in Chapter 2.0 of this document.

\subsection{RADIATION PROTECTION PROGRAM ELEMENTS}

The purpose of a radiation protection program is to provide control in the storage, handling, and use of radioactive material. Personnel responsible for radiation protection need to ensure that the program accomplishes its purpose. Consequently, a QA-radiation protection program is needed to verify that activities are conducted as desired and that established regulations and standards are met. 
Functions for which a QA-radiation protection program should be developed include, but are not limited to: (1) calibration of radiation detection and measurement equipment, (2) external dosimetry, (3) biosurveillance, (4) radiation and contamination surveillance, and (5) airborne radioactivity surveillance and respiratory protection. The services and the resulting data for the first three functions identified above are most commonly provided by vendors to $\amalg W$ disposal sites. This may present a problem for the $\amalg W$ site in that a day-to-day overview of the work is not possible as compared to in-house services such as airborne surveillance. The following two sections recommend QA program elements that may be applied to vendors for their calibration, external dosimetry, and biosurveillance services. These elements can then provide mechanisms to ensure that the vendor services have been satisfactorily accomplished. The other radiation protection functions listed above should be evaluated by in-house auditing as discussed in Section 8.5.

\subsubsection{Vendor Selection}

The $\amalg W$ disposal site needs a process not only to evaluate the end proct or service of a vendor but to select a vendor initially. A vendor, as fined here, is any individual or organization, independent of the $\amalg W$ disposal site, under contract to furnish items or services. The selection of a vendor is a two-fold process. The first is the determination of the vendor's capability and the second is the assurance of quality performance by the vendor. The quality of performance is specified through the use of procurement requirements.

A formalized process to determine the vendor's capability should be used. Written procedures should be developed for vendor evaluation. The results of vendor evaluations should be documented for use in future evaluations. The determination of the vendor's capability should include, as a minimum, an evaluation by the $\amalg W$ site of the following:

- history of 'vendor's product or service based on experience of other users

- vendor's current QA records supported by documented qualitative or quantitative information

- vendor's current technical capability, facilities and personnel

- product samples.

Procurement requirements to ensure quality should include as a minimum:

- statement of the scope of the work to be provided by the vendor

- technical requirements that describe the items or services to be supplied

- test, inspection, and acceptance requirements

- QA requirements

- reporting and documentation of nonconformances

- special instructions regarding action levels, i.e. , external dosimetry overexposures. 
The items outlined above should be part of a formal written procurement request for a product or service from the vendor.

\subsubsection{Vendor Evaluation}

It is the $\amalg W$ disposal site's responsibility to evaluate the vendor's QA program and ensure that it is appropriate and satisfies the requirements for the items or services being furnished. The first step towards this goal is the receipt of a certificate of conformance from the vendor. This certificate is defined as a written statement, signed by a qualified party, certifying that the items or services comply with specific requirements as established by regulations, standards and the $\amalg W$ site itself.

The reliability of the vendor's program can be further evaluated through the use of QC samples. The analysis of QC samples provides a means to determine the precision and accuracy of the monitoring processes. The QC definitions of interest are:

- Accuracy--The degree of agreement of the observed value with the conventionally true value of the quantity being measured.

- Analytical Blank--A sample having all of the constituents of the unknown sample except those to be determined.

- Precision--The degree of agreement of repeated measurements of the same parameter.

- Spiked Sample--A sample to which a known amount of radioactive material has been added.

- Split Sample--A homogeneous sample that is divided into parts, each of which is analyzed by independent organizations.

Analytical blanks provide a means to detect and measure radioactive contamination of analytical samples and also provide information on the adequacy of background subtraction. The analysis of split samples provides a means to determine precision, whereas the analysis of spiked samples provides a means to determine accuracy. The determination of the precision and accuracy of the monitoring processes should be accomplished through the use of both intralaboratory and inter-laboratory measurements. Intra-laboratory analysis of split samples should be performed routinely from samples that are as homogeneous as possible. Inter-laboratory analysis of samples split between one or more independent laboratories should also be performed routinely. It is an important part of the QA program, because it provides a means to detect errors that might not be detected by intra-laboratory measurements alone. These independent laboratories should be those whose measurements are traceable to the National Bureau of Standards (NBS).

The following two sections describe the recommended QA-radiation protection programs for instrument calibration and external dosimetry. 


\subsubsection{Instrument Calibration}

Detection and measurement instruments require calibration in a known radiation field or a comparison with instruments with known responses to ensure their reliability for use in the field. Calibration as defined here is the process of determining the response or reading of an instrument relative to a series of conventionally true values. At $\amalg W$ disposal sites these calibrations are performed on a yearly basis usually through a contract with a calibrations laboratory and/or a vendor, and are designated the primary calibrations. Upon receipt of the calibrated instruments, $\amalg W$ site personnel should assure themselves that the instruments have been properly calibrated and are responding adequately before allowing their field use. To provide for this assurance, an "in-house" test of the instrument response should be made as soon after the primary calibration as possible. This test should consist of a check of the instrument's response to a known source of radiation. If the instrument reading on any scale differs by more than $\pm 20 \%$ from the accepted value, then the instrument should be returned to the calibration facility for maintenance, repair, and recalibration, as required.

It must be pointed out that a formal, detailed QA program for vendor instrument calibration needs to be established, particularly if the calibrations are not performed "in-house." It is a poor practice to accept data (of any type) on "faith" whether generated by a vendor or "in-house."

\subsubsection{External Dosimetry}

External dosimetry devices (dosimeters) are usually supplied to $\amalg W$ dis posal sites by vendors. After use, the vendors process the dosimeters and supply exposure reports to the $\amalg W$ sites. In order to ensure that the exposure data is reliable, the $\amalg W$ sites should perform QA checks on the vendor's data. To accomplish this, QC dosimeters are exposed to various known exposure levels (spiked samples) and are sent with the regular staff member dosimeters to be processed. In addition, control (blank) dosimeters representative of background radiation levels should be sent to the vendor at the same time. The exposure results of these dosimeters, as determined by the vendor, are then compared to the values determined by the $\amalg W$ site. The conclusions of this comparison allow the $\amalg W$ site to either accept the vendor's data or require the vendor to adjust its analysis accordingly.

Formal written procedures should be developed for the performance of the $\mathrm{QC}$ checks. These procedures need to include the following items:

- The number of dosimeters to be "spiked" to each exposure level so the results can be considered statistically valid. As a minimum, three dosimeters should be spiked at each exposure level.

- Range of spiked exposure values determined to be representative of exposure range in the field. As a minimum, the range should cover 0-5 rem. 
a The number of different exposure values required to cover the exposure range. As a minimum, one exposure level below $500 \mathrm{mrem}$, one between 500 mrem and 1 rem, and one greater than 1 rem should be used.

a The number of control dosimeters required for statistical validity. As a minimum, three dosimeters should be stored in an area where exposure to $\amalg W$ is minimized.

a The frequency of inclusion of $Q C$ dosimeters with occupationally exposed dosimeters to be processed by the vendor. As a minimum, a quarterly frequency is recommended.

The spiking of dosimeters should be accomplished using the type of radiation (gamma and beta) expected to be emitted from LLW. In addition, energy levels for spiking should be representative of the energy levels of the radiation emitted from the waste packages.

If the exposure data reported by the vendor differs by more than $\pm 20 \%$ from the accepted $Q C$ values, an investigation should be conducted by the $\amalg W$ site to resolve the discrepancy. All QA data and investigations of external dosimetry results need to be documented in writing.

$\amalg W$ disposal sites that process their own dosimeters also need to meet these outlined QA criteria. In order to accomplish this, it is recommended that the QA function be provided by an independent laboratory. As defined here, an independent laboratory may be either an in-house group independent of the radiation protection function or a laboratory outside of the licensee business structure.

\subsection{IN-HOUSE AUDITS}

The radiation protection programs at $\amalg W$ disposal sites should provide for a review of the program on at least a yearly basis. A QA audit is the mechanism that should be used to accomplish this. It is a formal examination of certain specific elements of the radiation protection program to verify that the program is being conducted in accordance with established written procedures and good practices. QA audits may be performed on vendor activities, as described previously in Section 8.4, or on "in-house" activities through the use of "in-house" audits.

"In-house" QA-radiation protection audits should be performed by a team that is organizationally independent of the radiation protection function. This does not mean that the latter has no QA responsibilities or functions, but rather that the line managers responsible for implementing radiation protection should not also be responsible for QA audits and evaluations of their own programs. 


\section{RECOMMENDATIONS}

This chapter has outlined a QA-radiation protection program for LLW disposal sites. The major recommendations made for program adequacy were:

- The person responsible for QA-radiationprotection functions should have three years of radiation protection experience of which one year should be from an $\amalg W$ disposal site.

- Establish a formalized process to select and evaluate vendor services. 


\subsection{PROCEDURES/DOCUMENTATION}

Formalized written procedures, in conjunction with documentation of activities and results, is essential for an effective radiation protection program. Written procedures should be used to control activities when necessary to meet established requirements. In contrast, documentation or recordkeeping should provide an indication of program effectiveness and establish a data base against which future measurements can be evaluated.

The following discussion covers the areas of: (1) procedure format,

procedure update and review, (3) documentation, and (4) record retention.

\subsection{PROCEDURE FORMAT}

Procedures should be developed to provide guidance for activities specifically associated with the radiation protection programs at LLW disposal sites. They should be prepared as formalized written documents. These procedures are necessary tools to ensure that specific guidance is provided for radiation protection tasks that: (1) must be done in a precise way, (2) must be done in the same way repetitively, (3) are complex and involved in detail, (4) require specific or unique instructions, and (5) must be controlled.

The areas of the radiation protection program that need, and are most benefited by, written procedures are: (1) training, (2) internal and external exposure control, (3) respiratory protection, and (4) surveillance. Procedure topics applicable to these areas include the following:

Qualification and Trainina

- selection

- radiation protection technicians

- radiation protection professionals

- radiation protection instructors

- general employee training

- radiation worker training

- radiation protection staff training

- radiation protection technicians

- radiation protection professionals

Internal and External Exposure Control

- AlARA

- biosurveillance

- in vivo counting

- urinalysis 
- fecal analysis

- nasal smears

- airborne radioactivity

- personnel dosimeters

- exposure limits

- dose models/calculations

- overexposures (administrative/regulatory)

- calibration and quality assurance

- reports to workers

$\underline{\text { Respiratory Protection }}$

- corporate pol icy

- training

a respirator fitting

a respirator maintenance

a selection, issuance, and use

$\underline{\text { Surveillance }}$

- radiological surveys

- radiation, contamination, airborne radioactivity

- requirements

- performance

- survey instruments

- maintenance

- calibration

- use

- radiological posting

a radiation work permits

- decontamination/release 1 imits

- personnel

- equipment. 
The written procedures should be developed by the $\amalg W$ site radiation protection group with input from other onsite management and corporate management. As a minimum, these procedures should include:

a procedure number to allow for future reference

- pracedure title

a approval signature

a approval date

a revision number

- number of pages in procedure.

\subsection{PROCEDURE UPDATE AND REVIEW}

Radiation protection procedures should be reviewed and approved by those responsible for the radiation protection program. A reviewer independent of the programs should also be involved in the review process. The review should occur prior to procedure issue or significant modifications, and periodically during use. Changes that substantially revise procedures or operations should be documented and the $\amalg W$ site personnel informed of the changes and the reason for the changes.

The basic purpose of reviewing the radiation protection procedures is to identify the items that affect the radiation exposure of site personnel and to assess those items to ensure that exposures will be reduced to ALARA. A checklis t may be of benefit in performing a procedure review. However, care must be taken to prevent the review from becoming a mechanical process rather than a true assessment. Procedures should be reviewed for: (1) applicability to the work, (2) clarity in describing what to do and how to do it, and (3) the impact of each step on radiation exposure. It is recommended that the review process be performed every two years as a minimum. In addition, the authorized reviewers should sign and date the procedures to indicate that they represent current policy.

\subsection{DOCUMENTATION}

Good recordkeeping is very important when dealing with radioactive material. It allows $\amalg W$ site personnel to: (1) evaluate the effectiveness of the radiation protection program, (2) trace the cause of trends, and (3) demonstrate conipliance with government regulations and licenses. In addition, formal records of radiation protection activities including accurate documentation of dosimetry data, survey measurements, and incident investigations can be a valuable ALARA tool. Without adequate and accurate records, it would be difficult to predict or meet ALARA goals.

Records should be of a quality that will enable them to be retained indefinitely without losing their legibility. The records retained for each individual should be maintained, either in individual files or in a system where the data can be easily and quickly retrieved. 
It is recommended that the records in the individual files be hard-paper copies, microfilm, or microfiche. Consideration should be given to maintain dual sets of records, stored at different locations, to ensure that the records are not lost in the event of a fire or other major catastrophe. If dual sets of records are not maintained, the records should be kept in a hardened location.

Records containing information relating to personnel should identify the person by name, social security number, birth date, and sex as a minimum.

Recordkeeping systems for the: (1) training, (2) internal and external exposure control, (3) respiratory protection, and (4) surveillance programs are discussed in the following sections.

\subsubsection{Training}

It is recommended that the LLW disposal site staff member responsible for the training program maintain a training file for each radiation protection course that is given. This file should contain the following information as a minimum:

- name of course

- date and location of course

- identity of instructor(s)

- description of course content including course outline, syllabus, and other subject-descriptive information

- identification of individuals in attendance (name, social security number, birth date, sex)

- performance requirements (tests, physical demonstrations, etc).

In addition, individual training records should be kept in each staff member's training file and should include:

- worker identification (name, social security number, birth date, sex)

- title and date of the training program

- identification of the instructor and training location

- a performance rating for each segment of training or each training program completed by the worker; numerical or letter grade and/or a written evaluation with the instructor's signature.

The individual training file should also include a record of the staff member's previous academic course work and experience obtained from other facilities. 


\subsubsection{Internal and External Exposure Control}

An individual exposure history file should be maintained for each staff member. This file should contain the following records as a minimum:

- occupational exposure records

- NRC-5 or equivalent

- NRC-4 or equivalent

- exposure evaluation for damaged or lost dosimetry

- records of exposure information requested by and from other organizations

- whole body count records

- urinalysis/fecal analysis records

- decontamination records

- accident/incident investigation reports.

The above mentioned records should include the following information where applicable:

- worker identification (name, social security number, birthdate, sex)

- date of overexposure or suspected intake

- work area and job description

- radionuclides involved

- identification of analysis personnel

- calculations and models used.

\subsubsection{Respiratory Protection}

Records generated from the respiratory protection program may be divided into two groupings. The first covers the areas of maintenance, cleaning, inspection, issuance, and return of respirators. Data obtained should be documented and the resulting records kept together in a centralized file. These records should include the following information as a minimum:

- status of inspection

- date of inspection

- inspector's signature

- date of respirator issuance

- identification of the staff member that the respirator was issued to

- signature of issuer.

Records pertaining to personnel training and respirator fitting should be kept in the individual training files for each staff member. These records should include the following information as a minimum: 
- worker identification (name, social security number, birthdate, sex)

- title and date of the training program

- identification of the instructor and training location

- a performance rating for each segment of training or each training program completed by the worker; numerical or letter grade and/or a written evaluation with the instructor's signature

- personnel respirator fitting status

- date of fitting

- signature of fitter.

\subsubsection{Surveillance}

Radiation and contamination surveys are conducted to assess the condition of a particular work area. The survey records should include the following information as a minimum:

- date and time of survey

- specific location or object surveyed

- purpose of survey

- type and serial number of survey instruments

- calibration date

- measurement results including types of radiation measured

- signature of surveyor.

If airborne radioactivity is monitored, the following information should be recorded:

- date and time of sampling

- specific location at which the air sample was collected

- purpose of sample

- type of sample collection equipment used

- flow rate, duration of sampling, and total volume sampled

- collection efficiency

- counting data: background, source count, gross count, net count, counting time, type of counting equipment, calibration date

- calculated concentration of airborne radioactive material, type of radiation

- signature of surveyor. 


\subsection{RECORD REIENIION}

The minimum retention period for all radiation protection records should be two years. However, because records relating to personnel exposure have both scientific and legal implications, the following records for each individual should be kept unti 1 the Nuclear Regulatory Commission authorizes disposition (10 CFR 20.401):

- internal and external exposure rcords

- calibration data associated with evaluation of the individual's exposure

- records of procedures and methods used to interpret and evaluate the individual 's exposure

- records which describe the radiological conditions to which personnel may have been exposed, i.e., survey reports, air monitoring results, etc.

- records describing unusual occurrences in which the individual was involved.

Records can be kept as hard copy (paper), or on microfilm or microfiche. The main considerations in choosing which method of retention to use are: (1) the storage space needed for the number of records generated, (2) the ease of accessibility to the stored information that each type of record provides, and (3) the admissibility of each type of record as evidence in a court of law.

An extensive records system kept as hard copy could involve many tons of paper and take up a lot of space. Easy access to such a system would require an excellent centralized filing system. For a sma11 waste operation with relatively few records, hard-copy files would be practical. More over, in terms of legal applications, hard copy is often the preferred method of records presentation; in a court of law, evidence on original hard copy is difficult to dispute. Microfilm or microfiche of the original copy would be an acceptable substitute.

If computer storage is used, space must be allotted for the computer itself, a terminal, and storage of the discs or tapes. It is difficult to guarantee that a computer program or data has not been tampered with, and the data records cannot be signed as a way to verify a record or a change in a record. To stand up as legal evidence, computer entries should be verified upon entry, and access to the computer strictly controlled. Therefore, it is not recommended that computer records be the primary record storage but only used as a backup to hard copy, microfilm or microfiche. 


\subsection{RECOMMENDATIONS}

This chapter has outlined the areas of procedure format, procedure update and review, documentation, and record retention for radiation protection programs at $\amalg W$ disposal sites. The major recommendations made for program adequacy were:

- Radiation protection procedures should be reviewed and updated as necessary, every two years as a minimum.

- The primary record keeping system should consist of hard copy, microfilm, or microfiche records only.

- The minimum retention period for all radiation protection records should be two years. 


\subsection{CFR 61 IMPACT}

Reducing radiation exposure to "as low as reasonably achievable" (ALARA) should be the goal of radiation protection programs at low-level waste (LLW) disposal sites. The importance of maintaining exposures ALARA to the workers (occupational) and the general public is recognized and emphasized in $10 \mathrm{CFR}$ Part 61.43 (licensing requirements for land disposal of radioactive waste) and in 10 CFR 20 (Standards for Protection Against Radiation).

Part 61 applies to the near surface land disposal of $\amalg W$ and does not elaborate on other options such as sea or extraterrestrial disposal. As defined in this regulation, near surface land disposal means the disposal of WW i $n$ or within the upper 30 meters of the earth's surface. In addition, $\amalg W$ is defined to be radioactive waste not classified as high-level waste, transuranic waste, spent nuclear fuel, or byproduct material. Classification of waste is discussed in detail in Section 10.1 of this document.

The effective lifetime of an $\amalg W$ disposal site can be broken down into the following five phases: (1) preoperational, (2) operational, (3) closure, (4) postclosure, and (5) institutional control. The discussion in the rest of this chapter will be primarily concerned with the operational phase and, in particular, the occupational exposures received during this phase. This operational phase is defined as that time period in which the $\amalg W$ receipt and disposal operations are carried out.

The stability of the $\amalg W$ disposal site over the long term is important to ensure continued site integrity. This in turn reduces the potential for migration and transport of radioactive material to offsite areas. The overall goal is to ensure the protection of the public health and safety. Attainment of this goal falls into two time frames: (1) the short-term operational phase, and (2) the long-term after-operations-cease phase. The most important per-

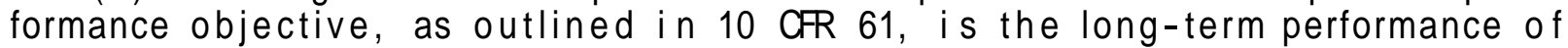
the land disposal facility after operations cease. This long-term objective is given a much greater emphasis than short-term objectives. The emphasis that is placed on the long-term performance objective of 10 CFR 61 is understandable. The protection of the public health and safety over the long-term is important and should be emphasized. However, as noted in 10 CFR 61 emphasis must also be given to short-term exposures. The following discussion will focus on several requirements of 10 CFR 61 and their importance from an ALARA viewpoint. ALARA recommendations will also be discussed.

Subpart D of 10 CFR 61 describes the technical requirements for land disposal of LLW. In particular, Section 61.52(a) discusses near surface disposal facility operation and disposal site closure. Subsections (4) and (5) of $61.52(a)$ state:

(4) Waste must be emplaced in a manner that maintains the package integrity during emplacement, minimizes the void spaces between packages, and permits the void spaces to be filled. 
(5) Void spaces between waste packages must be filled with earth or other material to reduce future subsidence within the fill.

The following discussion covers the areas of: (1) segregation of $\longleftarrow W$, (2) placement of $\amalg W$ containers, (3) void spaces, and (4) alternative $\amalg W$ containers. These discussions will be based on the occuptional exposures that may result from $10 \mathrm{CFR} 61 \mathrm{criteria}$ and the application of ALARA principles to reduce them.

\subsection{SEGREGATION OF $\amalg W$}

The radioactive waste buried at a disposal site is typically not a homogeneous mixture. Therefore, the evaluation of any waste disposal site and the application of ALARA principles should include consideration of the total impacts from all waste disposed of at the disposal site even if not covered under regulatory authority. These wastes may include byproduct, source, special nuclear material, and naturally occurring and accelerator produced material. As given in regulatory guidance, these materials are defined to be:

- "Byproduct Material" means any radioactive material (except special nuclear material) yielded in or made radioactive by exposure to the radiation incident to the process of producing or utilizing special nuclear material.

- "Source Material" means: (1) uranium or thorium, or any combination thereof, in any physical or chemical form or (2) ores which contain by weight one-twentieth of one percent $(0.05 \%)$ or more of uranium, thorium or any combination thereof.

- Special Nuclear Material" means: (1) plutonium, uranium-233, uranium enriched in the isotope 233 or in the isotope 235 , and any other material which the Commission determines to be special nuclear material, or (2) any material artificially enriched by any of the foregoing.

Sections 61.55 and 61.56 further classify $\amalg W$ by physical and chemical form and activity levels. This is done in order to help achieve a more stable waste form and thus a more stable waste site. The waste classification system allows for three categories: (1) Class A waste, (2) Class B waste, and (3) Class C waste. As defined in $10 \mathrm{CFR}$ 61.55(a)(2), Tables 1 and 2 not shown:

(i) Class A waste is waste that is usually segregated from other waste classes at the disposal site. The physical form and characteristics of Class $A$ waste must meet the minimum requirements set forth in $\S 61.56(a)$. If Class A waste also meets the stability requirements set forth in $\S 61.56(\mathrm{~b})$, it is not necessary to segregate the waste for disposal. 
(ii) Class $B$ waste is waste that must meet more rigorous requirements on waste form to ensure stability after disposal. The physical form and characteristics of Class B waste must meet both the mini$\mathrm{mm}$ and stability requirements set forth in $\S 61.56$.

(i i i) Class $C$ waste is waste that not only must meet more rigorous requirements on waste form to ensure stability but also requires additional measures at the disposal facility to protect against inadvertent intrusion. The physical form and characteristics of Class $\mathrm{C}$ waste must meet both the minimum and stability requirements set forth in $\S 61.56$.

(iv) Waste that is not generally acceptable for near-surface disposal is waste for which waste form and disposal methods must be different, and in general more stringent, than those specified for Class $C$ waste. In the absence of specific requirements in this part, proposals for disposal of this waste may be submitted to the Commission for approval, pursuant to $\S 61.58$ of this part.

One way to reduce exposures is to ensure that the waste does not need to be resorted at the disposal site because of waste classification mixing. It should be the responsibility of the waste generators to ensure that the waste has been properly sorted prior to packaging (also that void spaces inside waste containers are minimized or filled). A waste generator that produces $\amalg W$ of more than one classification should set up a program to train employees in how to classify and sort waste with the least amount of occupational exposure and to emphasize its importance. One method for operational control is to provide multiple waste containers, labeled or color coded for each classification of waste, and require their use. The workers would then be instructed in the proper disposal of each type of LLW. A universal coding or labeling system should be used throughout the industry. Color coding is preferred because it would allow $\amalg W$ classification identification from a distance which would be consistent with ALARA.

\subsection{PLACEMENT OF $\amalg W$ CONTAINERS}

The placement of $\amalg W$ containers in the burial trench is performed by a select group of site personnel called trench workers. These personnel receive a large portion of the site's monthly occupational exposure and it is important to minimize this exposure. Presently, the trench workers deal with many different types of waste containers including 55-gallon drums, shielded casks, and wooden and metal boxes. The variety of container types is shown in Figure 23. 


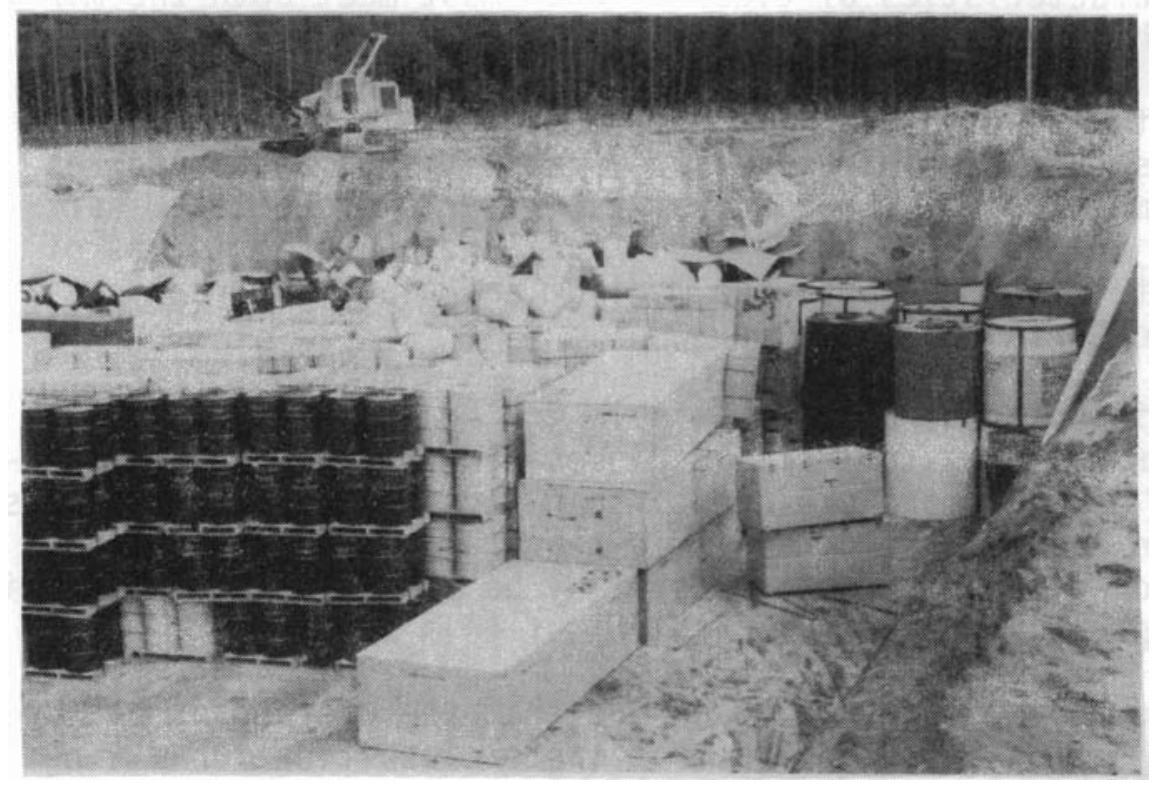

FIGURE 23. Variation of Waste Container Types

Section 61.52(a)(4) of $10 \mathrm{CR}$ Part 61 covers the subject of $\amalg W$ container placement, and states:

"Waste must be emplaced in a manner that maintains the package integrity during emplacement, and minimizes the void spaces between packages, and permits the void spaces to be filled."

With present operations, void spaces are minimized and easily filled through several practices. To accomplish this, boxes may be stacked one layer at a time. Most of this operation can be done remotely to minimize exposure to the trench workers. This method not only helps minimize void spaces but the resulting wall of stacked containers can be used as shielding (if the radiation fields from the containers are low). Figure 24 shows how a wall of stacked boxes has been constructed to help contain the waste behind it and also to provide radiation shielding to the rest of the trench. This is recommended as a good ALARA practice. Conversely, casks and drums are not easily stacked and large void spaces exist due to their cylindrical shape. Fiftyfive gallon drums may be prestacked on wooden pallets and secured in place by wooden side bars or cables. However, this may not reduce the total exposure for burial, but shift the occupational exposure from the trench workers to the 
waste generator employees. To minimize occupational exposures, it is essential that ALARA or operational controls be implemented. The following discussion covers possible methods and equipment to be used. These include: (1) alternative shaped LLW containers, (2) shielded containers, (3) prestacked LLW containers, (4) remote handling equipment, and (5) preplanning and mock-ups .

The use of alternative shaped LLW disposal containers can be beneficial to reduce occupational exposures to ALARA. Square or rectangular containers would be preferred because of their stability for stacking in a gravitational field and the minimization of void spaces upon stacking. Alternative LLW containers are discussed in more detail in Sections 10.3 and 10.4 of this document.

The use of shielded LLW disposal containers may allow lower exposures for the same handling time. This could significantly reduce exposures during the placement of containers. It is recommended that shielded containers be used whenever practicable. However, this option may not be economically feasible.

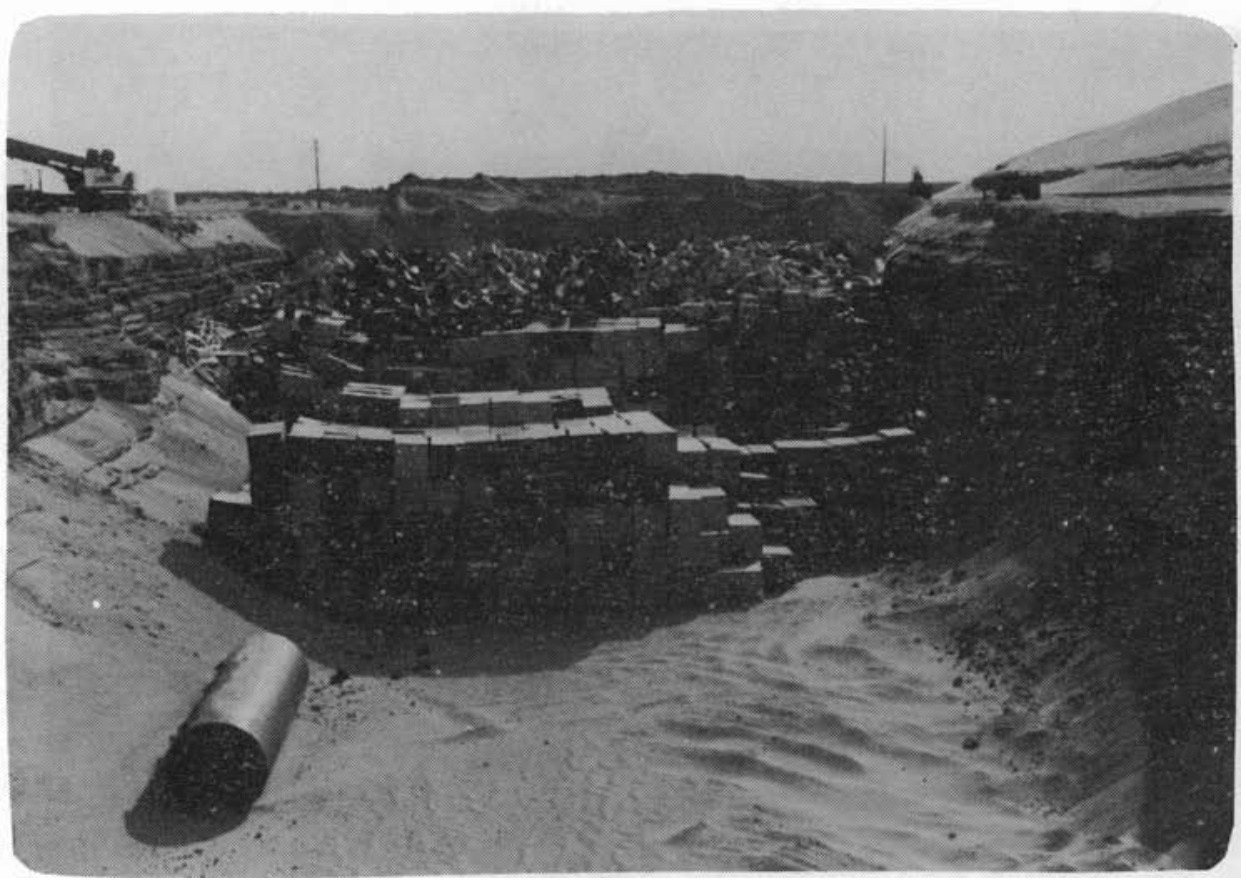

FIGURE 24. Use of Container Stacking for Radiation Shielding 
When using $\amalg W$ disposal containers that are not easily placed, it may be advantageous to prestack and secure them before burial. An example of this type of container is the standard 55-gallon drum. This method of prestacking is currently being used to help ensure stability during transport from the waste generator to the $\amalg W$ disposal site. Figure 25 shows prestacked pallets of 55-gallon drums placed in a trench. As discussed above for boxes, the prestacked wall of drums provides a retaining wall in addition to a radiation shielding wall. However, no analysis of potential exposure savings has been made. Consequently, ALARA evaluations should be performed on a case-by-case basis.

The approach that appears to have the greatest potential to reduce exposures to ALARA is by using remote handling devices. This type of equipment, depending upon its sophistication, may actually decrease present occupational exposures to trench workers. The remote handling devices should be capable of placing the $\amalg W$ waste containers in position in the trench and releasing its hold with no hands-on assistance from personnel. At present, the major disadvantages of this approach are cost and availability of state-of-the-art equipment. Figure 26 shows one example of a currently used remote handling system for 55-gallon drums and depicts the end result of placement.

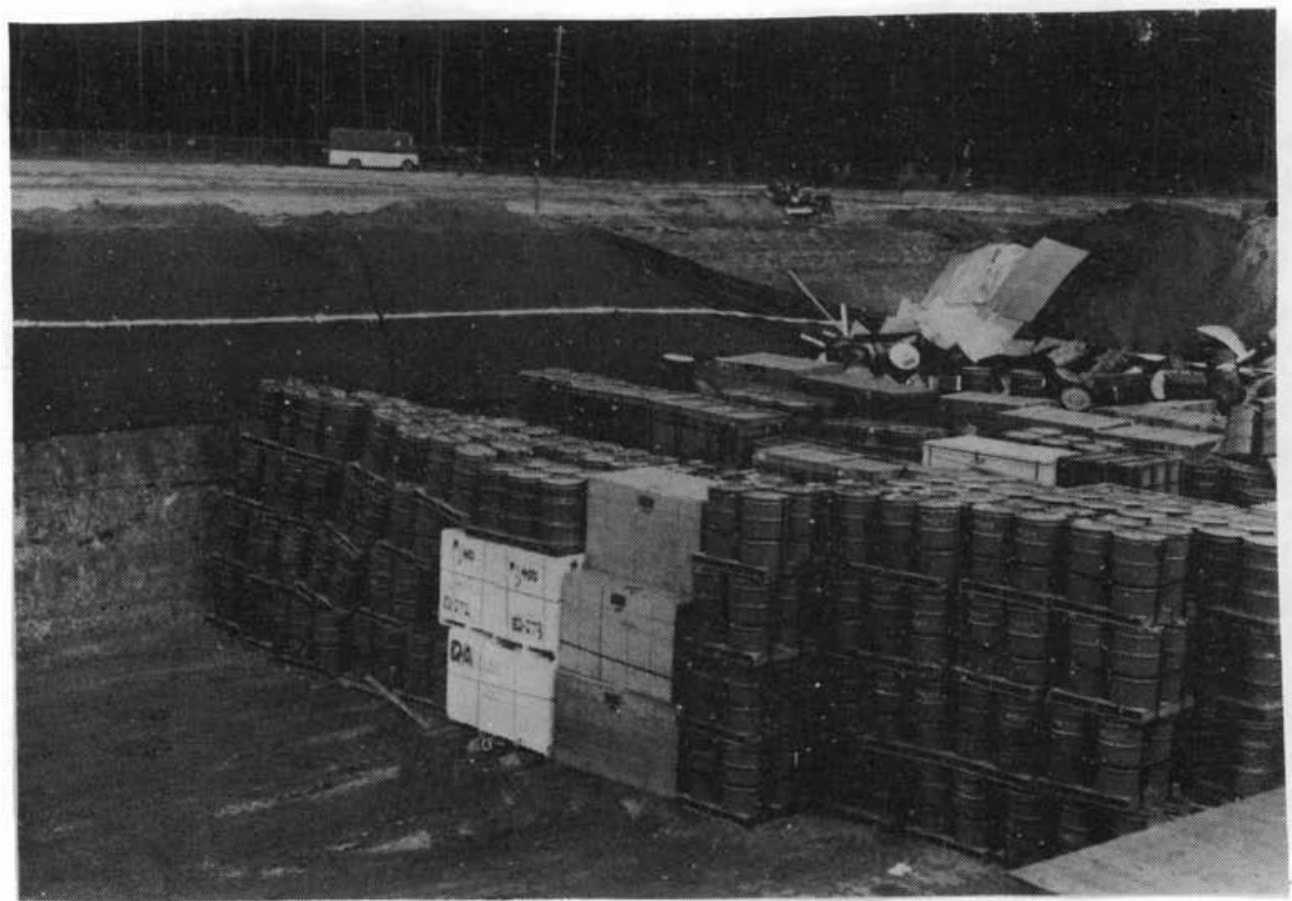

FIGURE 25. Prestacked Pallets of 55-Gallon Waste Drums 


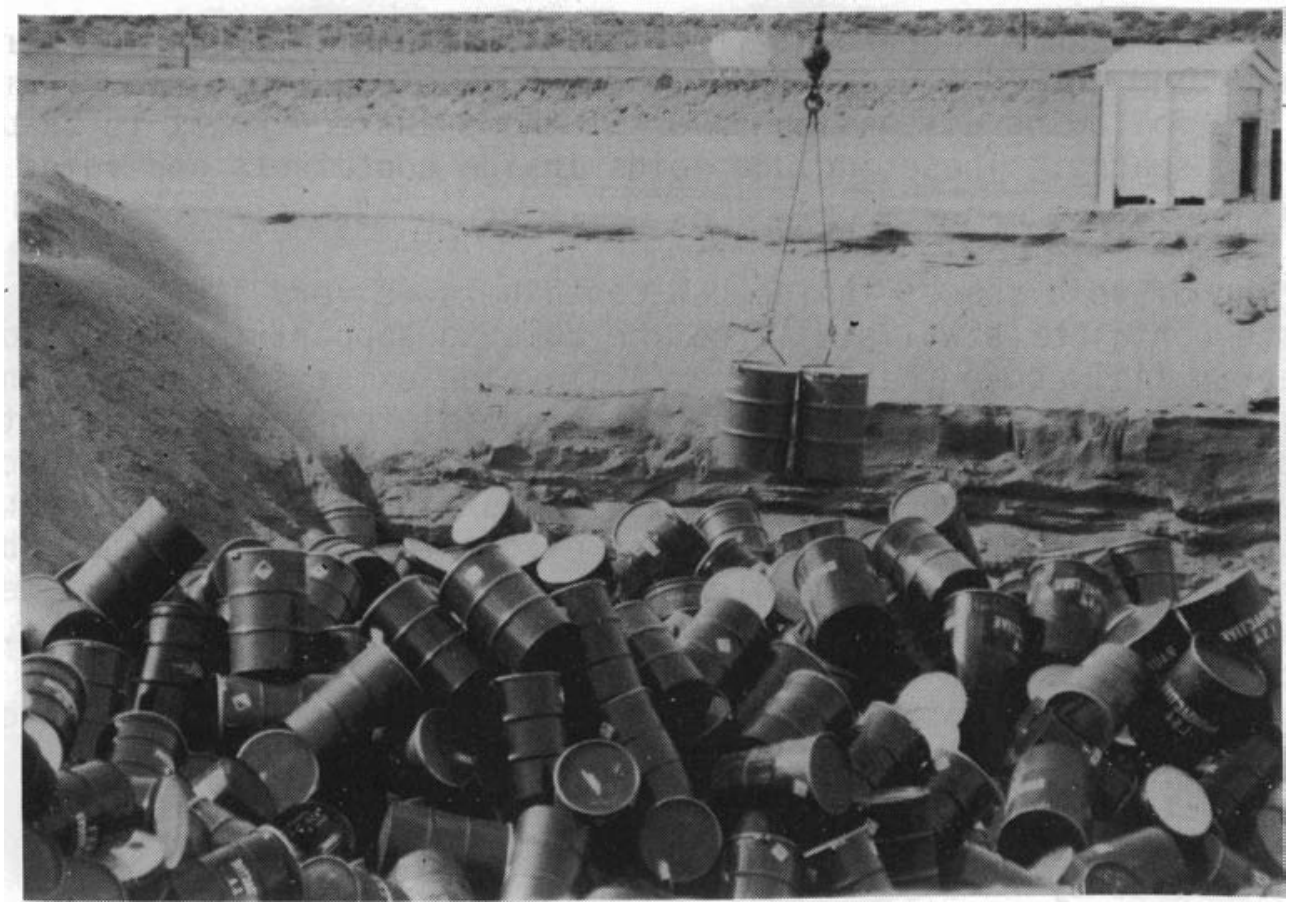

FIGURE 26. Example of Currently Used Remote Handling Device

The most cost effective exposure reduction option for $\amalg W$ emplacement is preplanning and mock-up training. Beneficial at any time, preplanning and mock-up training would be most effective when handling high activity $\amalg W$ or unusual shapes or sizes of disposal containers. Mock-ups are not only useful to train equipment operators and waste handlers but also as testing devices for the personnel responsible for development of waste handling procedures. Preplanning and mock-up training are recommended, especially if alternate waste containers, shielded containers, prestacked containers, and remote handling devices are developed to reduce exposures to ALARA.

\subsection{VOID SPACES}

A void by definition is a space that is empty of material. There are two types of voids that are of interest in the disposal of $\amalg W$. The first type is the void inside the waste container resulting from incomplete filling of the container. The second type is the void created when the waste container does not perfectly match adjacent containers when emplaced. For example, 55-gallon drums, because of their cylindrical shape, leave significant voids when emplaced in multiple rows.

Section 61.52(a)(5) of 10 CFR Part 61 covers the subject of void spaces between waste containers, and states:

"Void spaces between waste packages must be filled with earth or other material to reduce future subsidence within the fill." 
Recently, there has been a concerted effort to fill the void spaces between waste containers and to reduce, where possible, the void spaces inside waste containers. The following discussion covers methods and equipment to be used for filling void spaces. These include voids inside containers and voids between containers.

The filling of void spaces inside $\amalg W$ containers is very important. With time, the waste container's walls will not be able to support the weight of the $\amalg W$ and earth fill above the container. If voids exist inside the container, subsidence will occur increasing the potential for radioactive material migration. To ensure that this potential is minimized, the void spaces inside the container should be filled. This is best done by the waste generator. The waste generator should make every effort to separate compactable waste from other waste. The compactable waste may then be placed in waste containers (usually 55-gallon drums) and compacted to minimize void space. The noncompactible waste should be packaged so the voids are filled with material during the loading operation. Various fill materials may be used. Some recommended properties for fill materials are:

- fine grain

- uniform consistency

- provide strength

- innocuous

- easily obtained

- relatively inexpensive

It must be emphasized that filling or compacting waste container contents may increase the potential for external or internal exposure to the waste generator employee. In each case, the RSO and the radiation protection staff need to ensure that shielding, protective devices, preplanning and mock-up training have been used wherever feasible to reduce exposures to ALARA.

The filling of void spaces between $\amalg W$ containers is also important to reduce subsidence and the potential of radioactive material migration. There are two methods recommended to fill voids between containers after emplacement in the trench. These are: layering of waste and filling with remotely operated equipment. Layering of waste means to place a single layer of waste containers on the floor of the trench and fill the void spaces before the next layer of containers is put down. This makes the filling of void spaces relatively easy and forms a level foundation for the next layer of containers. If remotely operated filling equipment is used in conjunction with this method, the occupational exposures may be greatly reduced. Remotely operated filling equipment as defined here is that equipment capable to transport fill material to the voids with minimal or no attendance of workers. Equipment that may meet this criteria could be based on pumping, vacuum, or conveyor techniques. In addition to the fill material properties recommended previously, fill material for remote filling operations should be easy to move. In other words, it must be capable of being pumped or drawn through hoses or carried along conduits. As mentioned previously, the use of rectangular $\amalg W$ disposal containers can minimize the filling effort. 
The primary disadvantages of remote filling equipment are cost and availability of state-of-the-art equipment.

\subsection{ALTERNATIVE $\Perp W$ CONTAINERS}

One alternative is the use of rectangular burial containers for $\amalg W$. The two primary advantages of rectangular containers are: the ease of placement and minimizing of void spaces.

The following properties should be considered in the design of rectangular waste containers:

- shielding

- easy to handle by crane or forklift

- capable of interlocking with other containers for stability

- structural strength

- ease of filling void spaces.

The primary disadvantages of using rectangular containers are: cost, availability, structural strength as compared to cylinders, and "opposition to change" from users and suppliers.

\subsection{CONCLUSIONS}

ALARA programs are presently implemented at waste generator locations and, more importantly at $\amalg W$ disposal sites. Subjects that need to be addressed by waste generators in connection with implementation of Part 61 include:

- segregation of waste

- filling of void spaces inside waste containers

- use of shielded एW containers.

Subjects that need to be addressed by $\amalg W$ disposal site operators include:

a color coding of Class $A, B$, and $C$ waste containers

a use of remote handling devices

- use of preplanning and mock-up training for waste emplacement

- use of remote filling equipment

- use of shielding, preplanning, and mock-up training for filling between waste containers

- use of various shaped $\amalg W$ containers. 


\section{BIBLIOGRAPHY}

\subsection{INTRODUCTION}

Code of Federal Regulations, Title 10, Part 61; "Licensing Requirements for Land Disposal of Radioactive Waste."

NUREG-0782 (Vol. 1-4), 1981; Draft Environmental Impact Statement on 10 CFR Part 61, "Licensing Requirements for Land Disposal of Radioative Waste."

\subsection{ALARA PROGRAM}

DOE/EV/1830-T5; "A Guide to Reducing Radiation Exposure to As Low As Reasonable Achievable (ALARA)," U.S. Department of Energy, 1980.

International Commission on Radiological Protection (ICRP), 1973. "Implications of Commission Recommendations That Doses Be Kept As Low As Readily Achievable." ICRP Publication 22, Pergamon Press, Oxford.

NUREG-0267,1977; "Principles and Practices for Keeping Occupational Radiation Exposures at Medical Institutions As Low As Reasonably Achievable," Draft.

NUREG-0761,1981; "Radiation Protectin Plans for Nuclear Power Reactor Licensees," Draft.

NUREG-0880,1982; "Safety Goals for Nuclear Power Plants: A Discussion Paper. "

NUREG/CR-0446,1979; "Determining Effectiveness of ALARA Design and Operational Features," United Nuclear Industries.

Regulatory Guide 8.8-1979; "Information Relevant to Ensuring That Occupational Radiation Exposures At Nuclear Power Stations Will Be As Low As Reasonably Achievable (ALARA)," Proposed Revision 4, Task OH 507-4.

Regulatory Guide 8.10-1975; "Operating Philosophy for Maintaining Occupational Radiation Exposures As Low As Is Reasonably Achievable," Revision 1.

Regulatory Guide 8.18-1977; "Information Relevant To Ensuring That Occupational Radiation Exposures at Medical Institutions Will Be As Low As Reasonably Achievable."

Regulatory Guide Draft-1980; "Information Relevant to Ensuring That Occupational Radiation Exposure at Uranium Mills Will Be As Low As Is Reasonably Achievable," Task 어 941-4. 
ANSI/ANS-3.1-1978; "American National Standard for Selection and Training of Nuclear Power Plant Personnel," American Nuclear Society, LaGrange Park, Illinois.

ANSI/ANS-3.1-1979; "Proposed American National Standard for the Qualification and Training of Personnel for Nuclear Power Plants," American Nuclear Society, LaGrange Park, Il1inois.

ANS-15.4-1976; "Proposed American National Standard for the Qualification and Training of Personnel for Research Reactors," American Nuclear Society, LaGrange Park, Illinois.

Regulatory Guide 1.8 (Second Proposed Revision)-1980; "Personnel Qualification and Training," U.S. Nuclear Regulatory Commission, Washington, D.C.

Regulatory Guide 8.13-1975; "Instruction Concerning Prenatal Radiation Exposure," U.S. Nuclear Regulatory Commission, Washington, D.C.

Regulatory Guide 8.27-1981; "Radiation Protection Training for Personnel a t Light-Water-cooled Nuclear Power Plants," U.S. Nuclear Regulatory Commission, Washington, D.C.

Regulatory Guide 8.29-1981; "Instruction Concerning Risks from Occupational Radiation Exposure," U.S. Nuclear Regulatory Commission, Washington, D.C.

\subsection{INTERNAL AND EXTERNAL EXPOSURE CONTROL}

ANSI N13.1-1966; "American National Standard Practice for Occupational Radiation Exposure Records System," New York, New York.

ANSI N13.11-1978; "Draft American National Standard Criteria for Testing Personnel Dosimetry Performance," New York, New York.

ANSI N323-1978; "American National Standard Radiation Protection Instrumentation Test and Calibration," New York, New York.

ANSI N343-1978; "American National Standard for Internal Dosimetry for Mixed Fission Products," New York, New York.

Code of Federal Regulations, Title 10, Part 20; "Standards for Protection Against Radiation."

DOE/EV/1830-T5; "A Guide to Reducing Radiation Exposure to As Low As Reasonably Achievable (ALARA)," U. S. Department of Energy, 1980. 
International Commission on Radiological Protection (ICRP)-1978; "Limits for Intakes of Radionuclides by Workers," ICRP Publication 30, Part 1 and Supplement to Part 1, Pergamon Press, Oxford.

International Commission on Radiological Protection (ICRP)-1980; "Limits for Intakes of Radionuclides by Workers." ICRP Publication 30, Part 2, Pergamon Press, Oxford.

Radiological Health Handbook. 1970. U. S. Department of Health, Education, and Welfare, Washington, D.C.

Regulatory Guide 8.2-1973; "Guide for Administrative Practices in Radiation Monitoring."

Regulatory Guide 8.3-1973; "Film Badge Performance Criteria."

Regulatory Guide 8.4-1973; "Direct-Reading and Indirect-Reading Pocket Dosimeters."

Regulatory Guide 8.7-1973; "Occupational Radiation Exposure Records Systems."

Regulatory Guide 8.10-1975; "Operating Philosophy for Maintaining Occupational Radiation Exposures as Low as Reasonably Achievable."

Regulatory Guide 8.26-1980; "Applications of Bioassay for Fission and Activation Products."

Regulatory Guide 8.29-1981; "Instruction Concerning Risks from Occupational Radiation Exposure."

\subsection{RESPIRATORY PROTECTION}

ANSI 288.2-1980; "Practices for Respiratory Protection," New York, New York.

Code of Federal Regulations, Title 10, Part 20-1982; "Standards for Protection Against Radiation," 10 CFR 20, Washington, D.C.

NUREG-0041,1976; "Manual of Respiratory Protection Against Airborne Radioactive Materials," Washington, D.C.

Regulatory Guide 8.15-1976; "Acceptable Programs for Respiratory Protection," Washington, D.C.

\subsection{SURVEILLANCE}

ANSI N13.4-1971; "American National Standard Specification of Portable Xor Gamma Radiation Survey Instruments." 
ANSI N13.12-1978; "Draft American National Standard Control of Radioactive Surface Contamination on Materials, Equipment, and Facilities to be Released for Uncontrolled Use."

ANSI N323-1977; "American National Standard for Radiation Protection Instrumentation Test and Calibration."

Code of Federal Regulations 49-1979; Offices of Federal Register.

Code of Federal Regulations 10-1982; Offices of Federal Register.

Radiological Health Handbook, 1970; U.S. Dept. of Health, Education and Welfare.

\subsection{CONTAMINATION CONTROL AND DECONTAMINATION}

Ayres, J. A. 1970. "Decontamination of Nuclear Reactors and Equipment." The Ronald Press Co., New York, New York.

Cember, H. 1969. "Introduction to Health Physics." Pergamon Press, Oxford, England.

Fitzgerald, J. J. 1969. "Applied Radiation Protection and Control." Gordon and Beach, New York.

Healy, J. W. 1980. "Proposed Policy for Decontamination and Decommissioning." Proceedings of DOE Decommissioning Criteria Workshop in Kansas City, April 15-16, 1980.

Henry, H. F. 1969. "Fundamentals of Radiation Protection." John Wiley \& Sons, Publisher, New York.

International Atomic Energy Agency. 1973. "Radiation Protection Procedures." IAEA Safety Series No. 38, Vienna.

Maugham, G. I - 1960. "Bibliography on Radioactive Decontamination of Areas and Equipment," DEG Information Series 147(R), UKAEA, Risely, Warrington, Lancashire.

NBS Handbook 48. 1951. "Control and Removal of Radioactive Contamination in Laboratories," U.S. Government Printing Office, Washington, D.C.

Norwood, W. D. 1975. "Health Protection of Radiation Workers." Charles C. Thomas, Publisher, Springfield, Illinois.

Osterhoot, M. M. 1979. "Decontamination and Decommissioning of Nuclear Facilities." Plenum Press, New York. 


\subsection{QUALITY ASSURANCE}

ANSI N45.2.10-1973; "Quality Assurance Terms and Definitions," New York.

ANSI/ASME N45.2-1979; "Quality Assurance Program Requirements for Nuclear Facilities," New York.

International Atomic Energy Agency. 1979. "Quality Assurance Records Systems." IAEA Safety Series No. 50-SG-QA2, Vienna.

Regulatory Guide 1.74-1974; "Quality Assurance Terms and Definitions," Washington, D.C.

\subsection{PROCEDURES/DOCUMENTATION}

ANSI N13.6-1966 (R 1972) ; "Practice for Occupational Radiation Exposure Records Systems," New York.

Code of Federal Regulations, Title 10, Part 19; "Notices, Instruction and Reports to Workers; Inspections, 1982."

Code of Federal Regulations, Title 10, Part 20; "Standards for Protection Against Radiation," 1982.

National Fire Protection Association. 1980. "Standard for the Protection of Records." Publication 232, Boston.

$10.0 \quad 10$ CFR 61 IMPACT

Code of Federal Regulations, Title 10, Part 61; "Licensing Requirements for Land Disposal of Radioactive Waste."

NUREG-0782 (Vol. 1-4),1981; Draft Environmental Impact Statement on 10 CFR Part 61, "Licensing Requirements for Land Disposal of Radioactive Waste."

NUREG/CR-0570 (Vol. 1-2),1980; "Techno1ogy, Safety and Costs of Decommissioning a Reference Low-Level Waste Burial Ground." 


\section{DISTRIBUTION}

No. of

Copies

OFFSITE

U. S. Nuclear Regulatory Commission

Division of Technical Information and Document Control

7920 Norfolk Avenue

Bethesda, MD 20014

9 S. M. Neuder

U.S. Nuclear Regulatory Commission

Division of Waste Management Office of MMSS

Washington, DC 20555

2 J. B. Martin

U. S. Nuclear Regulatory Commission

Division of Waste Management

Office of MMSS

Washington, DC 20555

1 Office of the Director

U.S. Nuclear Regulatory Commission

Office of MMS

Washington, DC 20555
No. of

Copies

ONSITE

40 Pacific Northwest Laboratory

J. B. Brown

G. W. R. Endres

T. H. Essig

L. G. Faust

W. A. Glass

D. E. Hadlock (15)

W. N. Herrington

D. P. Higby

G. R. Hoenes

C. D. Hooker

R. L. Kathren

M. R. Kreiter

L. H. Munson

B. L. Murphy

R. W. Perkins

J. M. Selby

S. L. Stein

C. M. Unruh

W. R. Wiley

Publishing Coordination (2)

Technical Information (5) 


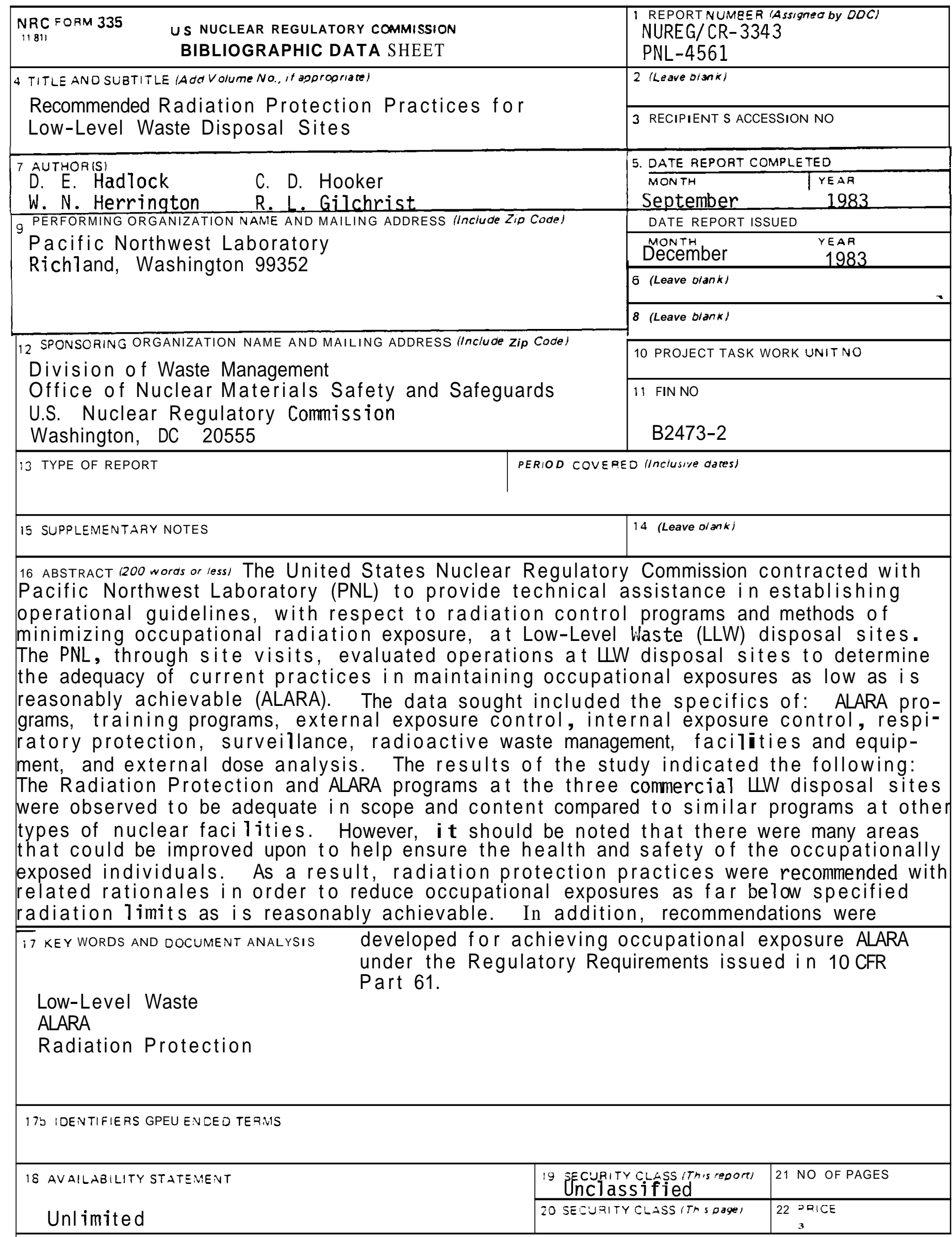

NACFORU 335 1111 